\title{
Isolation, purification and characterization
}

\section{of proteins from indoor strains of Chaetomium globosum \\ that are antigenic to humans}

Natacha B. Provost, B.Sc.

A thesis submitted to the Faculty of Graduate Studies in partial fulfillment of the requirements for a degree of

\author{
Master of Science \\ Department of Chemistry \\ Carleton University \\ September 2010
}

(C) Copyrighted 2010 
Library and Archives

Canada

Published Heritage

Branch

395 Wellington Street

Ottawa ON K1A ON4

Canada
Bibliothèque et

Archives Canada

Direction du

Patrimoine de l'édition

395, rue Wellington

Ottawa ON K1A ON4

Canada
Your file Votre référence

ISBN: 978-0-494-71595-6

Our file Notre référence

ISBN: 978-0-494-71595-6
NOTICE:

The author has granted a nonexclusive license allowing Library and Archives Canada to reproduce, publish, archive, preserve, conserve, communicate to the public by telecommunication or on the Internet, loan, distribute and sell theses worldwide, for commercial or noncommercial purposes, in microform, paper, electronic and/or any other formats.

The author retains copyright ownership and moral rights in this thesis. Neither the thesis nor substantial extracts from it may be printed or otherwise reproduced without the author's permission.
AVIS:

L'auteur a accordé une licence non exclusive permettant à la Bibliothèque et Archives Canada de reproduire, publier, archiver, sauvegarder, conserver, transmettre au public par télécommunication ou par l'Internet, prêter, distribuer et vendre des thèses partout dans le monde, à des fins commerciales ou autres, sur support microforme, papier, électronique et/ou autres formats.

L'auteur conserve la propriété du droit d'auteur et des droits moraux qui protège cette thèse. Ni la thèse ni des extraits substantiels de celle-ci ne doivent être imprimés ou autrement reproduits sans son autorisation.
In compliance with the Canadian Privacy Act some supporting forms may have been removed from this thesis.

While these forms may be included in the document page count, their removal does not represent any loss of content from the thesis.
Conformément à la loi canadienne sur la protection de la vie privée, quelques formulaires secondaires ont été enlevés de cette thèse.

Bien que ces formulaires aient inclus dans la pagination, il n'y aura aucun contenu manquant. 


\section{ABSTRACT}

Chaetomium globosum grows on damp cellulosic materials indoors and can adversely affect human health through allergic and toxic reactions. To study allergic response, exposure assessments must be done by measuring human allergens or antigens. The goal of this research was to identify $C$. globosum proteins that are antigenic to humans. Screening against human sera from atopic patients by ELISA and immunoblotting a 45 and $47 \mathrm{kDa}$ protein were recognized as antigenic. Their characterization was accomplished by liquid chromatography tandem mass spectrometry (LC-MS/MS) and they were identified as chitosanases. The target proteins were purified by anion exchange and gel filtration and their antigenicity was confirmed by the production of polyclonal antibodies in rabbits. Cross-reactivity tests ensured that other fungi did not produce the antigenic proteins. Further testing on monoclonal antibodies will determine their ability to specifically and selectively detect $C$. globosum antigens to assess their exposure in the indoor environment. 


\section{ACKNOWLEDGEMENTS}

I would like to thank the Carleton University chemistry department for the financial assistance provided for the completion of this research. I would also like to thank Dr. Miller for his help and encouragement in obtaining my master's degree.

I would like to thank all past and present students from Dr. Miller's laboratory that worked by my side and helped me during this process. I would like to thank Aaron Wilson and Sally Liang for their assistance and for guiding me in the early stages of my research project. I would like to thank Wen Luo for showing me how to make proper

gels and Westerns. I would like to thank Don Belisle for answering any questions that arose, especially regarding ELISAs. I would like to thank Chunhua Shi for his help with protein purification and for his input on any other problems I might have encountered. I would like to show appreciation to Shari Levac, Mark Sumarah, David McMullin, Geoff Plint and Luke Johnson for their advice in exasperating times and their friendships have made the completion of this degree much more enjoyable. I am grateful for Mark Sumarah who looked over this thesis time and again.

I would like to express thanks to my two sisters, Annie and Josée Provost, my best friend Anne Lauzon and my boyfriend Steven Tshakatumba for their love and support, for believing in my capabilities, for their understanding during stressful times and for listening to my frustrations. I finally did it!

Last but not least, I would like to show gratitude to my parents, André and Shirley Provost, for their unconditional love and their continued support throughout this whole process. They have made this journey possible. 


\section{Isolation, purification and characterization of proteins from indoor strains of Chaetomium globosum that are antigenic to humans}

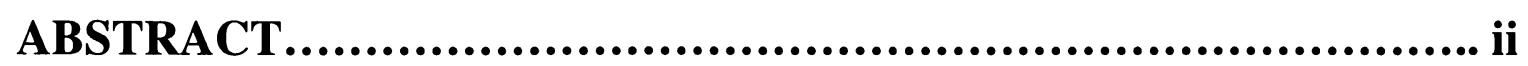

LIST OF FIGURES.................................................. vi

LIST OF TABLES..................................................... viii

ABBREVIATIONS.......................................................ix

INTRODUCTION........................................................... 1

1.1- Fungi

1.2- Fungi and the built environment ........................................................ 3

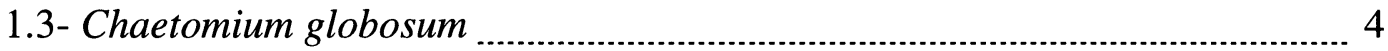

1.4- Health issues related to fungi ……........................................................... 7

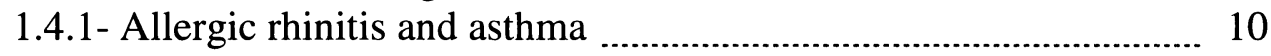

1.4.2- Allergic bronchopulmonary aspergillosis (ABPA) ....................... 11

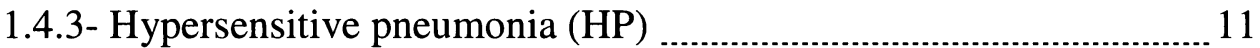

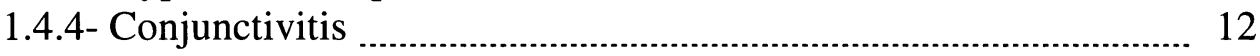

1.5- Chaetomium globosum and health issues ............................................... 12

1.6- Biological mechanism associated with allergy .............................................. 15

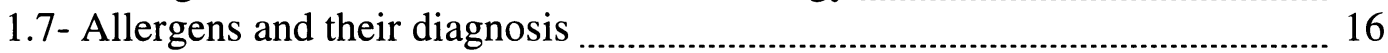

1.8- Detection of fungi indoors ................................................................... 19

1.8.1- Difficulties related with the detection of C. globosum indoors ..... 24

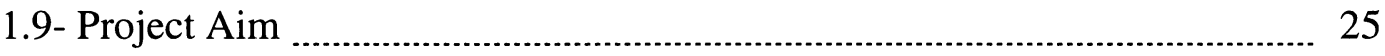

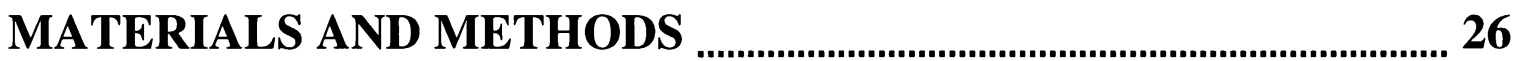

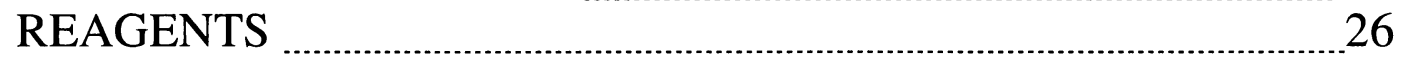

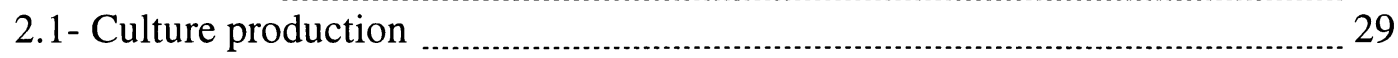

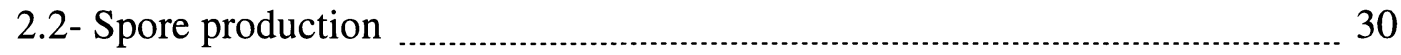

2.3- Extracellular protein extraction ........................................................ 31

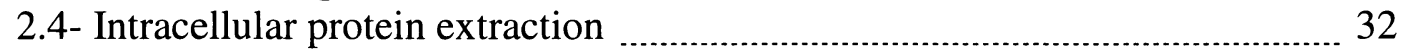

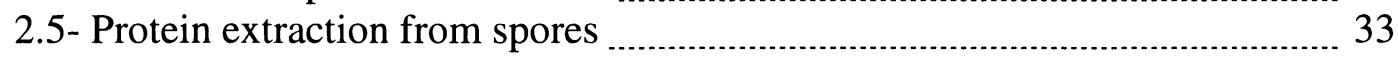

2.6- Protein concentration ……………………………………………................ 33

2.7- Indirect Enzyme Linked Immuno-Sorbent Assay (indirect ELISA) ............ 34

2.8- Sodium Dodecyl Sulfate-Polyacrylamide Gel Electrophoresis (SDS-PAGE)

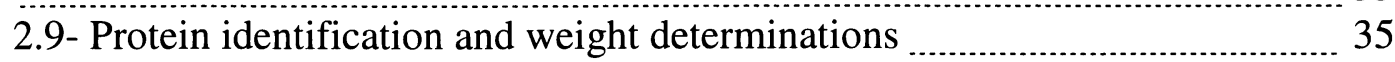

2.10- Immunoblotting ............................................................................... 37

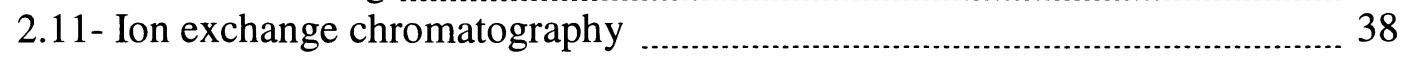

2.12- Gel filtration chromatography _........................................................... 38

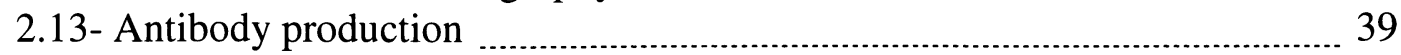

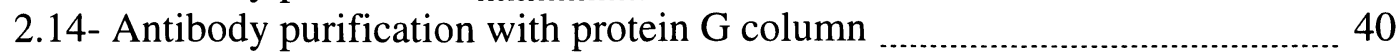




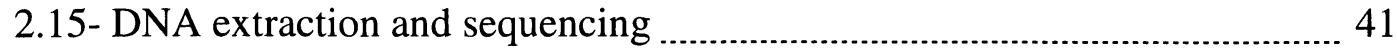

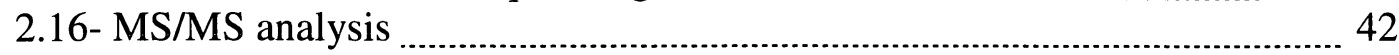

2.17- Determination of isoelectric point (pI) .................................................... 43

2.18- Glycoprotein assay ……................................................................ 44

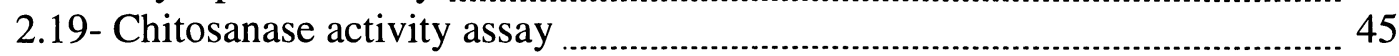

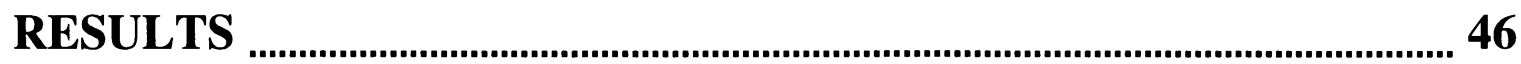

3.1- Culture and spore production, protein extraction and concentration ............ 46

3.1.1- C. globosum protein and spore production ................................... 46

3.1.2- Protein extraction from culture filtrate (extracellular), cells

(intracellular) and spores ......................................................................... 46

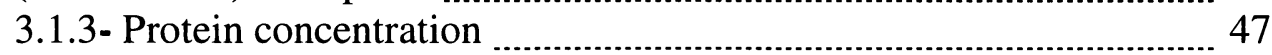

3.2- C. globosum human antigen screening using extracellular proteins

3.2.1- Initial antigen screening with ELISA ……................................. 47

3.2.2- Initial antigen screening with immunoblotting ............................... 51

3.3- Selection of antigenic proteins, detection in cells and spores and cross-

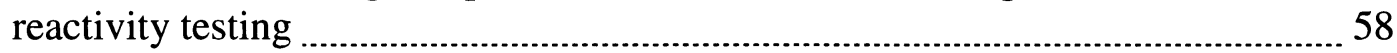

3.3.1- Selecting C. globosum target proteins ......................................... 58

3.3.2- Verifying the presence of the target antigenic proteins in cells and spores

3.3.3- Cross-reactivity of different fungal species to target antigenic proteins

3.4- Purification of C. globosum target proteins ............................................. 75

3.4.1- Ion exchange chromatography ..................................................... 75

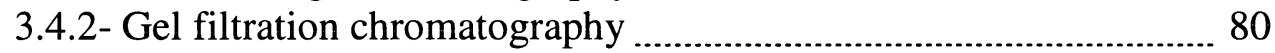

3.5- Polyclonal antibody production …….................................................. 84

3.5.1- Polyclonal antibodies produced in rabbits .................................. 84

3.5.2- Analysis of the polyclonal antibodies from test-bleeds ...................... 84

3.5.3- Purification of polyclonal antibodies ............................................. 86

3.5.4- Cross-reactivity testing with the RpAbs ....................................... 88

3.6- Characterization of the target antigens ………...................................... 92

3.6.1- MS/MS

3.6.2- Isoelectric point (pI)

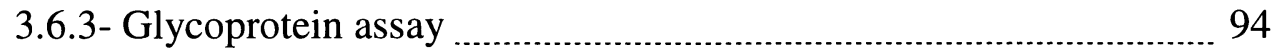

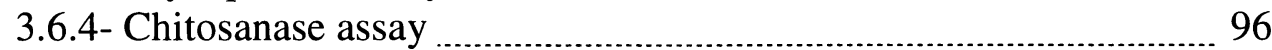

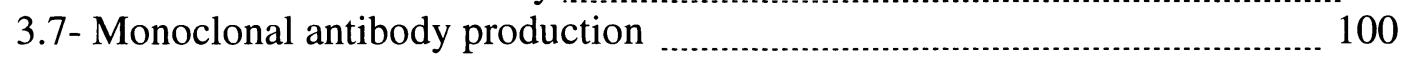

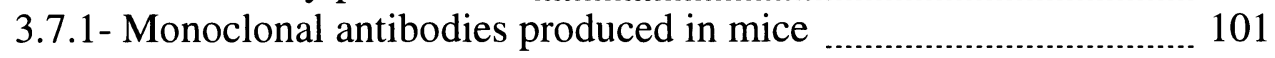




\section{LIST OF FIGURES}

Figure 1- C. globosum A - lemon-shaped spores (x 1000) and B - grown on malt extract agar (MEA)

Figure 2- A - Vertical cross-section of C. globosum's fruiting body. B - Enlargement of clavate asci with eight lemon-shaped spores

Figure 3- Molecular structure of chaetoglobosin A ……........................................ 14

Figure 4- Average ELISA response of all C. globosum culture extracts against all HpAbs

Figure 5- Average ELISA response of all C. globosum culture extracts against HpAbs

50

Figure 6- Immunoblot comparing the response of HpAb QC 2797 to different $C$.

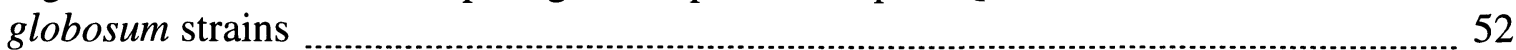

Figure 7- Immunoblot comparing the response of HpAb QC 3351 to different $C$.

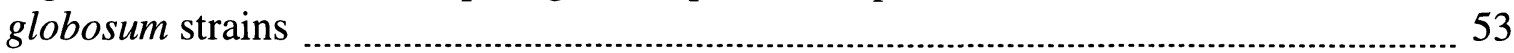

Figure 8- Immunoblot comparing the response of $\mathrm{HpAb}$ QC 3352 to different $C$.

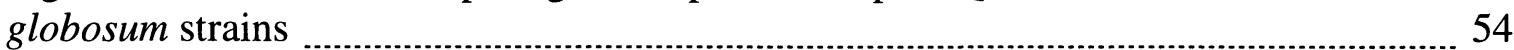

Figure 9- Immunoblot comparing the response of HpAb QC 3349 to different $C$.

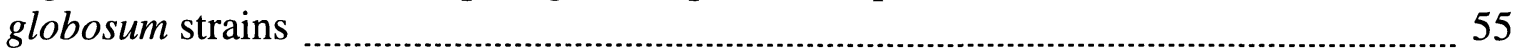

Figure 10- Immunoblot comparing the response of $\mathrm{HpAb}$ QC 3342 to different $C$.

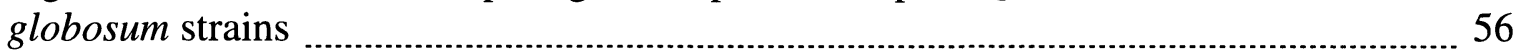
Figure 11- A three-dimensional graph containing ELISA (OD values; $\mathrm{X}$ axis) and immunoblot ( $\mathrm{Y}$ axis) response of $C$. globosum strains against 23 individual human sera ( $\mathrm{Z}$ axis)

Figure 12- Silver stain comparing the amount of the 45 and $47 \mathrm{kDa}$ proteins produced in all the $C$. globosum strains

Figure 13- Immunoblot comparing the response of HpAbs to C. globosum strain UAMH 7142

Figure 14- Silver stain displaying the presence of the 45 and $47 \mathrm{kDa}$ proteins in cells (A) and spores (B)

Figure 15- Immunoblots of C. globosum cells against HpAbs QC 3351 (A), QC 3352 (B) and QC 2797 (C)

Figure 16- Immunoblot showing the response of the 45 and $47 \mathrm{kDa}$ proteins from spores against HpAbs QC 2797

Figure 17- Immunoblot comparing the response of C. globosum strain UAMH 7142 to

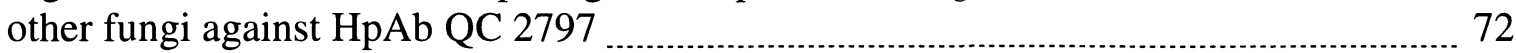

Figure 18- Immunoblot comparing the response of C. globosum strain UAMH 7142 to

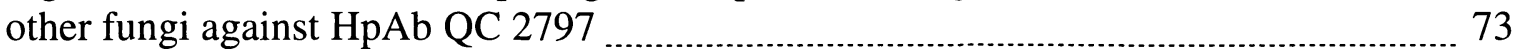

Figure 19- Silver stain demonstrating the presence of proteins in other fungi that have similar molecular weights to $C$. globosum target proteins .......................................... 74 Figure 20- Silver stain comparing the amounts of proteins obtained with the $3 \times$ acetone and the concentrator 76

Figure 21- Silver stain of the different fractions eluted from anion exchange column

Figure 22- Immunoblot confirming the 45 and $47 \mathrm{kDa}$ proteins eluted from anion exchange column against $\mathrm{HpAb}$ QC 2797 
Figure 23- Elution fractions for the protein standards from gel filtration column 80 Figure 24- Silver stain of elution fractions of the $47 \mathrm{kDa}$ protein from gel filtration column

Figure 25- Immunoblots demonstrating the response of the 45 and $47 \mathrm{kDa}$ protein from culture filtrate $(\mathrm{CF})$ and spores (SP) after the rabbits were immunized with spores $(\mathrm{CF} 1 \&$ SP1) and after the second antigen boost (CF2 \& SP2)

Figure 26- CBB stained gel of the rabbit polyclonal antibody 305 and 675 after a protein G column purification

Figure 27- ELISA results demonstrating the activity of the antibody 305 (A) and 675 (B) against the $47 \mathrm{kDa}$ protein

Figure 28- Immunoblots demonstrating the response of $C$. globosum strain UAMH 7142 compared to other fungi using the rabbit polyclonal antibodies 305 (A) and 675 (B) .... 89 Figure 29- ELISA results demonstrating the response of C. globosum and different fungi using the rabbit polyclonal antibody 305

Figure 30- Immunoblots demonstrating the antigenicity of the 45 and $47 \mathrm{kDa}$ proteins using the RpAbs $305(\mathrm{~A})$ and $675(\mathrm{~B})$

Figure 31- LTQ-FT spectrum of the sample CHG47 (A) and CHG45 (B)

Figure 32- Alignment of the LTQ-FT spectra for the 45 and $47 \mathrm{kDa}$ proteins and the peptide sequences associated

Figure 33- Silver stained isoelectric focusing strip (pH 3-10), arrow indicates a pI of 4.5 for the $C$. globosum $47 \mathrm{kDa}$ protein

Figure 34- CBB stained gel (A) and glycoprotein stain (B) demonstrating that the $47 \mathrm{kDa}$ target proteins is not glycosylated

Figure 35- Calibration curve of the optical densities of reduced sugar produced when glucose is treated with dinitrosalicylic acid reagent

Figure 36- Reduced sugar produced when $47 \mathrm{kDa}$ protein and chitosan are incubated at different temperatures with dinitrosalicylic acid reagent

Figure 37- Reduced sugar produced when $47 \mathrm{kDa}$ protein and chitosan are incubated for different amounts of time with dinitrosalicylic acid reagent

Figure 38- Immunoblot performed on culture filtrate from C. globosum against preimmunized sera and serum from mouse 1 to 4

Figure 39- Catalytic mechanism (hydrolysis of $\beta-1,4$ glycosidic bond between two glucosamine) by chitosanase 


\section{LIST OF TABLES}

Table 1- Summary of immunoblot response of some C. globosum proteins to a few HpAbs

Table 2- Immunoblot response of $C$. globosum target proteins against all HpAbs ........ 63

Table 3- Protein recovery for each purification step for C. globosum. 83

Table 4- ELISA results (done by Immunoprecise) for IgG and IgM antibody response to $47 \mathrm{kDa}$ antigen 100 


\section{ABBREVIATIONS}

$\mathbf{1}^{\mathbf{0}} \mathbf{A b}$ - Primary antibody; used in both ELISA and immunoblotting protocols $\mathbf{2}^{\mathbf{O}} \mathbf{A b}$ - Secondary antibody; used in both ELISA and immunoblotting protocols ABPA - Allergic bronchopulmonary aspergillosis

AP - Alkaline phosphatase

CBB - Commassie brilliant blue stain

DAOM - Department of Agriculture, Ottawa, Mycology, Ottawa ON

ELISA - Enzyme linked immune-sorbent assay.

GC/MS - Gas chromatography/mass spectrometry

HIA - Halogen immunoassays or hay infusion agar

HP - Hypersensitivity pneumonitis

HpAb - Human polyclonal antibody; atopic patient serum

HPLC - High pressure liquid chromatography

HRP - Horseradish peroxidase

IgE - Immunoglobulin E

IgG - Immunoglobulin G

IgM - Immunoglobulin M

kDa - kilodaltons (1000 Da)

LAL - Limulus Amoebocyte Lysate Assay

LMW - Low molecular weight marker, expressed in kilodaltons $(\mathrm{kDa})$

LTQ-FT - Linear Trap Quadrupole Fourier Transform

mAb - Monoclonal antibody

MEA - Malt extract agar

MmAb - Mouse monoclonal antibody

MS/MS - Tandem mass spectrometry

MVOC - Microbial volatile organic compound

MW - Molecular weight, expressed in $\mathrm{kDa}$

OD - Optical density

pAb - Polyclonal antibody

PCA - Potato carrot agar

pNGASE - Peptide: N-glycosidase

RpAb - Rabbit polyclonal antibody

TLC - Thin layer chromatography

TLR - Toll-like receptor

UAMH - University of Alberta Microfungus Collection and Herbarium

VOC - Volatile organic compound

WA - Water agar 


\section{INTRODUCTION}

\subsection{Fungi}

Fungi represent a very large kingdom with an estimated 1.5 million species, with $\sim 100,000$ morphospecies that are described (Deacon, 2006). These organisms are very diverse, they can be divided into two groups; macrofungi that include mushrooms as well as toadstools and microfungi comprise what are often called molds (Carlile et al., 2001). Fungi are eukaryotes that can live as parasites, saprophytes and mutualists (Cooke, 1977). They lack chlorophyll therefore they do not photosynthesise their carbon nutrients, they are heterotrophs that obtain their nutrients by degrading dead organic matter through the excretion of enzymes (Ingold, 1961). Fungi are ubiquitous in nature, they can grow over a wide temperature range and in a variety of ecological niches as long as conditions are suitable and nutrients are available (Horner et al., 1995). Some are very adaptable organisms, they have the ability to shut down their metabolism if conditions do not permit growth and they can stay dormant until favourable conditions return (Watling, 2003). Fungal cell walls are rigid, permeable to water and substrates in solution, they contain chitin, cellulose-like substances and glucans (Ingold, 1961). Fungi reproduce by spores either asexually or sexually. Based on their reproductive structures they are classified as Ascomycetes, Basidiomycetes or Phycomycetes (Kendrick, 2001). In the case of filamentous fungi, spores can propagate to new areas through wind and water. Humans and animals also contribute to spore redistribution. If a suitable environment is found the spore will germinate to ensure its survival (Hawker, 1957). The spore initially germinates into a germ tube that grows into a filament (hypha). The hypha branches to create hyphae and further branching and aggregation forms the mycelium (Watling, 
2003). The differences observed in the surface texture, shapes, sizes and colour of fungal spores are useful in the identification of fungi (Lockey and Ledford, 2008) but increasingly modern taxonomy is needed (Seifert, 2009). Spores constitute a large part of indoor and outdoor air particles, they can be detected in ambient air, in dust and on surfaces in the built environment. Spores found within indoor air primarily come from outdoor sources in buildings lacking mold damage (Foto et al., 2005; Miller et al., 2008).

The ability of filamentous fungi to decompose complex organic substances is a biodegradative process of great ecological importance since it helps to liberate a variety of elements, such as hydrogen, carbon, oxygen, nitrogen, phosphorous, potassium, sulphur, iron, calcium, magnesium and zinc, that are used for the continued existence of various organisms (Singh, 1994). Other beneficial roles for fungi include production of antibiotics, other metabolites that may have useful biological properties (e.g., statins) and the manufacture of a wide variety of foods like alcohol, bread and cheese (Carlile et al., 2001). However, fungi can also cause detrimental effects, including being pathogens to plants, animals and humans. They are amongst the most frequent microorganisms that destroy manufactured food, they are responsible for spoilage of crops and they can cause the deterioration of many damp building materials resulting in large economic losses (Miller et al., 2008; Pitt and Hocking, 2009). The presence of fungi in the indoor environment can affect population health because they can produce aerosols that comprise several contaminants (e.g., allergens, low molecular weight toxins, triple helical B1,3-D-glucan (Horner et al., 1995; Miller et al., 2010; Rand et al., 2010) and possibly 
volatile organic compounds (VOCs), when there is growth of fungi (Horner and Miller, 2003; Miller et al., 1988).

\subsection{Fungi and the built environment}

There are certain requirements that are necessary to promote fungal growth on substrates in an indoor environment: the presence of nutrients (oxygen, carbon, nitrogen, phosphorus and several minerals), adequate temperature and sufficient amounts of water. The availability of water for a given material depends on its water activity $\left(\mathrm{a}_{\mathrm{w}}\right)$, it can be defined as the ratio between vapour pressure of water in a material and the vapour pressure of pure water. Each fungus has a minimum $a_{w}$ and optimal $a_{w}$ for growth (Miller, 2010; Miller et al., 2008). Although, most filamentous fungi cannot survive in a place where the $a_{w}$ is below 0.64 . When water in a material is high, $a_{w} \geq 0.90$, this creates ideal conditions for hydrophilic fungi to grow (e.g., Chaetomium globosum and Stachybotrys chartarum). Slightly xerophilic fungi will grow when the $\mathrm{a}_{\mathrm{w}}$ is between 0.8-0.9 (e.g., Cladosporium species and Aspergillus fumigatus). Moderately xerophilic fungi will grow when $a_{w}$ is between 0.75-0.79 (e.g., Penicillium brevicompactum and Aspergillus versicolor). Fungi that favour dry conditions $(\mathrm{aw}<0.75)$ for growth are classified as extreme xerophiles (e.g., Wallemia sebi and Eurotium species; Flannigan and Miller, 2001). The damp indoor conditions that enable mold growth are typically the result of a moisture problem. This problem can be explained by lack of ventilation, condensation, water leakage, infiltration of water from the outdoors and to more obvious extent, floods (NAS, 2004; Prezant et al., 2008b). 
Fungi produce various degrading enzymes that are specific to different substrates. This, in combination with chemical composition and the water availability of the substrate, will dictate the fungal species that will germinate. Building materials that are susceptible to biodeterioration by fungi include wallpaper, gypsum wallboard, paints, wood, manufactured wood and insulation (Miller et al., 2008). Fungi that are common colonizers of the indoor environment under wet conditions include: Aspergillus versicolor, Chaetomium globosum, Cladosporium sphaerospermum sensu stricto, $C$. halotolerans, Penicillium chrysogenum and Stachybotrys chartarum sensu latto (Flannigan and Miller, 2001; Miller et al., 2008).

\subsection{Chaetomium globosum}

From fungi common on wet or damp buildings, Chaetomium globosum is the most common species isolated on wet cellulosic building materials (Domsh et al., 1999; Fogle et al., 2007; Miller et al., 2008). It has been reported as one of the top 12 species isolated on wallboard in North America (Miller et al., 2008). C. globosum is hydrophilic, it is thought of as a tertiary colonizer because it grows in very wet conditions, where the water activity of the substrate can reach $\geq 0.90$. Moreover, this cellulolytic species is common in soils and has a worldwide distribution. Habitats where this species has been isolated include straw, seeds, cereals, dung, polyurethane foam and fabrics, cardboard, paper and cotton. When the cellulolytic activity of several fungi were tested, C. globosum very strongly degraded cotton fabrics (Flannigan and Miller, 2001). Different damp building materials from the United States and Canada were examined and 7 Chaetomium species 
were isolated. Out of these species, C. globosum was common on wallboard, solid wood and textiles and frequent on insulation, manufactured wood and ceiling tiles (Miller et al., 2008). C. globosum is evidently tolerant to calcium salts because it is recovered from gypsum wallboard, a material that mainly contains calcium salts (Miller et al., 2008). It is abundant in bathrooms and kitchens and often found on mattresses, carpets and window frames (Piecková, 2003). C. globosum can damage food and feeds and it can also grow on pharmaceuticals like herbal drugs and cosmetics (Udagawa et al., 1979).

C. globosum species have a distinctive morphology, they firstly grow as white coloured colonies but their continued growth differentiates into a greyish olive-green to dark oliveblack color on MEA (figure 1B; Seth, 1970). Their texture can be described as cottony and their odour as moldy or musty (Carlile et al., 2001). Fogle (2007) determined that the optimal growth temperature for C. globosum was between $16-25^{\circ} \mathrm{C}$, it would not grow at temperatures $>37^{\circ} \mathrm{C}$ and the highest growth was observed at neutral $\mathrm{pH}$.
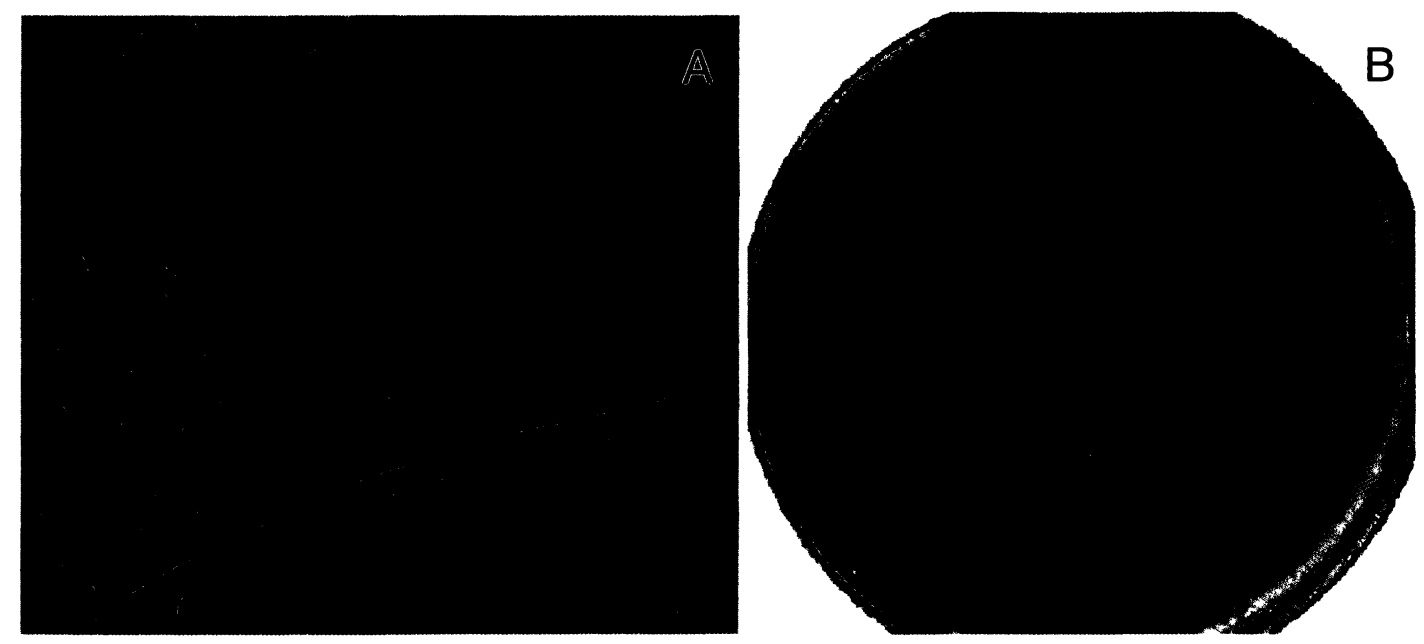

Figure 1: C. globosum A - lemon-shaped spores $(\times 1000)$ and $\mathbf{B}$ - grown on malt extract agar (MEA) 
Chaetommium globosum are characterized by the presence of hyphae that are septate with large, globose to subglobose fruiting bodies, called the ascocarp or more specifically the perithecium (figure 2A; Larone, 2002). The perithecium for C. globosum is opaque and dark coloured (Seth, 1970). The distinctive characteristic of these species is the presence of perithecial hairs (setae), they are long unbranched, undulate to very loosely coiled and lightly roughened with a light olive brown color (Kendrick, 2001; Seth, 1970). The perithecium contains clavate (club-shaped) asci that enclose 8 ascospores (figure 2B; Carlile and Watkinson, 1994; Seth, 1970). In comparison to other fungi, C. globosum ascospores are large, $10 \mu \mathrm{m}$, usually brown and lemon-shaped as displayed in figure $1 \mathrm{~A}$ (Seth, 1970). Once the spores have reached maturity, the asci lyse and release them inside the perithecium in a mucilaginous matrix. After water is absorbed the ostiole (opening of the perithecium) releases the spores as a viscous mass and the perithecial hairs are used as support and add protection against predators (Kendrick, 2001). The spores are resistant to heat and their dispersal demands rain, insects and animals rather than air (Seth, 1970; Guarro et al., 1999; Piecková, 2003). However, Chaetomium species are considered atypical Sordariales because they lack the ability of using an active discharge of spores (Seth, 1970; Kendrick, 2001). The ascospores have the ability to adapt to various conditions; they can survive more than 10 years under air dry conditions (Deshmukh and Rai, 2005). 


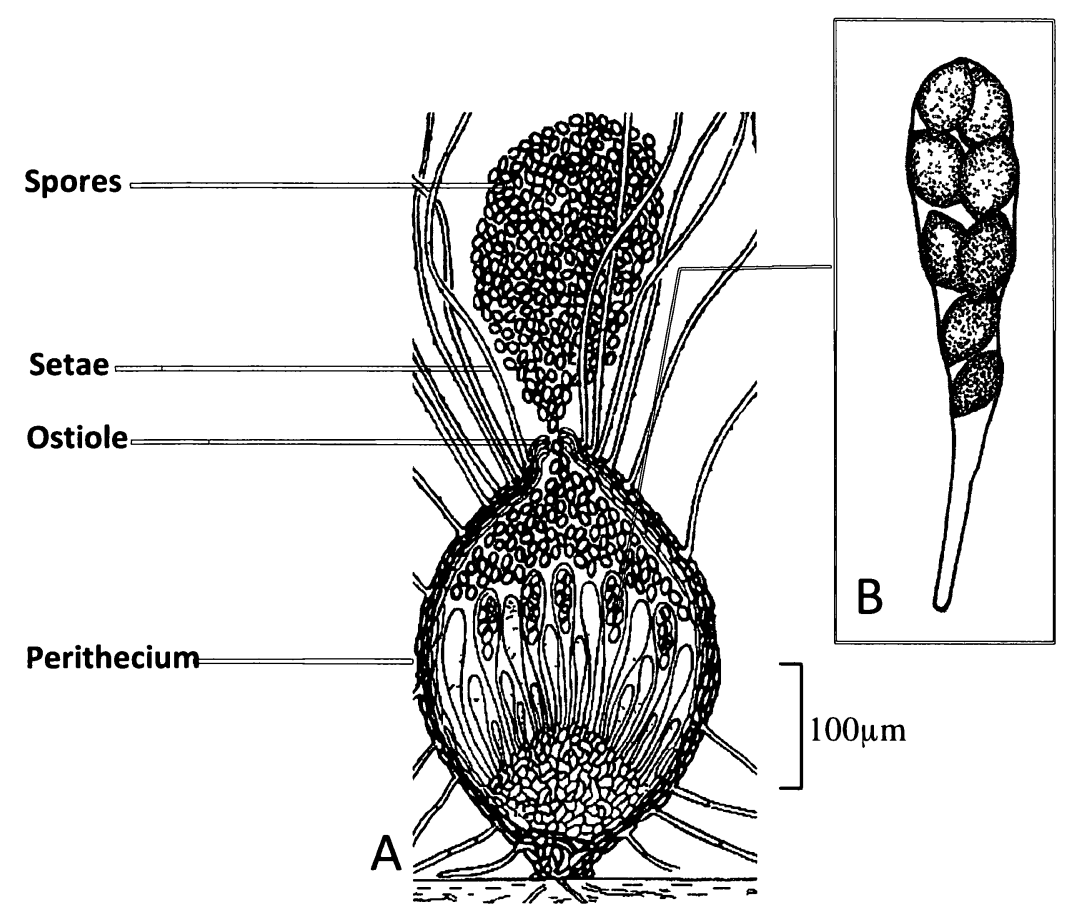

Figure 2: A - Vertical cross-section of C. globosum's fruiting body. B - Enlargement of clavate asci with eight lemon-shaped spores (Adapted from: Ingold, 1961).

\subsection{Health issues related to fungi}

Building related illnesses are associated with poor indoor air quality that can be attributed to a variety of factors including: limited ventilation, presence of air conditioners, exposure to volatile irritants (e.g., tobacco smoke) and microbial agents from damp buildings (e.g., fungal propagules). Symptoms of building related illness include: eye, nose and throat irritation, fatigue, nausea, headache, dizziness, skin reddening and asthma-like symptoms. The severity of these symptoms depends on the duration of the exposure and occupant health before the exposure but once the exposure leaves the symptoms generally subside (Hung et al., 2005). 
The presence of fungi indoors can make the occupants more susceptible to developing mycoses; various superficial and systemic infections, these will however vary with the type of fungal species, the circumstances of exposure and the immune system capabilities of the individual (Ammann, 2005). A few factors influence the ability of fungi to be pathogenic to its hosts. Invasive fungal infections usually affect immunocompromised individuals (Hung et al. 2005), More than 100 species of fungi contribute to human and animal infections but the impact of exposure from the built environment on opportunistic infections has not been assessed (Hung et al., 2005; Simon-Nobbe et al., 2008).

When there is mold growth indoors, the majority of the exposure shifts from spores to spores, spores to mycelial fragments and much smaller particles (Foto et al., 2005; Salares et al., 2009; Miller et al. 2010). If spores or mycelium fragments that are present indoors are inhaled, they can result in a range of respiratory symptoms and allergic reactions for the occupants because of the presence of low molecular weight compounds (such as toxins), $\beta 1,3-\mathrm{D}$-glucan, volatile organic compounds (VOCs) and allergens (Flannigan and Miller, 2001; Health Canada, 2004; Jarvis and Miller, 2005). Between 10 to $30 \%$ of North American homes have enough mold contamination to elevate the risk of respiratory diseases (Jarvis and Miller, 2005).

Toxins are secondary metabolites produced by fungi. They grow when limited amounts of nutrients are available and are characteristic of the different environments the fungi colonize (Jarvis and Miller, 2005). Routes of contact of these toxins can be through dietary, respiratory or dermal exposures and their health effects include skin rashes, 
dizziness, nausea and immunosuppression (Health Canada, 2004). However, toxicoses due to toxins affecting humans have not been well characterized and cannot be associated with occupant exposure to mold-damaged buildings (NAS, 2004).

Glucans, in various forms and configurations, are the main structural component of fungal cell walls and differ in biological activity (Hung et al., 2005). The anamorphic Trichomaceae and related hyphomycetes possess a linear $\beta 1,3-\mathrm{D}$-glucan in a triple helical form. This is known to activate the dectin receptor causing inflammatory responses in animals (Rand et al., 2010). Symptoms of exposure include eye, nose and throat irritation, dry cough, itching skin, hoarseness and tiredness (Hung et al., 2005).

VOCs are organic molecules that exist as free vapour or adsorbed to particles (NAS, 2000). VOCs are released during the active growth of fungi, specific mixtures can probably be attributed to particular species (Horner and Miller, 2003). Exposure to these VOCs is known to cause nasal irritation (Strom et al., 1990) but their affect on human health is unclear (Horner and Miller, 2003).

Fungal proteins have varying physical, chemical and functional properties that generate an immunological response through creation of antibodies. Allergens that are present on the fragments of spores or hyphae can illicit immunological reactions that are two to five times higher than intact spores because they can penetrate deeper into the lungs (Green et al., 2006a, Miller et al., 2010). Individuals exposed to mold allergens will usually present an exaggerated response of immunoglobulin $\mathrm{E}(\mathrm{IgE})$ antibodies but the presence of $\operatorname{IgG}$ 
antibodies and IgM antibodies is also possible (Horner et al., 1995; NAS, 2000). The various diseases associated with allergy are described in greater detail below. Exposure to fungal allergens can elicit symptoms of wheezing, sneezing, itchy eyes and coughing but can also cause allergic illnesses such as allergic rhinitis, asthma, allergic bronchopulmonary aspergillosis, hypersensitive pneumonia and conjunctivitis (Singh, 1994; Kurup, 2002).

\subsubsection{Allergic rhinitis and asthma}

Allergic rhinitis and asthma occur more frequently in atopic patients, these patients are predisposed to allergic responses because they possess elevated levels of IgE antibodies (Hung et al., 2005). Some symptoms of rhinitis are usually nasal discharge, sneezing and congestion resulting from nasal inflammation (Day and Ellis, 2001). In a study by Flannigan et al. (2001), 25.8\% of the people diagnosed with rhinitis were sensitized to molds.

Asthma is characterized as a reversible airway obstruction and persistent airway inflammation induced by the interaction of an allergen with an IgE antibody (Hung et al., 2005). In Canada, the maximum attributable risk for fungal caused asthma is ca. $20 \%$. This value was derived after removing other common household contaminants that affect respiratory health such as pets, dust mites, smoking, endotoxins and socio-economic factors (Dekker et al., 1991). Many studies established that asthmatics with an underlying mold allergy living in damp environments and/or being exposed to fungi 
indoors could have increased their asthma symptoms (NAS, 2000; NAS, 2004). With the recent climate change observed, there is growing concern because fungi that were usually absent or present in limited amounts will increase and ultimately cause additional asthma and allergies (Wolf et al., 2010).

\subsubsection{Allergic bronchopulmonary aspergillosis (ABPA)}

Allergic bronchopulmonary aspergillosis (ABPA) is a pulmonary disease caused by the long term exposures of high concentrations of Aspergillus fumigatus, but sometimes other Aspergillus species (Dillon et al., 2007; Hung et al., 2005). Chronic A. fumigatus spore inhalation can lead to some people becoming allergic because they are exposed to allergens and toxins that cause an immunological response that involves $\operatorname{IgE}$ and $\operatorname{IgG}$ antibodies (Day and Ellis, 2001; Horner et al., 1995). The spores have the ability to penetrate in the lower respiratory tract and colonize the bronchial tree causing damage to the bronchial wall and surrounding tissues (Dillon et al., 2007).

\subsubsection{Hypersensitive pneumonia (HP)}

Hypersensitive pneumonia is an immunological lung disorder characterized by the inflammation of the lungs due to large exposures to a wide array of organic agents including chemicals, low molecular weight compounds and microbial agents (Hung et al., 2005; Hodgson and Flannigan, 2001). Symptoms can include chest tightness, coughing and wheezing, these are reversible if patient exposure is discontinued, permanent lung 
damage can occur if the exposure persists (Hung et al., 2005). Building related exposures to microbial agents has been linked to causing HP but is more often encountered in occupational settings (e.g., farming, pigeon breeding and malting; Hung et al., 2005; Hodgson and Flannigan, 2001).

\subsubsection{Conjunctivitis}

Conjunctivitis is the inflammation of the clear membrane (conjunctiva) that covers the inside of the eyelid as well as the eyeball (Hung et al., 2005). If an allergen is the cause of the inflammation, it is called an allergic conjunctivitis and is associated with symptoms of swelling, redness, itching and tearing of the eye (Simoni et al., 2007).

\subsection{Chaetomium globosum and health issues}

Superficial infections caused by $C$. globosum are rare, only a small number of cases have been reported in the literature; two of these were skin infections (Costa et al., 1988; Yu et al., 2006) and four were nail infections (Guarro et al., 1995; Hattori et al., 2000; Naidu et al., 1991; Stiller et al., 1992). More than half of these superficial infections were opportunistic because the patients had a pre-existing condition. Oxyconazole was used to cure a cutaneous lesion caused by C. globosum (Costa et al., 1988) and intraconazole for a toenail infection (Hattori et al., 2000). 
Chaetomium species have also been reported to cause invasive infections in patients with impaired immunity (Piecková, 2003), five cases were attributed to C. globosum (Abbott et al. 1995; Yeghen et al., 1996; Lesire et al., 1999; Teixeira et al., 2003; Aribandi et al., 2005). The invasive infections of the lungs and brain caused fatal diseases in its patients (Abbott et al. 1995, Yeghen et al., 1996; Lesire et al., 1999; Aribandi et al., 2005) but a patient with an infection of the cervical lymph nodes survived following amphotericin B treatment (Teixeira et al., 2003). The reliability of the reports associating C. globosum with invasive disease is questionable because of inadequate documentation. (Barron et al., 2003) For example, the brain infection by $C$. globosum was later identified as $C$. atrobrunneum (Abbott et al. 1995).

The study of $C$. globosum as an indoor contaminant is important in relation to human health since this fungus produces toxins (Flannigan and Miller, 2001). Toxins produced by $C$. globosum that are often isolated are cytochalasins, the chaetoglobosins. These toxins are cytoskeleton modifiers that inhibit locomotion and cytoplasmic division of mammalian cells (Ueno and Hsieh, 1985). Chaetoglobosins A-G and $\mathrm{J}$ are produced by C. globosum species. All are cytotoxic to various culture cell lines at low doses (Piecková, 2003; Fogle et al., 2007; Udagawa et al., 1979). For example, growth inhibition of HeLa cells occurs at $3.2-10 \mu \mathrm{g} / \mathrm{ml}$ for chaetoglobosin A and at $10-32 \mu \mathrm{g} / \mathrm{ml}$ for chaetoglobosin C. The toxicity of chaetoglobosins depends on the route of entry, they have low or no toxicity when ingested (Udagawa et al., 1979; Nielson et al., 1999). Binder and Tamm (1973) determined that an oral administration of chaetoglobosins had no adverse effects on mice at concentrations as high as $400 \mathrm{mg} / \mathrm{kg}$. High toxicity is 
observed when chaetoglobosins are injected intravenously in animal testing and no data has been published on the effects of the inhalation of chatoglobosins (Nielson et al., 1999). Subcutaneous injections done on mice by Binder and Tamm (1973) established an $\mathrm{LD}_{50}$ of $6.5 \mathrm{mg} / \mathrm{kg}$ mice for males and $17.8 \mathrm{mg} / \mathrm{kg}$ for females. The chaetoglobosins all have similar structures (figure 3), they all bear an indol-3-yl group and a 13-membered macrocycle (Sekita et al., 1976).

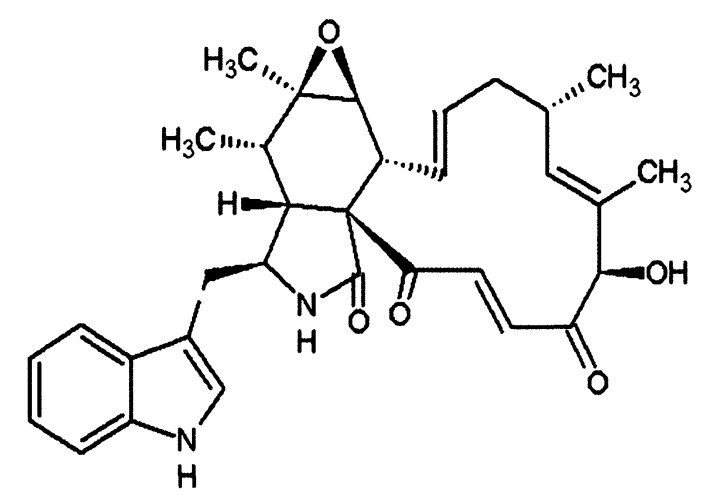

Figure 3: Molecular structure of chaetoglobosin A

Another toxin produced by $C$. globosum is chaetomin, it was isolated during the analysis of spoiled corn implicated in mycotoxicoses (Udagawa et al., 1979; Brewer and Taylor, 1978). Toxicity experiments on rats and young turkeys proved that chaetomin was toxic (Udagawa et al., 1979; Brewer et al., 1972). It was also determined that chaetomin can act as an antibiotic against gram positive bacteria and possesses antifungal properties (Brewer et al., 1972; Piecková, 2003).

The presence of C. globosum species in indoor environments is known to elicit IgEmediated allergies, even though their spores are large and deposited less easily in the 
lungs they have been known to still cause sinusitis and pneumonia if inhaled (Huppert et al., 1978; Aru et al., 1997; Nielson et al., 1999; Yu et al., 2006). The Allergen Nomenclature Sub-Committee of the World Health Organization (WHO) and the International Union of Immunological Societies (IUIS) maintain a list of accepted allergens, thus far no allergens have been characterized for any Chaetomium species (www.allergen.org, 2010).

\subsection{Biological mechanism associated with allergy}

An allergic reaction requires a previous exposure to an antigen (i.e., sensitization), the interaction between antigen and antibody creates a hypersensitive response and is due to the involvement of immunoglobulin E (IgE; Gould et al., 2003). IgE possess a high affinity to the FceRI receptor on mast cells, when it is bound and an antigen ligates, through the variable region, an array of inflammatory reactions involving the airways, blood vessels and gastrointestinal tract are induced. Degranulation occurs and chemical mediators such as histamine, prostaglandins, proteases, chymases and esterases are secreted and chemokines, leukotrienes and cytokines are synthesized. This is referred to as the immediate allergic response. This provokes a more sustained inflammation, the late phase response, resulting in the recruitment of effector cells; $\mathrm{T}_{\mathrm{H}} 2$ lymphocytes, eosinophils and basophils. The eosinophils in turn release proteins, free-radicals and additional chemical mediators that orchestrate an amplified inflammatory cascade (Janeway et al., 2005). 
The development of allergic reactions is associated with both environmental and genetic factors (von Mutius, 2002). Strachan (1989) introduced a concept called the "hygiene hypothesis" suggests that allergy is developed due to the lack of exposure to infectious disease at a young age, resulting in an underdeveloped immune system. An environment where the individual is not surrounded by older siblings capable of transmitting infection makes them prone to allergenic diseases (Strachan, 1989). This could cause a disruption with the usually existing balance of $T_{H} 1$ and $T_{H} 2$ helper T-cells, resulting in that individual developing additional $\mathrm{T}_{\mathrm{H}} 2$ cells that have proinflammatory effects (Schaub et al., 2006). Atopic individuals are genetically predisposed to develop allergies. Their amount of $\operatorname{IgE}$ is around 1000 times higher than in healthy individuals (Gould et al., 2003). It has been discussed that Toll-like receptors (TLRs) and endotoxin receptor CD14 are possibly involved with the genetic component of allergenic disease (Eder et al., 2004; Jackola et al., 2006; Kabesch et al., 2004).

\subsection{Allergens and their diagnosis}

Allergens can induce an $\operatorname{IgE}$ response, they possess 2 binding sites (i.e., epitopes) for IgE antibodies, once cross-linked they can facilitate mast cell degranulation and epitopes that bind $\mathrm{T}$ cells to favor the production of $\mathrm{T}_{\mathrm{H}} 2$ cells. Allergens are characterized by their biological functions; they can be enzymes, enzyme inhibitors, ligand binding proteins or structural proteins (Chapman et al., 2000). The nomenclature used to name allergens uses the first 3 letters of the genus name, followed by the first letter of the species and then a number indicating the chronologic order of discovery (Chapman et al., 2007). 
Structural similarities as well as homologous epitope amino acid sequences can explain the cross-reactivity associated with certain allergens (Fedorov et al., 1997). Environmental allergens can be from biological or chemical origins (i.e., fungi, pollen, insects, animal dander, dust mites, food and latex). Many allergens from the Ascomycetes and Basidiomycetes have been discovered, however the characterization of fungal allergens is lagging for various reasons, discussed below, except for Cladosporium herbarum, Alternaria alternata and Aspergillus fumigatus the most studied fungi (Horner et al., 1995).

Allergic sensitization can be demonstrated by in vivo methods such as skin testing and by in vitro methods that measure IgE antibodies in the blood. Skin prick tests (SPT) usually apply a commercially prepared allergen or protein extracts into the skin, wheal and flare reactions correlates with inflammatory mediators activated during an allergy (Hung et al, 2005). These tests rapidly assess an allergic response but however several limitations exist for building-associated fungi. The extracts used are not standardized, they are manufactured by different companies, and they vary in protein composition caused by strain and batch-to-batch variability, growth and storage conditions and protein extraction methods (Hung et al., 2005; Simon-Nobbe et al., 2008). The lack of standardized fungal allergen products affects the specificity and sensitivity of diagnostic tests (Esch, 2004). For example, when skin prick tests were analyzed $6-15 \%$ of the population exhibited allergy to fungi (Horner et al., 1995). This is only an estimate because it is based on inconsistent test reagents (Miller and Day, 1997). Additionally, cross-reactivity is observed between commercially available fungal allergen extracts making it difficult to 
demonstrate that a specific fungus in the built environment is linked to allergy (Hung et al., 2005). In a study where extracts manufactured from two different companies were analyzed using skin prick tests, dissimilarities where observed in the results; for instance, $4 \%$ of patients had a positive response to C. globosum from one company compared to 7\% with the other (Beezhold et al., 2008).

In vitro methods, such as inhibition radioallergosorbent testing (RAST), Pharmacia ImmunoCAP (CAP) assays, halogen immunoassays (HIA), ELISAs and Western blots, can detect allergen specific serum IgE antibodies in allergic subjects (Carrer et al. 2001; Green, 2006a \& b; Simon-Nobbe et al., 2008). RAST inhibition requires radioisotopes and sera from sensitized individuals and usually needs more of the less available purified antigen (Hung et al., 2005). ELISA test kits for dust mite, cat, dog, cockroach, mouse and rat allergens have been purified at present (Pate et al., 2005; NAS 2000). Their high throughput, accurate quantitation and specificity make them widely used for environmental allergen measurements (Chapman et al., 2001). ELISA has been successfully implemented for the identification of only a few fungi. The fungal allergens for Alternaria alternata and Aspergillus fumigatus are well characterized and the production of monoclonal antibodies has made their identification using ELISA achievable (Dillon et al., 2007; Sporik et al., 1993). Limitations for ELISA testing are that only a few fungal allergens have been characterized. Further, techniques used for their production and maintenance are critical for reproducibility and accuracy and many fungi share common antigens, therefore antibody specificity is limited and crossreactivity to other fungi can be encountered (Chapman et al., 2001; Sporik et al., 1993). 
The use of monoclonal antibodies in ELISA tests can overcome some problems of crossreactivity because they are epitope specific (Green et al., 2006a). The development of methods that detect specific fungal allergens is considered crucial for assessments of mold related exposures (NAS, 2000). Halogen immunoassays (HIA) and Western blots use immunestaining with human serum to characterize the sensitization of a patient to allergens. HIAs use fungal particles directly obtained from the patient's environment (Green et al., 2006a). A study comparing the conventional techniques of SPT and CAP with the newer HIA revealed that HIA correlated with the diagnostic results of the CAP system and to a lesser extent with the SPT (Green et al., 2006b). The presence of IgG antibodies in serum are considered an indirect marker for exposure to fungi and can be used in immunoblotting tests (Douwes et al., 2003). However, no quantitative relation between IgG levels and airborne exposures has been established. Therefore, the presence of $\operatorname{IgG}$ antibodies in serum can represent a sign for exposure but not necessarily of disease (Douwes et al., 2003).

\subsection{Detection of fungi indoors}

A variety of sampling techniques exist to detect the presence of fungal growth in an indoor environment. Accurate detection is necessary to estimate exposure levels. For this purpose, the most widely used techniques involve collecting from areas of visible growth and evaluating the collection of fine dust (Miller, 2010). Although, the contamination is often hidden in wall cavities and extensive destructive testing needs to 
be carried out to properly document exposure and properly estimate the degree of risk (Miller, 2010).

Direct methods of sampling involve culture-based and non-culture-based methods that are based on taking a sample collection of the actively growing fungi and culturing it on different media for visual identification and using microscopy for identification, respectively. The use of indirect methods can also be employed. This requires detecting metabolic by-products of fungal growth (Prezant et al., 2008b). The culture-based methods employ techniques like swab sampling, bulk sampling, tape sampling, agar slide, imprint with contact plates and air sampling to collect the fungal species present indoors (Miller, 2010). Air sampling can be done with small volumes of air in a small amount of time but activity in the room prior to sampling, pressure changes and amount in settled dust are factors that affect the variability of theses samples (Hung et al., 2005).

Air sampling using a sticky surface, like an Air-O-Cell cassette, can also be used and spores can directly be counted and identified (Hung et al., 2005). This enables a large percentage of spores to be captured; this does not provide much taxonomic information because of unidentifiable features of the spores but can allow estimations on the diversity of unculturable fungi present in the air. A number of disadvantages are associated with using the culture-based methods for identifying fungi, they include; time consuming, the propagule must be viable (e.g., some spores are perishable while others have very long half-lives), morphological identification requires considerable experience, the appropriate medium should be used for fungal growth and slow growing fungi can be overlooked if 
they are outcompeted by other fungi (Hung et al., 2005; Prezant et al., 2008b). The tape sampling and mounting scrapings of the mold-damaged area are usually used for the nonculture based methods (i.e., microscopy). With this technique, hyaline spores are often overlooked and the taxonomic information obtained is limited (Miller, 2010). Morphology alone can sometimes be challenging for the identification of certain fungi. Therefore, examining the chemotaxonomy and genotype can be useful for a more reliable identification (e.g., de la Campa et al., 2007; Scott et al., 2004).

Indirect methods for the identification of fungi growing in the built environment entail the analysis of secondary metabolites (e.g., toxins), volatile compounds (e.g., VOCs) or cellular components (e.g., ergosterol and $\beta 1,3$-D-glucans). During active growth, fungi emit VOCs as a function of total fungal biomass, meaning that different fungi will likely produce amounts of VOCs that are similar, however there are considerable differences in the type of VOCs produced between different species (Horner and Miller, 2003). Some VOCs are most likely to be exclusively from microbial sources (e.g., 3-methyl-1-butanol, 2-hexanone and 2-heptanone). These metabolites are usually sampled from indoor environments using adsorbent trap cartridges and identified using gas chromatography and mass spectrometry (GS/MS; Miller et al., 1988). Microbial VOC (MVOC) sampling devices are usually small and can be used in hidden areas (e.g., wall cavities) providing insight in situations where mold was undetected from culturable sampling. Often the data recovered from MVOCs sampling is not normalized per unit of fungal biomass (e.g., $\mathrm{CO}_{2}$ or mycelial dry weight) making their interpretation difficult or even meaningless (Horner and Miller, 2003). 
Toxins are present on fungal particles and can be sampled by air samplers but the volume of air used must be larger because of their very low levels and other compounds present can interfere with the analysis. Moreover, toxins can still be detected even if the fungal propagule is not viable (Hung et al., 2005). Bulk samples or even culturing the fungi present indoors can also be used for the recovery of toxins. They are usually analysed using thin layer chromatography (TLC) and high performance liquid chromatography (HPLC; Dillon et al., 1999; Hung et al., 2005). Nevertheless, only a few standards are available and most protocols used for the identification of toxins come from agricultural samples rather than indoor environments making their analysis difficult (Dillon et al., 1999).

Cellular compounds like ergosterol and $\beta 1,3-\mathrm{D}$-glucans are usually good indicators of mold growth in the built environment because they are unaffected by different growth conditions (Foto et al., 2004; Miller and Young, 1997). Ergosterol is the primary membrane sterol of ascomycetes and can be used to measure fungal biomass of areas with visible mold growth but does not provide qualitative information and it is easily biodegradable and photodegradable (Dillon et al., 2007; Miller, 2001 and 2010). It is usually recovered from air filters using a microwave-assisted extraction and identified using GC/MS and its quantification is done with internal standards such as dehydrocholesterol (Hung et al., 2005; Miller and Young, 1997). Triple helical $\beta 1,3-D-$ glucans can only be measured by the factor $G$ of the Limulus Amoebocyte Lysate Assay (LAL; Foto et al., 2004; Iossifova et al., 2008). No standard for the fungal glucan exists but curdlan is often used as a reference standard (Hung et al., 2005). A major 
shortcoming of these chemical methods of fungal detection is that cellular components can be used to quantify total fungal biomass present in the environment but are not associated with the presence a specific fungal species and only a few VOCs and secondary metabolite profiles are available for indoor fungi. Therefore, these methods often have to be used in combination with other identification methods (Horner and Miller, 2003; Seifert and Lévesque, 2004).

Enzyme-linked immunosorbent assays (ELISA) and polymerase chain reaction (PCR) assays are being considered as alternatives for fungal identification and exposure assessments (Sporik et al., 1993). As previously described, ELISAs are widely used to measure allergens, especially in settled dust, but very few fungal allergens are available therefore making their detection from indoor environments more challenging when using this technique (Douwes et al., 2003). PCR assays can be developed to detect specific fungal spores from an air sample containing a mixture of non-target organisms and materials. Primers are designed to amplify the region in ribosomal DNA for a specific fungi and the PCR assay detects its presence (Seifert and Lévesque, 2004). A drawback to the PCR assay is that it cannot be used to quantify the amount of DNA present in a sample. However, a quantitative (QPCR) assay using fluorescent dye can be incorporated in the amplified products making quantification of target DNA in a sample possible by measuring the fluorescent signal (Hung et al., 2005; Seifert and Lévesque, 2004). PCR accuracy is limited because of certain matrices. Furthermore, the data recovered from PCR methods does not correlate with the traditional methods of detection nor do they relate to exposure (Dillon et al., 2007). 


\subsubsection{Difficulties related with the detection of $C$. globosum indoors}

Various characteristics of $C$. globosum are linked to its underrepresentation in water damaged buildings. For example $C$. globosum consists of large spores, therefore, when air samples are solely used for comparison to other smaller spore forming fungi their frequency in indoor environments is underestimated (Shelton et al., 2002). C. globosum propagules have a short life span and the spores are released in a slimy matrix making their isolation difficult (Flannigan et al., 2001; Andersen and Nissen, 2000). In a study by Gravensen et al. (1986) Chaetomium species were not detected in any of the air samples of the water-damaged houses but $25 \%$ of the dust samples from the same locations contained the fungus. In addition, often methods of culturing are unfavourable for the detection of $C$. globosum species in the built environment. The standard media used for the detection of fungi indoors (DG-18 and MEA) are not selective toward $C$. globosum therefore enabling faster growing fungi to out compete them (Andersen and Nissen, 2000). Chaetomium species are particularly found in cavities and under the surface of the building materials (Guarro et al., 1999).

Our laboratory has taken the approach of isolating proteins from building-associated fungi that are antigenic to humans and using them as tools for indoor exposure assessments. C. globosum was investigated because it represents a hydrophilic fungus that is commonly isolated indoors. It has been associated with allergy but little is known about the impacts of its metabolites on health effects and no allergens have yet to be determined. A reliable way to assess disease associated with fungi in the indoor environment would be to develop "standardized methods for assessing exposure to fungal 
allergens ... preferably based on the measurements of allergens rather than culturable or countable fungi" (NAS, 2000).

\subsection{Project Aim}

The objective of this research is to identify, purify and characterize proteins from $C$. globosum that are antigenic to humans. After enzyme-linked immunosorbent assays (ELISA) and immunoblotting tests, possible target antigens are selected and their antigenicity is verified by the production of polyclonal antibodies in rabbits. Moreover, monoclonal antibodies that are sensitive and specific to the target antigens will also be produced that may be useful to assess exposure to C. globosum. 


\section{MATERIALS AND METHODS}

\section{REAGENTS}

5X protein sample loading buffer - $15 \%$ sodium dodecyl sulfate (SDS, J.T. Baker, Phillipsburg, NJ) 50\% glycerol (EDH, USA), 0.05\% bromophenol blue (USB, Cleveland, $\mathrm{OH}), 5 \% \beta$-mercaptoethanol (Sigma-Aldrich, Oakville, ON) and 30\% 624mM Tris/HCl (Sigma-Aldrich, Oakville, ON), pH 6.8.

Ammonium sulfate $\left(\mathbf{N H}_{3}\right)_{2} \mathbf{S O}_{4}$ - generally used for protein precipitations (SigmaAldrich, Oakville, ON).

AP-conjugated anti-human IgG antibody - alkaline phosphatase (AP) conjugated mouse anti-human IgG (Sigma-Aldrich, Oakville, ON). Diluted 2000x in 1\% BSA/TBST.

AP-conjugated anti-rabbit IgG antibody - alkaline phosphatase (AP) conjugated goat anti-rabbit IgG (Sigma-Aldrich, Oakville, ON). Diluted 30 000x in 1\% BSA/TBST.

AP-conjugated anti-mouse IgG antibody - alkaline phosphatase (AP) conjugated goat anti-mouse IgG (Sigma-Aldrich, Oakville, ON). Diluted 25 000x in 1\% BSA/TBST.

BCIP developing solution - Liquid substrate system (BCIP/NBT 5-Bromo-4-chloro-3indolyl phosphate dipotassium/nitrotetrazolium blue chloride) for membranes (SigmaAldrich, Oakville, ON). Typically $5 \mathrm{~mL}$ of solution added directly to membrane.

Blocking solution (immunoblot) - 1\% (w/v) bovine serum albumin (BSA; SigmaAldrich, Oakville, ON) dissolved in TBST buffer.

Coating buffer - Buffer promoting protein adhesion to ELISA plate. 50mM carbonatebicarbonate, pH 9.6 (Sigma-Aldrich, Oakville, ON).

Developing solution $-0.625 \mathrm{~g}$ sodium carbonate and made up to $25 \mathrm{~mL}$ with ultrapure deionized water. A $5 \mu \mathrm{L}$ aliquot of formaldehyde $(37 \% \mathrm{w} / \mathrm{v})$ was added just prior to use (GE Healthcare, Piscataway, NJ).

Enneatin media - culture media specific for protein production. The media contains $50 \mathrm{~g}$ maltose (Sigma-Aldrich, Oakville, ON), $8 \mathrm{~g}$ peptone (Difco, Lawrence, KS), $5 \mathrm{~g}$ yeast extract (Sigma- Aldrich, Oakville, ON), 0.75g $\mathrm{KH}_{2} \mathrm{PO}_{2}$ (Sigma- Aldrich, Oakville, ON), 0.5g $\mathrm{MgSO}_{4}-7 \mathrm{H}_{2} \mathrm{O}$ (J.T. Baker, Phillipsburg, NJ ) and $0.067 \mathrm{~g} \mathrm{CaCl} 2-2 \mathrm{H}_{2} \mathrm{O}$ (Difco, Lawrence, KS) per L of ultrapure de-ionized water.

Equilibration buffer I (20mL) contained 0.91g Trizma Base (Sigma- Aldrich, Oakville, ON), $14.12 \mathrm{~mL}$ of $8.5 \mathrm{M}$ urea (Sigma- Aldrich, Oakville, ON), 0.4g SDS (J.T. Baker, Phillipsburg, NJ), 4mL glycerol (BDH, Toronto, ON) and 0.4g DTT (Sigma- Aldrich, Oakville, ON). 
Equilibration buffer II (20mL) was similar to equilibration buffer I, except $0.4 \mathrm{~g}$ DTT (Sigma- Aldrich, Oakville, ON), was replaced with 0.5g Iodoacetamide (Sigma- Aldrich, Oakville, ON).

Fixation solution - Fixation solution was composed of $7.5 \mathrm{~mL}$ ethanol, $2.5 \mathrm{~mL}$ glacial acetic acid and then made up to $25 \mathrm{~mL}$ with ultrapure de-ionized water (GE Healthcare, Piscataway, NJ).

HRP-conjugated anti-human IgG antibody - horseradish peroxidase (HRP) conjugated

goat anti-human IgG (Sigma-Aldrich, Oakville, ON). Diluted 2000x in 1\% BSA/TBST.

HRP-conjugated anti-rabbit IgG antibody - horseradish peroxidase (HRP) conjugated goat anti-rabbit IgG (Sigma-Aldrich, Oakville, ON). Diluted 5000x in 1\% BSA/TBST.

HRP-conjugated anti-mouse IgG antibody - horseradish peroxidase (HRP) conjugated

goat anti-mouse IgG (Sigma-Aldrich, Oakville, ON). Diluted 5000x in 1\% BSA/TBST.

Laemmli running buffer system (running buffer) - $15 \mathrm{~g}$ Tris (Sigma-Aldrich, Oakville, ON), 72g glycine (Sigma-Aldrich, Oakville, ON), 10g SDS (USB, Cleveland), dissolved up to $1 \mathrm{~L}$ with ultrapure de-ionized water.

PBST buffer - Phosphate buffered saline, with Tween-20. 80g NaCl (Sigma-Aldrich, Oakville, ON), 26.8g Na $2 \mathrm{HPO}_{4}-7 \mathrm{H}_{2} \mathrm{O}$ (EMD, Cincinnati, $\mathrm{OH}$ ) $2 \mathrm{~g} \mathrm{KCl}$ (Sigma-Aldrich,

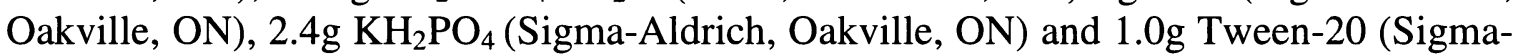
Aldrich, Oakville, $\mathrm{ON}$ ) in $700 \mathrm{~mL}$ ultrapure de-ionized water. The $\mathrm{pH}$ was adjusted to 7.4 with $1 \mathrm{M} \mathrm{HCl}$ and the solution was diluted to $1 \mathrm{~L}$ with ultrapure de-ionized water.

Q-sepharose anion exchange resin - Q Sepharose Fast Flow Anion exchanger (GE Healthcare, Piscataway, NJ), wet bead size: $45-165 \mu \mathrm{m}$ (pre-swollen in $20 \%$ ethanol).

Rehydration buffer $(10 \mathrm{~mL})$ consisted of $9.41 \mathrm{~mL} 8.5 \mathrm{M}$ urea (Sigma-Aldrich, Oakville, ON), 0.2g Chaps (Bio-Rad, Mississauga, ON), 76.7mg DTT (Sigma-Aldrich, Oakville, $\mathrm{ON}), 50 \mu \mathrm{L}$ Ampholytes (Bio-Rad, Mississauga, ON) pH 3-10 and 5 $\mu \mathrm{L} 1 \%$ bromophenol blue (USB, Cleveland, OH).

SDS-PAGE gels (10\%) - The $10 \%$ acrylamide gel was made by mixing $1.7 \mathrm{~mL}$ of $30 \%$ acrylamide (Bio-Rad, Mississauga, ON), $1.3 \mathrm{~mL}$ of $1.5 \mathrm{M}$ Tris/HCl buffer, $\mathrm{pH} 8.8,50 \mu \mathrm{L}$ $10 \%$ SDS (J.T. Baker, Phillipsburg, NJ), 50 $\mu \mathrm{L}$ of $10 \%$ ammonium persulfate (APS; USB, Cleveland, $\mathrm{OH}$ ) and $5 \mu \mathrm{L}$ TEMED (N,N,N',N'-Tetramethylethylenediamine (SigmaAldrich, Oakville, ON).

The stacking gel was made by mixing $1.4 \mathrm{~mL}$ ultrapure de-ionized water, $0.33 \mathrm{~mL} 30 \%$ acrylamide mix (Bio-Rad, Mississauga, ON), 0.25mL 1.0M Tris/HCl buffer ( $\mathrm{pH} 6.8$ ), $20 \mu \mathrm{L}$ of $10 \%$ ammonium persulfate (USB, Cleveland, $\mathrm{OH}$ ) and $2 \mu \mathrm{L}$ of TEMED (SigmaAldrich, Oakville, ON). 
Sensitizing solution - 7.5mL ethanol (Commercial Alcohols, Brampton, ON), $1 \mathrm{~mL}$ sodium thiosulphate (5\%w/v) (GE Healthcare, Piscataway, NJ), $1.7 \mathrm{~g}$ sodium acetate (GE Healthcare, Piscataway, NJ) made up to $25 \mathrm{~mL}$ with ultrapure de-ionized water. $125 \mu \mathrm{L}$ aliquot of glutardialdehyde (25\%w/v) (GE Healthcare, Piscataway, NJ) was added just prior to use.

Sephacryl gel filtration resin - Sephacryl S-300-HR resin (Sigma-Aldrich, Oakville, ON), wet bead size: $25-75 \mu \mathrm{m}$ (pre-swollen in $20 \%$ ethanol).

Silver solution $-2.5 \mathrm{~mL}$ of silver nitrate solution $(2.5 \%$ w/v) (GE Healthcare, Piscataway, NJ) and made up to $25 \mathrm{~mL}$ with ultrapure de-ionized water. Just prior to adding the silver solution to the gel, $10 \mu \mathrm{L}$ of formaldehyde (37\% w/v) (GE Healthcare, Piscataway, NJ) was added to the solution.

Stopping solution - $0.365 \mathrm{~g}$ of EDTA- $\mathrm{Na}_{2} \cdot 2 \mathrm{H}_{2} \mathrm{O}$ (GE Healthcare, Piscataway, NJ) and made up to $25 \mathrm{~mL}$ with ultrapure de-ionized water.

TBST buffer - 60.5g Trizma base (Sigma-Aldrich, Oakville, ON), 87.6g NaCl (SigmaAldrich, Oakville, ON), 5.6g of Tween-20 (0.05\%) (Sigma-Aldrich, Oakville, ON) dissolved in $600 \mathrm{~mL}$ ultrapure de-ionized water, adjusted to $\mathrm{pH} 7.4$ with $1 \mathrm{M} \mathrm{HCl}$ and then made up to $1 \mathrm{~L}$ with ultrapure de-ionized water.

TMB developing solution (ELISA) - 3,3',5,5' tetramethybenzidine liquid substrate for ELISA (Sigma-Aldrich, Oakville, ON).

Towbin buffer (transfer buffer) - 12g Trizma base (Sigma-Aldrich, Oakville, ON), 57.6g glycine (MP Biomedicals, Solon, OH), 4g SDS (J.T. Baker, Phillipsburg, NJ) in $200 \mathrm{~mL}$ ethanol (Commercial Alcohols, Brampton, ON) made up to $1 \mathrm{~L}$ with ultrapure deionized water.

Transfer membrane - Hybond-PVDF membrane (GE healthcare - Amersham Biosciences, Piscataway, NJ), membrane used for protein transfer in immunoblotting.

Tris buffer $-50 \mathrm{mM}$ Tris/HCL buffer, $\mathrm{pH} 7.5 \quad\left(6.057 \mathrm{~g} / \mathrm{L} \quad \mathrm{ddH}_{2} \mathrm{O}\right.$ Trizma base $\left(\mathrm{NH}_{2} \mathrm{C}\left(\mathrm{CH}_{2} \mathrm{OH}\right)_{3}\right)$ (Sigma-Aldrich, Oakville, $\left.\mathrm{ON}\right)$, acidified to $\mathrm{pH} 7.5$ with $\left.1 \mathrm{M} \mathrm{HCl}\right)$.

Ultrapure water - distilled, de-ionized water 


\subsection{Culture production}

C. globosum strains were received from Paracel Laboratories Ltd. (Ottawa, ON) and the Microfungus Collection and Herbarium from the University of Alberta (Edmonton, AB). All fungal strains were collected from indoor air samples or indoor materials from across Canada. The strains from Paracel Laboratories were identified by Dr. J. D. Miller and were confirmed by ITS sequencing done at DNA Landmarks Inc. (Saint-Jean-surRichelieu, QC). The sequenced strains were confirmed to be $C$. globosum and were deposited in the National Mycological Herbarium at the Department of Agriculture, located in Ottawa, Ontario (DAOM). The other strains (DAOM 234120, UAMH 7142 and UAMH 7773) were obtained from culture collections therefore sequencing was not required. The ITS sequences as well as the DAOM accession numbers for each strain can be found in tables A1.1 and A1.2 of the appendix.

Each strain was individually transferred to $2 \%$ sterile malt extract agar (MEA) slants. The slants were incubated in the dark at $25^{\circ} \mathrm{C}$ until sufficient growth was obtained, usually 14 days. The slants were capped and then sealed with parafilm and stored in $4^{\circ} \mathrm{C}$ until further use. The following inoculation procedure was carried out for all strains. Enniatin medium was used for the fermentation of the cultures because it produces large amounts of proteins and peptides (Traber et al., 1989). It has been used to produce extracellular antigens (e.g. Xu et al., 2008; Wilson et al., 2009). The medium was autoclaved at $121^{\circ} \mathrm{C}$ for 12min. A slant was macerated in sterile ultrapure water using a Polytron homogenizer (Brinkmann Instruments, Rexdale, Ontario). A 5\% (v/v) aliquot was then used to inoculate $2.8 \mathrm{~L}$ Fernbach flasks containing $560 \mathrm{~mL}$ of medium and $2.0 \mathrm{~L}$ 
Erlenmeyer flasks containing $400 \mathrm{~mL}$ of medium. The flasks were placed in the dark on a rotary shaker with a speed of $220 \mathrm{rpm}$ for $96 \mathrm{~h}$ at $25^{\circ} \mathrm{C}$. All cultures were filtered through cheesecloth to separate the cells from the culture filtrate. The cells were washed with ultrapure water and frozen at $-20^{\circ} \mathrm{C}$ and later freeze-dried. The culture filtrate was used for extracellular protein extraction.

\subsection{Spore production}

A variety of different agar media; malt extract agar, potato carrot agar, hay infusion agar and water agar containing a filter paper (Samson et al., 2002) were tested to determine which media would produce the highest amounts of $C$. globosum spores. The malt extract agar (MEA) consisted of $20 \mathrm{~g}$ malt and $18 \mathrm{~g}$ of agar per liter of ultrapure water. The water agar (WA) contained $20 \mathrm{~g}$ of agar in $1 \mathrm{~L}$ of ultrapure water. The MEA and WA were autoclaved for $12 \mathrm{~min}$ at $121^{\circ} \mathrm{C}$, the media was placed in a water bath of $45^{\circ} \mathrm{C}$ for $10 \mathrm{~min}$ and poured into sterile Petri dishes. For potato carrot agar (PCA) 40g of carrots and $40 \mathrm{~g}$ of potatoes were separately washed, peeled, chopped and boiled in $1 \mathrm{~L}$ of ultrapure water for $5 \mathrm{~min}$. Each extract was strained through cheesecloth, $250 \mathrm{~mL}$ of each were combined and $30 \mathrm{~g}$ of agar was added to the mixture. The solution was heated to dissolve the agar then ultrapure water was added to make it up to $1 \mathrm{~L}$. The PCA medium was sterilized by autoclaving at $121^{\circ} \mathrm{C}$ for $12 \mathrm{~min}$. Hay infusion agar (HIA) was made as follows; $50 \mathrm{~g}$ of hay was added to $1 \mathrm{~L}$ of ultrapure water and autoclaved for $30 \mathrm{~min}$ at $121^{\circ} \mathrm{C}$. It was filtered through cheesecloth and cooled to room temperature. Once the $\mathrm{pH}$ was adjusted to 6.2 with dipotassium phosphate and the volume was readjusted to $1 \mathrm{~L}$, 
$15 \mathrm{~g}$ of agar were added and autoclaved for $15 \mathrm{~min}$ at $121^{\circ} \mathrm{C}$. Once the PCA and the HIA were autoclaved they were placed in a water bath of $45^{\circ} \mathrm{C}$ for $10 \mathrm{~min}$ and poured into sterile Petri dishes. The MEA, WA, PCA and HIA plates were left to solidify for $1 \mathrm{~h}$ at room temperature, under sterile conditions. Once the WA plates solidified a sterile filter paper (Whatman, 55mm) was added on the surface.

The plates with different media were inoculated with conidia of one strain of $C$. globosum and incubated in the dark for 3 weeks at $25^{\circ} \mathrm{C}$. The plates were air dried in a fume hood for 1 week until the agar was dry, at which point the spores were harvested using a suction vacuum equipped with a filter paper. The spores were then removed from the filter paper using a spatula and stored in vials at $4^{\circ} \mathrm{C}$ (Murad et al., 1993). The water agar containing a filter paper was the medium that produced the most abundant amount of spores and was then used to produce spores for all 14 strains.

\subsection{Extracellular protein extraction}

The harvested culture filtrate was treated by two different methods to extract the extracellular proteins. The first method, involved slowly mixing the culture filtrate with ice-cold acetone in a 1:1 ratio in order to remove non-protein material such as lipids and cell debris. This $50 \%(\mathrm{v} / \mathrm{v})$ acetone/culture filtrate solution was then kept at $-20^{\circ} \mathrm{C}$ overnight to allow complete precipitation. Subsequently the non-protein material was removed by centrifuging at $17,400 \times \mathrm{g}$ for $10 \mathrm{~min}$ at $4^{\circ} \mathrm{C}$ and was then discarded. The supernatant was mixed with an additional 1:1 ratio of ice-cold acetone. The resulting 
$75 \%(\mathrm{v} / \mathrm{v})$ acetone/culture filtrate solution was left at $-20^{\circ} \mathrm{C}$ overnight and then centrifuged at $17,400 \times \mathrm{g}$ for $8 \mathrm{~min}$ to precipitate the protein out of solution. The supernatant was removed and the pellet was kept on ice in a fume hood for $2 \mathrm{~h}$ to insure that the residual acetone evaporated. The extracellular proteins obtained were pooled together, dissolved in $50 \mathrm{mM}$ Tris- $\mathrm{HCl}$ buffer, $\mathrm{pH} 7.5$ and stored at $-20^{\circ} \mathrm{C}$ until further use.

The second method involved mixing the culture filtrate with $100 \mathrm{mmol} \mathrm{NaCl}$ and $1 \mathrm{mmol}$ of a cocktail of protease inhibitors (Benzamidine hydrochloride, 1-10-Phenanthroline and Phenylmethane sulfonyl fluoride). Once dissolved the solution was centrifuged at $30,000 \times \mathrm{g}$ for $30 \mathrm{~min}$ at $4^{\circ} \mathrm{C}$. The supernatant was then filtered through cheesecloth to ensure all cell debris and lipids were removed. The culture filtrate was concentrated fifty times (50x) through a Hydrosart membrane with a 10,000Da cut-off (Vivaflow 200 concentrator) at a speed of $10 \mathrm{~mL} / \mathrm{min}$ for $12 \mathrm{~h}$ to obtain the extracellular proteins. A buffer exchange (50mM Tris- $\mathrm{HCl}$ buffer, $\mathrm{pH} 7.5)$ was performed on the protein and it was stored at $-20^{\circ} \mathrm{C}$ until further use.

\subsection{Intracellular protein extraction}

The lyophilized fungal cells $(10.00 \mathrm{~g} \pm 0.02)$ were rehydrated in $100 \mathrm{~mL}$ of $50 \mathrm{mM}$ Tris$\mathrm{HCl}$ with $0.05 \%$ Tween buffer for $10 \mathrm{~min}$ on ice. The suspended cells were then homogenized on an ice bath using a Polytron homogenizer (Brinkmann Instruments, Rexdale, Ontario) at maximum speed for $5 \times 3 \mathrm{~min}$ with $10 \mathrm{~min}$ intervals. The homogenate 
was then centrifuged at $17,400 \times \mathrm{g}$ for $10 \mathrm{~min}$ at $4^{\circ} \mathrm{C}$. Salt precipitation using ammonium sulfate was used to precipitate the proteins. Ammonium sulfate was slowly added to the cell lysate supernatant with constant stirring and on ice to reach $50 \%$ saturation. The solution was kept at $4^{\circ} \mathrm{C}$ overnight to allow complete protein precipitation. The nontarget proteins were removed by centrifuging at $17,400 \times \mathrm{g}$ for $10 \mathrm{~min}$ at $4^{\circ} \mathrm{C}$. The supernatant was removed from the pellet and set aside for the $60 \%$ ammonium sulfate precipitation. The pellet was re-dissolved in $50 \mathrm{mM}$ Tris- $\mathrm{HCl}$ buffer $(\mathrm{pH} 7.5)$ and stored at $-20^{\circ} \mathrm{C}$ until further use. The same procedure was followed for $70 \%$ and $80 \%$ ammonium sulfate saturations.

\subsection{Protein extraction from spores}

The spores were weighed on a Mettler 163 analytical balance $(3.00 \mathrm{mg} \pm 0.02)$ in a plastic vial with a polystyrene bead. The spores were fragmented using a Spex-Certiprep mixer mill (model 5100, Metuchen, NJ) for 30min. When spores were used for immunoblotting or ELISA they were resuspended by shaking for $2 \mathrm{~h}$ at $4^{\circ} \mathrm{C}$ in $0.3 \mathrm{~mL}$ of Tris buffer, $\mathrm{pH}$ 7.5 or $0.3 \mathrm{~mL}$ of PBST, pH 7.5 respectively.

\subsection{Protein concentration}

The protein concentration was determined using the Bradford Protein Assay Kit (BioRad, Hercules, CA). Protein samples were diluted with ultrapure water to $150 \mathrm{uL}$ in a 96 well Nunc-immuno MaxiSorp plate (Sigma, Oakville, ON). In a separate well $150 \mathrm{uL}$ of 
ultrapure water was used as the blank. An equal amount of Bradford reagent was then added to the different wells at room temperature. After 10min the optical density was measured at $595 \mathrm{~nm}$ using a microplate spectrophotometer (Max340PC, Molecular Devices, Mississauga, ON). A standard calibration curve made with different concentrations of BSA was used to determine the protein concentration of each sample.

\subsection{Indirect Enzyme Linked Immuno-Sorbent Assay (indirect ELISA)}

The required antigen dilution was done using coating buffer $(50 \mathrm{mM}$ carbonatebicarbonate, pH 9.6, Sigma-Aldrich, Oakville, ON). The 96 well microplate (NuncImmuno MaxiSorp plates) was coated with $100 \mathrm{uL}$ of antigen per well and incubated overnight on a microplate shaker at $4^{\circ} \mathrm{C}$. Coating buffer was used as the blank used in this assay. The following steps were done at room temperature. The plate was coated with blocking buffer (2\% BSA-PBST) and incubated for $1 \mathrm{~h}$. The plate was washed $3 \times 5 \mathrm{~min}$ with $150 \mathrm{uL}$ of PBST. The plate was incubated for $1 \mathrm{~h}$ with the primary antibody. When human sera (HpAbs), rabbit polyclonal antibodies (RpAbs) or mouse monoclonal antibodies (MmAbs) were used as primary antibody they were respectively diluted $1,500 \times, 40,000 \times$ and $500 \times$ in $1 \%$ BSA-PBST. The plate was washed $3 \times 5$ min with $150 \mathrm{uL}$ of PBST. The respective horseradish peroxidase (HRP) conjugated secondary antibody was diluted with $1 \%$ BSA-PBST and incubated for $1 \mathrm{~h}$. HRP conjugated anti-human IgG (dilution of $1 / 2,000$ ), HRP conjugated anti-rabbit IgG (dilution of $1 / 5,000$ ) or HRP conjugated anti-mouse IgG (dilution of $1 / 5,000$ ). The content of the plate was emptied and the plate was washed $3 \times 5 \mathrm{~min}$ with $150 \mathrm{uL}$ of PBST. The color was developed by 
adding 100uL TMB liquid substrate (Sigma-Aldrich, Oakville, ON) for 10min. The reaction was stopped with $50 \mathrm{uL}$ of $0.5 \mathrm{M}$ sulfuric acid. The absorbance reading was done at $450 \mathrm{~nm}$ with a microplate spectrophotometer.

\subsection{Sodium Dodecyl Sulfate-Polyacrylamide Gel Electrophoresis (SDS-PAGE)}

All protein samples were normalized using the Bradford assay and then mixed with $5 x$ loading buffer in a $4: 1$ ratio $(\mathrm{v} / \mathrm{v})$. The samples where then boiled for $5 \mathrm{~min}$ and immediately afterwards they were put on ice to cool. The samples were then loaded on $10 \%$ acrylamide gels containing 10 or 15 lanes. The electrophoresis was done using a Laemmli buffer system with a mini VE Vertical Electrophoresis System (GE Healthcare Bio-Sciences Inc., QC) connected to a Power Pac 1000 gel electrophoresis power supply. The proteins were separated using a constant voltage of $100 \mathrm{~V}$ for $20 \mathrm{~min}$ followed by $200 \mathrm{~V}$ for $50 \mathrm{~min}$ or until the bromophenol blue dye reached $1 \mathrm{~cm}$ from the bottom of the gel. A low molecular marker (LMW-SDS Marker Kit, GE Healthcare Bio-Sciences Inc., QC) was used to determine the molecular weight of the proteins being separated once they were stained by the appropriate method.

\subsection{Protein identification and weight determinations}

Staining of the gels was performed to visualize the different proteins and to determine their molecular weight. Coomassie brilliant blue staining (CBB) was used for proteins that had concentrations above 50ng. The gel was removed from the caster and placed in 
a glass bowl where it was covered with $25 \mathrm{~mL}$ of $\mathrm{CBB}$ stain reagent and incubated overnight on a rotary shaker. The gel was destained the next day by washing with ultrapure water for 30min and visualized.

A silver stain was used if the total protein concentrations were below 50ng. Once the gel was removed from the mold it was placed in a fixation solution and was incubated for 30min. All steps involved in the silver stain were left on a rotary shaker for the duration of the incubation time. Once the fixation solution was removed the gel was placed in sensitizing solution for $30 \mathrm{~min}$. Then the gel was washed $4 \times 5 \mathrm{~min}$ with ultrapure water. The silver solution was then added for $20 \mathrm{~min}$ and the gel was washed with ultrapure water for $2 \times 1 \mathrm{~min}$. The developing solution was added and once the desired intensity was reached the gel was put in a stop solution for $10 \mathrm{~min}$. The gel was then washed with ultrapure water and scanned with a GS800 densitometer (Bio-Rad Laboratories (Canada) Ltd., Mississauga, ON).

The low molecular weight marker (LMW-SDS Marker Kit, GE Healthcare Bio-Sciences Inc., QC) was used to determine the molecular weight of the different proteins tested. This particular marker contains proteins with a known molecular weight: Phosphorylase B (97kDa), albumin $(66 \mathrm{kDa})$, ovalbumin $(45 \mathrm{kDa})$, carbonic anhydrase $(30 \mathrm{kDa})$, trypsin inhibitor $(20.1 \mathrm{kDa})$ and lactoalbumin $(14.4 \mathrm{kDa})$. These native proteins are used as standards to determine the molecular weight of the unknown proteins. 


\subsection{Immunoblotting}

Once the proteins were separated by SDS-PAGE, as described above, they were transferred on a Hybond-polyvinylidene difluoride (PVDF) membrane (GE Healthcare Bio-Sciences Inc., QC) using the method described by Towbin et al. (1979). A Hoefer miniVE electrotransfer (GE Healthcare Bio-Sciences Inc., QC) unit was used for the electro-transfer at a constant current of $400 \mathrm{~mA}$ for $30 \mathrm{~min}$ in an ice bath. Following the transfer, the marker was cut and placed in $\mathrm{CBB}$ to stain and the rest of the membrane was blocked in $1 \%$ bovine serum albumin in $0.5 \mathrm{M}$ Tris-buffer with $0.05 \%$ Tween 20 (TBST, $\mathrm{pH}$ 7.4) at room temperature for $1 \mathrm{~h}$. The blocking solution was removed and the membrane was incubated overnight at $4^{\circ} \mathrm{C}$ with the primary antibody. When human sera (HpAbs), rabbit polyclonal antibodies (RpAbs) or mouse monoclonal antibodies (MmAbs) were used as primary antibody they were respectively diluted 2,000x, 10,000x and $800 x$ in $1 \%$ BSA-TBST unless stated otherwise. The membrane was washed $3 \times 5$ min with TBST buffer and then incubated with the respective secondary antibody, alkaline phosphatase (AP) conjugated anti-human IgG (dilution of 1/2,000), AP conjugated anti-rabbit IgG (dilution of $1 / 30,000$ ) or AP conjugated anti-mouse IgG (dilution of $1 / 25,000$ ). The membrane was incubated at room temperature for $1 \mathrm{~h}$ and washed again $3 \times 5 \mathrm{~min}$ with TBST buffer. The immunodevelopment was obtained by incubating the membrane in 5-bromo-4-chloro-3-indolyl-phosphate/nitro blue tetrazolium (BCIP/NBT, Sigma-Aldrich, Oakville, ON). The membrane was rinsed with water and once it was dried it was scanned with the GS 800 densitometer. 


\subsection{Ion exchange chromatography}

Protein purification was performed using anion exchange chromatography. A glass column $(1 \times 17 \mathrm{~cm})$ was packed with $10 \mathrm{~mL}$ of Q-sepharose fast flow (GE Healthcare BioSciences Inc., QC). All buffers used in chromatography were filtered using a $0.22 \mu \mathrm{m}$ polyethersulfone membrane (Corning Incorporated Life Sciences, Lowell, MA). Tris buffer (20mM, pH 9) was used to equilibrated the column by washing with 10 column volumes using a peristaltic pump (Amersham biosciences Pump P1, GE Healthcare BioSciences Inc., QC) at a flow rate of $2 \mathrm{~mL} / \mathrm{min}$. Approximately $300 \mathrm{mg}$ of total protein from the concentrator were added to the column using a flow rate of $1 \mathrm{~mL} / \mathrm{min}$. The column was washed with 3 column volumes of Tris buffer. The elution was done using gradient elution $(0-50 \%, 800 \mathrm{~mL})$ with increasing concentrations of $1 \mathrm{M}$ sodium chlorideTris buffer, pH 9. Fractions $(12 \mathrm{~mL})$ were collected in 70 tubes using ÄKTAprime ${ }^{\mathrm{TM}}$ plus fraction collector (GE Healthcare Bio-Sciences Inc., QC). The protein from all the different fractions were run on an SDS-PAGE and silver stained to assess the presence and purity of the target proteins. The different fractions containing the target proteins were pooled together, concentrated and desalted using a 10kDa cut off Amicon Ultra-15 centrifuge tube (Millipore, Billerica, MA). The column was then washed using $1 \mathrm{M}$ $\mathrm{NaCl}$-Tris buffer to get rid of any proteins still bound to the column. The column was then stored in $20 \%$ ethanol until next use. The regeneration of the column can be obtained by washing with Tris buffer. 


\subsection{Gel filtration chromatography}

Further purification was done using gel filtration to separate by molecular weight any other proteins remaining with the target protein. A $96 \times 1.6 \mathrm{~cm}$ column was packed with Sephacryl S-300-HR resin (Sigma-Aldrich, Oakville, ON). The column was washed with $20 \mathrm{mM}$ Tris buffer- $200 \mathrm{mM} \mathrm{NaCl}(\mathrm{pH} 7.5)$ at a flow rate of $1 \mathrm{~mL} / \mathrm{min}$. A calibration curve was determined by running five different standard proteins (calibration kit, SigmaAldrich, Oakville, ON); carbonic anhydrase $(29 \mathrm{kDa})$, albumin $(66 \mathrm{kDa})$, alcohol dehydrogenase (150kDa), $\beta$-amylase $(200 \mathrm{kDa})$ and blue dextran $(2,000 \mathrm{kDa})$. The protein sample from ion exchange was loaded to the column using a $1 \mathrm{~mL}$ syringe and a flow rate of $1 \mathrm{~mL} / \mathrm{min}$. The fractions were collected every $5 \mathrm{~mL}$ with a fraction collector. The different fractions were silver stained and pooled together if they contained the target protein. Immunoblotting was performed to confirm the identity of the purified protein.

\subsection{Antibody production}

As mentioned above three sources of antibodies were used in these experiments. ProGene Ltd. (Lenexa, KS) provided us with human polyclonal antibodies (HpAbs). The human serum was obtained from atopic patients that showed fungal sensitization when clinically tested (Pharmacia ImmunoCap). A complete list of HpAbs can be found in Appendix A1.3. The dilution used for these antibodies when used in immunoblot testing were $1 / 2,000$ with $1 \%$ BSA-TBST and $1 / 1,500$ with $1 \%$ BSA-PBST for ELISA, unless stated otherwise. 
The rabbit polyclonal antibodies (RpAbs) and the mouse monoclonal antibodies (MmAbs) were both produced by ImmunoPrecise Antibodies Ltd. (Victoria, BC). For the RpAbs production two rabbits were initially injected with $1 \mathrm{mg}$ of spores from $C$. globosum strain UAMH 7142. One of the rabbits (305) was then boosted three times following successive 21 days increments with $0.5 \mathrm{mg}$ of $47 \mathrm{kDa}$ pure protein extract. The other rabbit (675) was only injected twice with $0.5 \mathrm{mg}$ of the $45 \mathrm{kDa}$ pure protein extract due to lack of pure material. The dilutions used for these antibodies for immunoblot testing were $1 / 40,000$ with $1 \%$ BSA-TBST and $1 / 80,000$ with $1 \%$ BSA-PBST for ELISA, unless stated otherwise. The MmAbs were produced by injecting $5 \mathrm{mg}$ of the $47 \mathrm{kDa}$ purified protein extract from gel filtration into four different mice. After three weeks, the mouse sera were screened using ELISA (done by ImmunoPrecise) for their antibody titre response. The mouse sera were further screened by immunoblotting against the culture filtrate of strain UAMH 7142. The dilutions used were $1 / 800$ with $1 \%$ BSA-TBST for all four samples. With the immunoblot results mouse \#1 and \#4 were then selected for the hybridoma production.

\subsection{Antibody purification with protein $G$ column}

Ammonium sulphate was mixed with ultrapure water up to $100 \%$ saturation. Ammonium sulphate was then slowly added to the rabbit polyclonal sera in a 50:50 (v/v) ratio and was left shaking at $4^{\circ} \mathrm{C}$ overnight. The sample was centrifuged at $17,400 \times \mathrm{g}$ for $10 \mathrm{~min}$ at room temperature. The supernatant was removed and PBS was added to redissolve the pellet. The sample was ultracentrifuged at $17,400 \times \mathrm{x}$ for $20 \mathrm{~min}$ using a micro de-salter 
with a $30 \mathrm{kDa}$ cut-off. The concentrated RpAbs/ammonium sulphate sample was added to the protein $\mathrm{G}$ column that was previously equilibrated with 10 column volumes of PBS binding buffer. This was done using a peristaltic pump at a flow-rate of $1 \mathrm{~mL} / \mathrm{min}$. The flow through was re-applied to the column another two times to achieve good binding of the antibody to the column. The elution buffer $(0.1 \mathrm{M}$ glycine- $\mathrm{HCl}, \mathrm{pH} 2.7)$ was then added to the column and it was washed with 7 column volumes to make sure all bound antibodies were eluted. The antibodies were collected in a tube containing neutralization buffer (1.5M Tris- $\mathrm{HCl}$ buffer, $\mathrm{pH} 8.8)$ to keep the antibodies at a stable $\mathrm{pH}$. The antibodies were concentrated using ultracentrifugation and the purity was verified with a CBB stained gel.

\subsection{DNA extraction and sequencing}

The genomic DNA isolation was performed using an UltraClean ${ }^{\mathrm{TM}}$ Microbial DNA Isolation Kit (MO BIO Laboratories, Inc., Carlsbad, CA). Around 1.8mL of fungal culture was added to a $2 \mathrm{~mL}$ collection tube. It was then centrifuged at $10,000 \times \mathrm{g}$ for $30 \mathrm{~s}$ at room temperature. The supernatant was decanted and another centrifugation was performed to completely remove media supernatant. The cell pellet was resuspended with a MicroBead solution and by gently vortexing. The cells were then added to a tube containing microbeads and an MD1 buffer, they were vortexed for $10 \mathrm{~min}$ at maximum speed to obtain cell lysis. The tubes were then centrifuged at $10,000 \times \mathrm{g}$ for $30 \mathrm{~s}$ at room temperature. The supernatant was transferred to a new $2 \mathrm{~mL}$ collection tube. A MD2 buffer was added and vortexed for $5 \mathrm{~s}$ then the tubes were incubated at $4^{\circ} \mathrm{C}$ for $5 \mathrm{~min}$ to 
remove any non-DNA material. The tubes were centrifuged at room temperature for $1 \mathrm{~min}$ at $10,000 \times \mathrm{g}$ and the supernatant was transferred to a new collection tube. The MD3 buffer was then added to the tubes and vortexed for $5 \mathrm{~s}$. The solution was added to a spin filter and centrifuged at $10,000 \times \mathrm{g}$ for $30 \mathrm{~s}$ at room temperature, the high concentration of salt in buffer MD3 enables the DNA to bind to the spin filter. Another centrifugation was performed to make certain no buffer is left on spin filter. The MD4 buffer was then added to the spin filter, this buffer contains ethanol to clean the DNA bound to filter. Centrifugation at $10,000 \times \mathrm{g}$ was done at room temperature for $1 \mathrm{~min}$. The spin filter basket was placed in a new collection tube and the MD5 buffer was added and centrifuged $10,000 \times \mathrm{g}$ for $30 \mathrm{~s}$ at room temperature. The DNA was collected, the absence of salt in this buffer released the DNA from the silica spin filter. The DNA concentration was measured using a nanodrop machine (Nanodrop ND-1000, Fisher Scientific, ON). The extracted genomic DNA and primers ITS1F (CTTGGTCATTTAGAGGAAGTAA) and ITS4 (TCCTCCGCTTATTGATATGC) were sent to DNA Landmarks Inc. (Saint-Jean-SurRichelieu, Qc) where PCR amplification and sequencing was performed. The resulting sequences were searched with the nucleotide Basic Local Alignment Search Tool (BLASTn), a database that contains nucleotide sequences, to confirm the taxonomy of the fungal strain.

\subsection{MS/MS analysis}

The purified target proteins were cut out of a CBB stained gel and sent to Health Canada for MS/MS determination. The mass-to-charge ratio of the ions from the protein sample were acquired by liquid chromatography tandem mass spectrometry (LC-MS/MS) using a 
Linear Trap Quadrupole Fourier Transform (LTQ-FT). This technique was used because of its high resolution and its ability to distinguish two ions with similar masses; very useful for large macromolecules like proteins (Bossio et al., 2002). The resulting peptide sequences were BLAST searched with the protein database to characterize the antigenic proteins.

\subsection{Determination of isoelectric point (pI)}

The first step consisted of rehydrating the purified protein sample. In a vial the rehydration buffer was mixed with the protein sample and $150 \mathrm{uL}$ was added to the $1^{\text {st }}$ and $2^{\text {nd }}$ lane of a disposable equilibration tray. The IPG ReadyStrips (Bio-Rad, Hercules, CA) $\mathrm{pH} 5-8$ and $\mathrm{pH} 3-10$ were taken out of the freezer $\left(-20^{\circ} \mathrm{C}\right)$ and were thawed for 15 mins prior to use. The IPG strips were placed over the protein sample for 1 hour. Mineral oil was added on top of the strips to act as a seal for the complete passive rehydration of the protein sample onto the strips. They were left overnight at room temperature. The next day the excess mineral oil was removed from the hydrated IPG strips and they were transferred to the focusing tray. Electrode wicks were placed on both sides of each lane being used. The electrode wicks were then covered with $10 \mu \mathrm{L}$ of ultrapure water and the IPG strips with $1 \mathrm{~mL}$ of mineral oil. The focusing tray was covered with a lid and placed in the 90-240 VAC basic unit PROTEAN IEF Cell (BioRad, Hercules, CA). The program, number 4, selected was recommended by the manufacturer and the temperature was kept at $20^{\circ} \mathrm{C}$ for the whole run. The first step consisted of a linear current increase for $20 \mathrm{~min}$ up to a $250 \mathrm{~V}$. The next step ran for $2 \mathrm{~h}$ with a linear current increasing up to $4,000 \mathrm{~V}$. In the final step a rapid ramp rate was used 
till the voltage hour had reached $20,000 \mathrm{~V}-\mathrm{hr}$ and the final current 4 current $4,000 \mathrm{~V}$. Once the electrofocusing was completed, the excess mineral oil was removed from the strips and they were transferred in a new equilibration tray. The tray was covered with a lid and wrapped with plastic saran wrap and stored at $-20^{\circ} \mathrm{C}$ overnight. The IPG strips were thawed for $15 \mathrm{~min}$ and rinsed with ultrapure water followed by $1 \mathrm{~mL}$ of each equilibration buffer I and II. The strip was then silver stained to visualize the target protein. The $\mathrm{pI}$ value was calculated according to the percentage of migration from the acidic end of the strip.

\subsection{Glycoprotein assay}

The glycoprotein staining kit (Pierce, Rockford, IL) was used to detect the sugar moiety of glycosylated proteins on SDS-PAGE gels. Horseradish peroxidase was used as the positive control, a soybean trypsin inhibitor was used as a negative control and the target protein was tested for the presence of sugar residues. After SDS-PAGE the gel was placed in a solution of $50 \%(\mathrm{v} / \mathrm{v})$ methanol/water. It was incubated at room temperature for 30 minutes. The gel was washed $2 \times 10 \mathrm{~min}$ with $3 \%(\mathrm{v} / \mathrm{v})$ acetic acid/water. The oxidizing solution was added for $15 \mathrm{~min}$ and washed with $3 \times 5 \mathrm{~min}$ of $3 \%(\mathrm{v} / \mathrm{v})$ acetic acid/water. The GelCode Glycoprotein stain reagent was then added to the gel for $15 \mathrm{~min}$. The color was developed when the stain reagent was removed and replace with the reducing reagent. The reaction was stopped after $5 \mathrm{~min}$ by washing with $3 \%(\mathrm{v} / \mathrm{v})$ acetic acid/water. The gel was rinsed with ultrapure water. If a magenta band appeared it would indicate that the protein contained a carbohydrate moiety. The gel was scanned using a GS800 densitometer imaging system. 


\subsection{Chitosanase activity assay}

The presence of reduced sugar produced by the target protein was assayed using a dinitrosalicylic colorimetric method. A calibration curve was first produced using glucose as the standard. Different amounts of glucose were solubilized with sodium acetate buffer $(0.05 \mathrm{M}, \mathrm{pH} 4.5)$. The dinitrosalicylic acid reagent was added to the mixture in a $1: 1(\mathrm{v} / \mathrm{v})$ ratio and incubated for $15 \mathrm{~min}$ at $90^{\circ} \mathrm{C}$ until a red-brown color was observed. The solution was cooled to room temperature in a cold water bath and the absorbance was read with a Cary Eclipse spectrophotometer (Varian, Mississauga, ON) at $575 \mathrm{~nm}$. The target protein was mixed with $20 \mu \mathrm{g}$ of chitosan in sodium acetate buffer and incubated for $1 \mathrm{~h}$ at $45^{\circ} \mathrm{C}$. The mixture was boiled in a water bath for $10 \mathrm{~min}$ and cooled to room temperature using cold water. The dinitrosalicylic acid reagent was added and the same procedure as mentioned above was followed. Different incubation times and temperatures were also tested to determine their effect on the activity of the chitosanase enzyme. 


\section{RESULTS}

\subsection{Culture and spore production, protein extraction and concentration}

\subsubsection{C. globosum protein and spore production}

All 14 strains of $C$. globosum were inoculated in 8L of Enniatin medium to produce large amounts of proteins and peptides. The strains of $C$. globosum used for these experiments are from different Canadian locations. The geographic distribution of each strain, accession number and sequences can be found in appendix table A1.1 and A1.2. The resulting culture filtrate and cells were separated and used for protein extraction. The sporulation of C. globosum strain UAMH 7142 was tested on several media (malt extract agar, potato carrot agar, hay infusion agar and water agar containing a filter paper). WA with a filter paper produced an average of $3.32 \mathrm{mg}$ of spores per plate, PCA produced $2.44 \mathrm{mg}$, HIA produced $1.76 \mathrm{mg}$ and MEA produced $1.39 \mathrm{mg}$ of spores. The water agar (WA) containing the filter paper was used as the medium for spore production for the remaining strains because it produced the highest yield of $C$. globosum spores.

\subsubsection{Protein extraction from culture filtrate (extracelluar), cells (intracellular) and spores}

The proteins were extracted from culture filtrate using two different methods. Acetone precipitation was used to obtain the extracellular proteins and a concentrator equipped with a 10,000 Da cut-off Hydrosart membrane. The proteins were extracted from the macerated cells using Tris buffer and ammonium sulfate precipitation. The spores were fragmented to release the proteins they contain and they were re-suspended in the 
appropriate buffer. Tris buffer was used if the proteins were used in immunoblotting experiments and PBST buffer was used for ELISA testing.

\subsubsection{Protein concentration}

The Bradford assay was used to determine the protein concentration of each sample analyzed. The acetone precipitation yielded $150 \mathrm{mg}$ of crude protein/batch ( $8 \mathrm{~L}$ of media) and the concentrator yielded $350 \mathrm{mg} / \mathrm{batch}$. The average amount of total protein extracted from $1 \mathrm{~g}$ of cells was $15 \mathrm{mg}$. The average amount of total protein recovered from $1 \mathrm{mg}$ of spores was $0.08 \mathrm{mg}$.

\subsection{C. globosum human antigen screening using extracellular proteins}

\subsubsection{Initial antigen screening with ELISA}

ELISA assays were used as the preliminary screening method for the detection of antigenic response of $C$. globosum extracts to human polyclonal antibodies (HpAbs). The identification numbers of the fourteen different $C$. globosum strains used as well as the list of human sera can be found in appendix tables A1.1 and A1.3 respectively.

The total response for each strain in relation to each $\mathrm{HpAb}$ was determined by ELISAs. At first a checkerboard ELISA (decreasing amounts of antigen from top to bottom and decreasing amounts of antibody from left to right) was performed to determine the appropriate amount of antigen per well and the dilution of the $\mathrm{HpAb}$ needed for a suitable 
detection. The amount of antigen used during the ELISA testing was 20ng of crude protein and the HpAbs were diluted 1,500x.

The ELISA data are displayed in the appendix figures A1.1 and A1.2 and tables A1.4 and A1.5 demonstrate the raw data used for these figures. A histogram summarizing the overall performance of the HpAbs can also be found in the appendix figure A1.3. The initial screening done by ELISA demonstrates the varied response that each human serum has to the different $C$. globosum strains tested (figure 4). A cross-section of the different C. globosum strains and their antigenic response to HpAbs obtain by ELISA can be found in figure 5. 


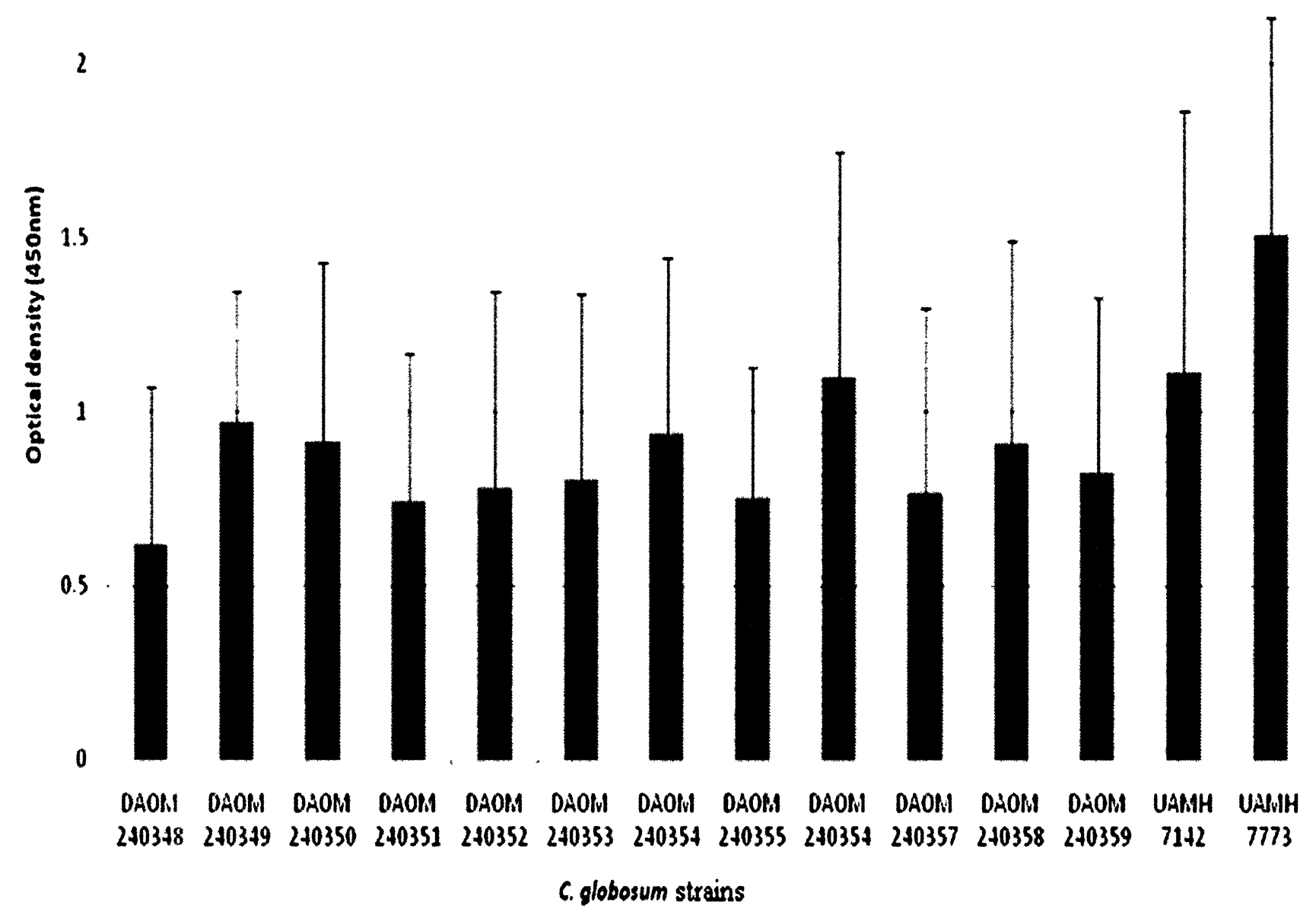




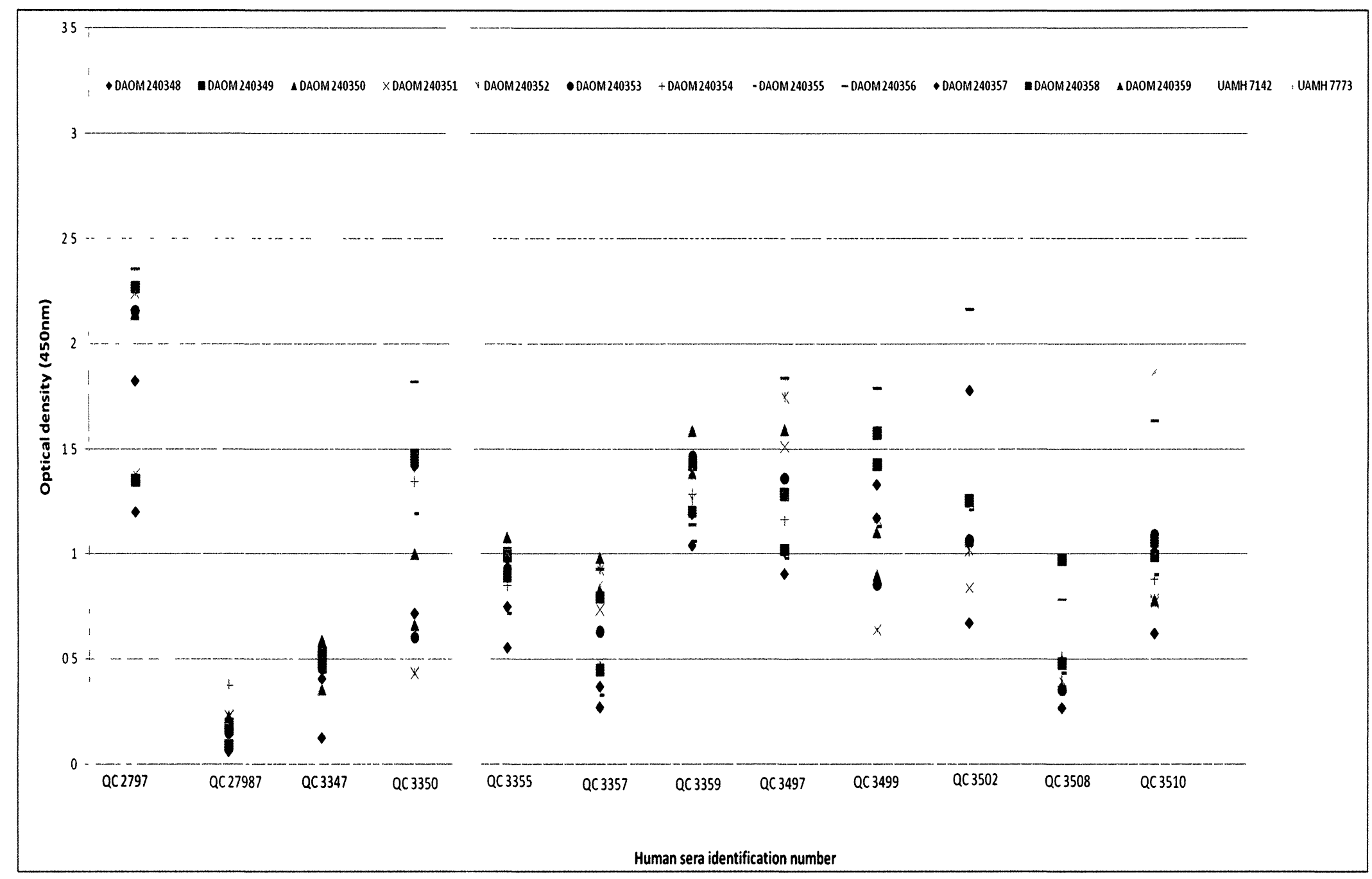

Figure 5: Average ELISA response of all C. globosum culture extracts against $\mathrm{Hp}$ Abs 


\subsubsection{Initial antigen screening with immunoblotting}

The antigenic activity of the different strains of $C$. globosum was tested against the HpAbs by immunoblotting. These immunoblots showed different proteins that are antigenic to the human sera from patients that had antibodies to fungal allergens. The first immunoblots performed were to determine if the HpAbs reacted in a similar fashion with the 14 different strains of $C$. globosum (figures 6 to 10). The $75 \%$ acetone protein extracts were used and $10 \mu \mathrm{g}$ of total protein was utilized in each lane. The HpAbs were diluted 2,000× unless stated otherwise.

The ELISA and immunoblot response of each strain against 23 different patient sera (HpAbs) were combined on a three-dimensional graph (figure 11). ELISA response of culture filtrate extracts of 14 strains of $C$. globosum are the $\mathrm{X}$ axis. The response on immunoblot graded on an arbitrary scale of $1-3$ to the target proteins are the $\mathrm{Y}$ axis and the 23 individual sera are the $\mathrm{Z}$ axis. The different colors in the image are where these combinations overlap. 


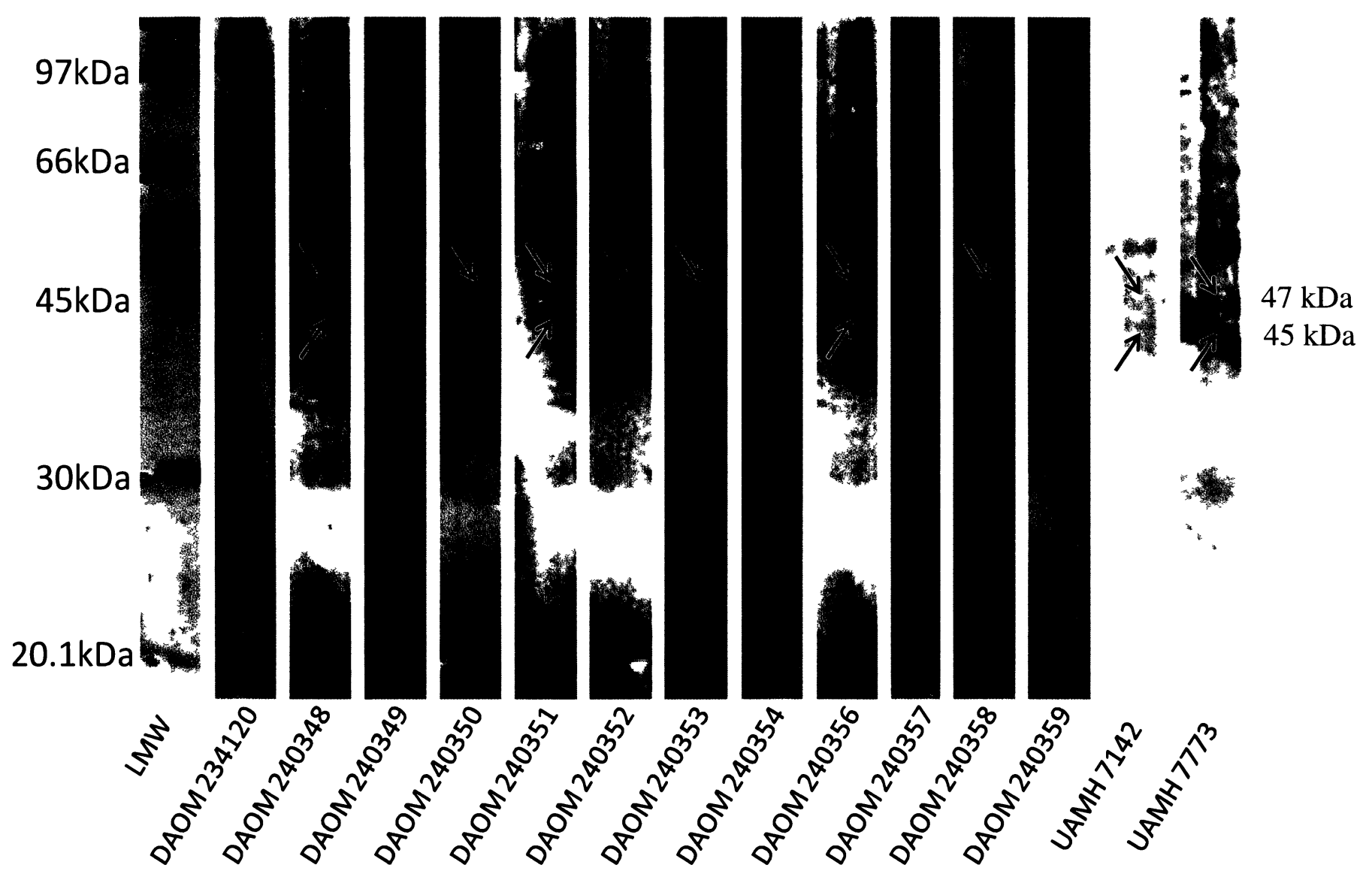

Figure 6: Immunoblot comparıng the response of $\mathrm{HpAb}$ QC 2797 to different $C$ globosum strains

$8 \mu \mathrm{g} / \mathrm{lane}$ of crude protein

Marker: LMW-SDS marker from GE Healthcare

Arrows indicate the 45 and $47 \mathrm{kDa}$ proteins

$1^{\circ} \mathrm{Ab}: \mathrm{HpAb}$ diluted $1 / 2,000$ with $1 \%$ BSA/TBST

$2^{\circ} \mathrm{Ab}$ : AP-anti-human IgG diluted 1/2,000 with $1 \%$ BSA/TBST 


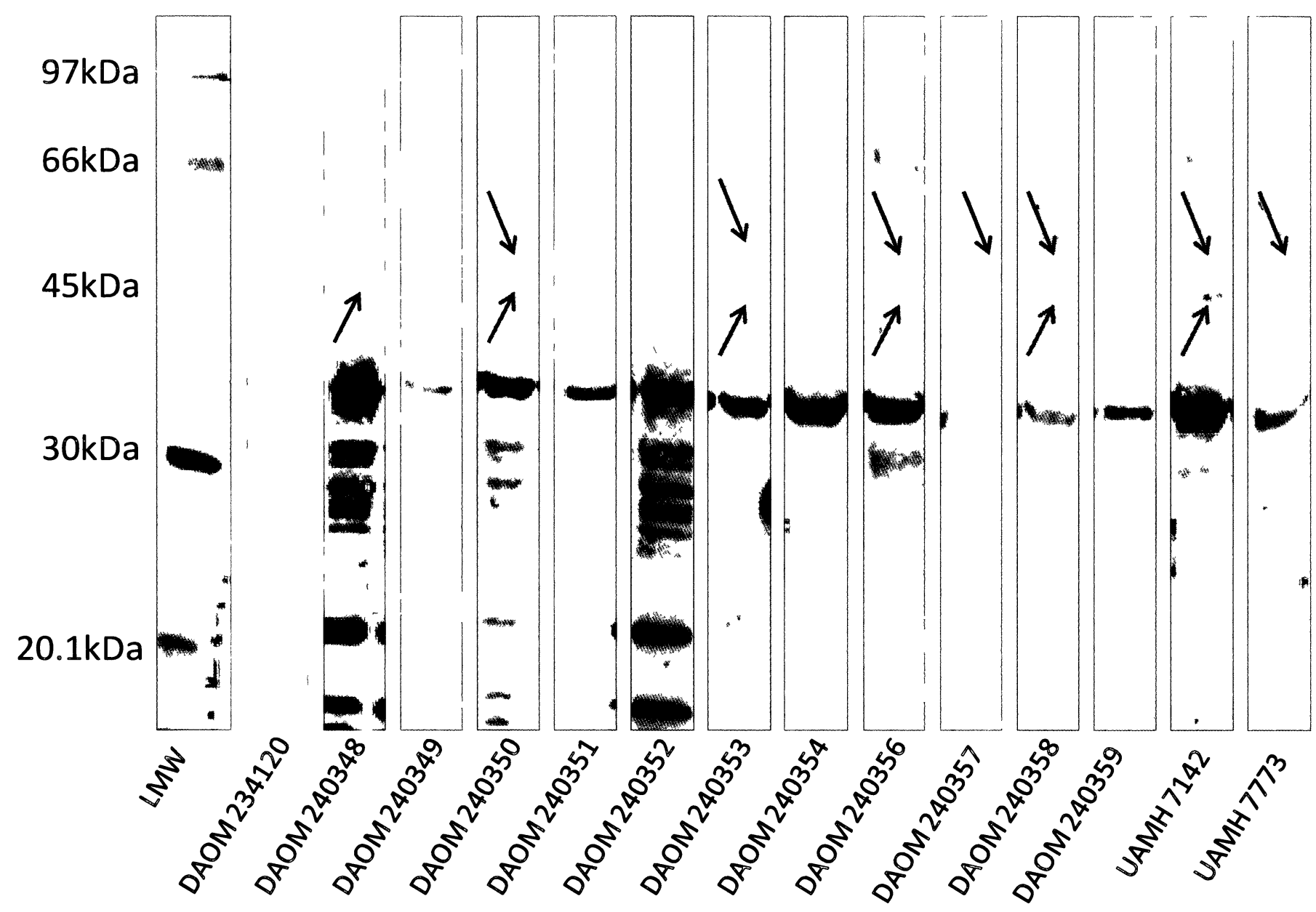

$47 \mathrm{kDa}$ $45 \mathrm{kDa}$

Figure 7: Immunoblot comparing the response of $\mathrm{HpAb}$ QC 3351 to different $C$. globosum strains

$8 \mu \mathrm{g} / \mathrm{lane}$ of crude protein

Marker: LMW-SDS marker from GE Healthcare

Arrows indicate the 45 and $47 \mathrm{kDa}$ proteins

$1^{\circ} \mathrm{Ab}: \mathbb{H p A b}$ dilluted $1 / 2,000$ with $1 \% \mathbb{B S A} / \mathrm{TBST}$

$2^{\circ} \mathrm{Ab}$ : AP-anti-human IgG dilluted $1 / 2,000$ with $1 \%$ BSA/TBST 


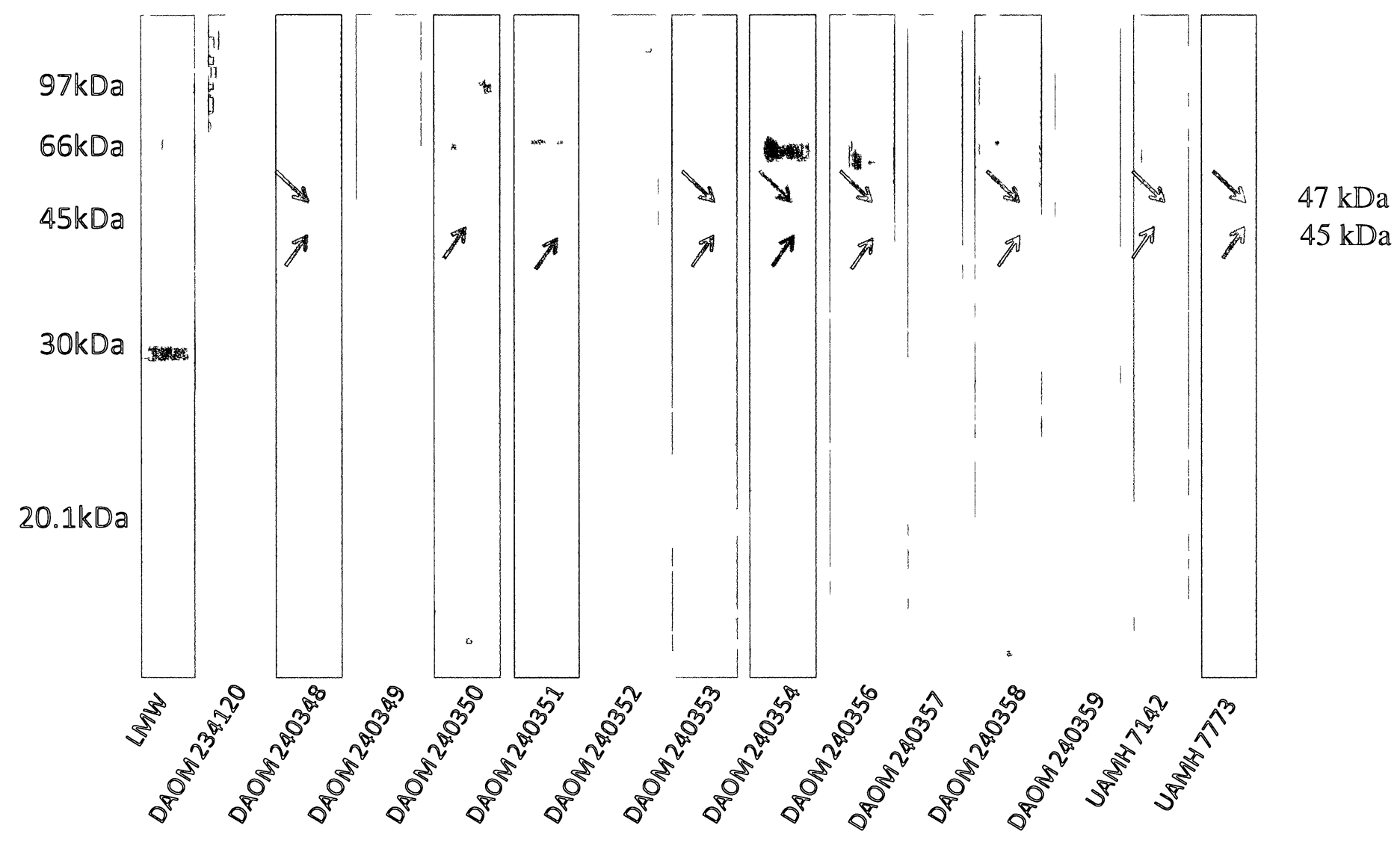

Fignure \&: Immunoblot comparing the response of $\mathbb{H p A b} Q \mathbf{Q C} 3352$ to different C. globosum strains

$8 \mu \mathrm{g} / \mathrm{lane}$ of crude protein

Marker: LMW-SDS marker from GE Healthcare

Arrows indicate the 45 and $47 \mathrm{kD}$ a proteins

$1^{\circ} \mathrm{Ab}: \mathbb{H p A b}$ diluted $\mathbb{1} / 2,000$ with $1 \% \mathbb{B S A} / \mathrm{TBST}$

$2^{\circ} \mathrm{Ab}$ : AP-anti-human IgG diluted $1 / 2,000$ with $1 \% \mathbb{B S A} / \mathrm{TBST}$ 


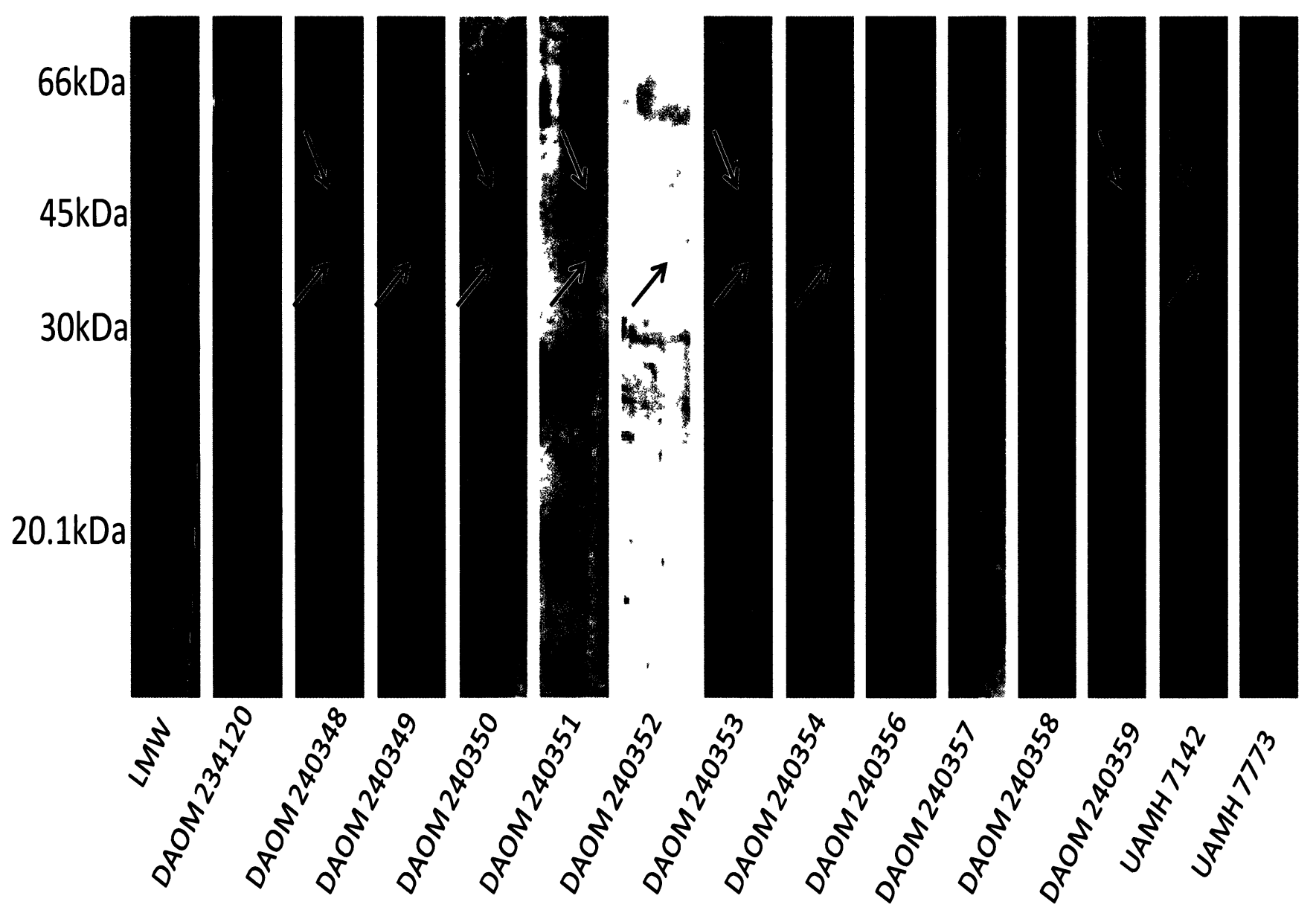

$47 \mathrm{kDa}$ $45 \mathrm{kDa}$

Figure 9: Immunoblot comparing the response of HpAb QC 3349 to different $C$. globosum strains

$8 \mu \mathrm{g} / \mathrm{lane}$ of crude protein

Marker: LMW-SDS marker from GE Healthcare

Arrows indicate the 45 and $47 \mathrm{kDa}$ proteins

$1^{\circ} \mathrm{Ab}: \mathrm{HpAb}$ diluted $1 / 2,000$ with $1 \% \mathrm{BSA} / \mathrm{TBST}$

$2^{\circ} \mathrm{Ab}$ : AP-anti-human IgG diluted 1/2,000 with $1 \%$ BSA/TBST 


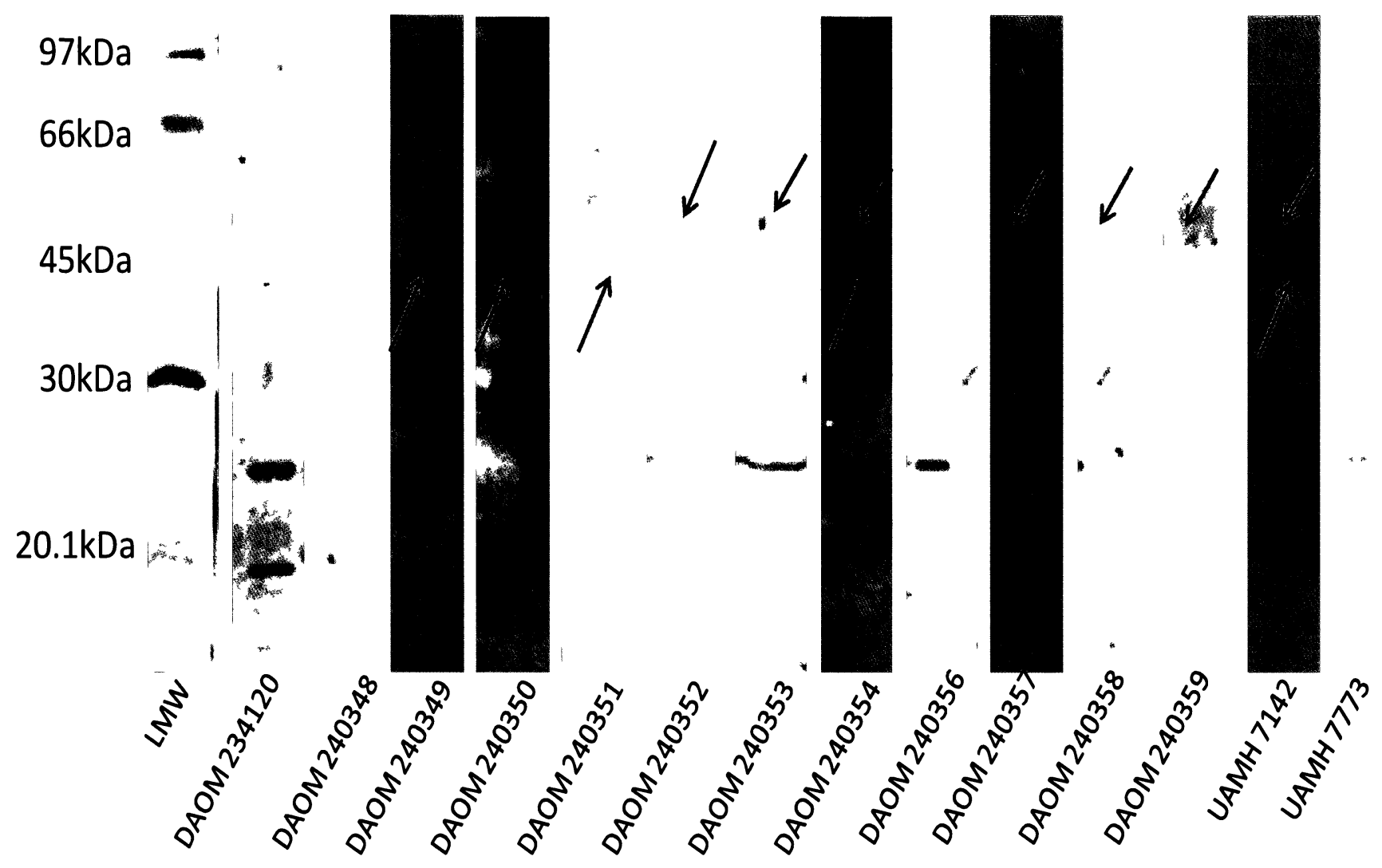

Figure 10: Immunoblot comparing the response of $\mathrm{HpAb} \mathrm{QC} 3342$ to different $C$. globosum strains

$8 \mu \mathrm{g} /$ lane of crude protein

Marker: LMW-SDS marker from GE Healthcare

Arrows indicate the 45 and $47 \mathrm{kDa}$ proteins

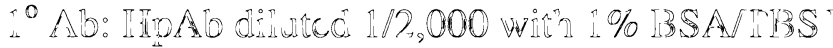

$2^{\circ} \mathrm{Ab}$ : AP-anti-human IgG diluted $1 / 2,000$ with $1 \%$ BSA/TBST 


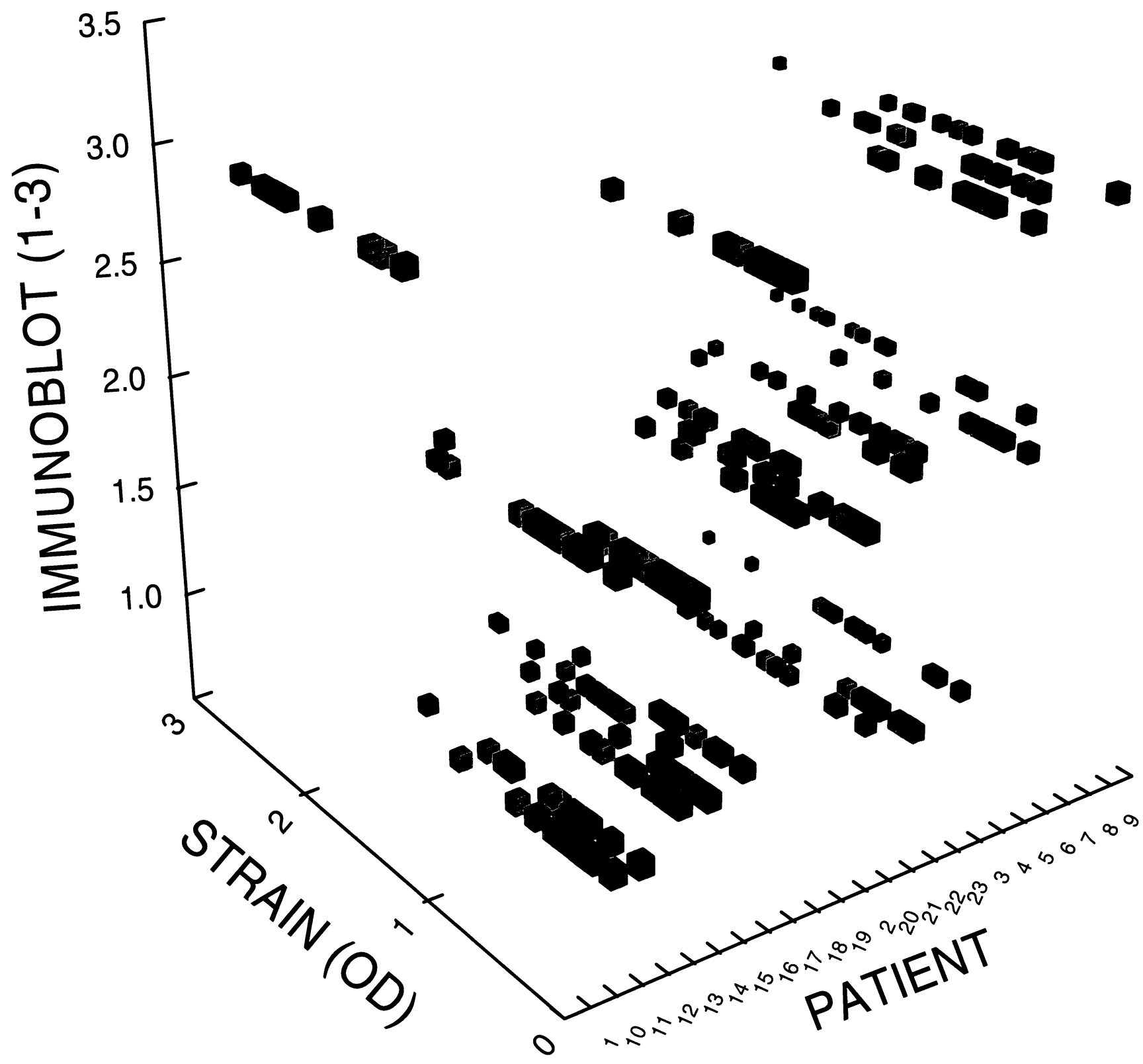

Figure 11: A three-dimensional graph containing ELISA (OD values; $\mathrm{X}$ axis) and immunoblot ( $\mathrm{Y}$ axis) response of $C$. globosum strains against 23 individual human sera ( $\mathrm{Z}$ axis) 


\subsection{Selection of antigenic proteins, detection in cells and spores and cross-reactivity testing}

\subsubsection{Selecting $C$. globosum target proteins}

After careful examination of the immunoblot experiments two proteins were identified as suitable for further investigation. Many different proteins showed a response to the human polyclonal antibodies. Some HpAbs reacted with several proteins but showed lower responses on ELISA while some HpAbs primarily responded to the target proteins and had high ELISA responses. The proteins at 45 and $47 \mathrm{kDa}$ were chosen for purification and polyclonal antibody production. A silver stain was made to visualize the different proteins produced by each C. globosum strain. The presence of the $45 \mathrm{kDa}$ and $47 \mathrm{kDa}$ proteins is present in all the 14 strains but in varying amounts (figure 12). These two human antigens are also identified with arrows in figures 6 to 10 and 12 . 


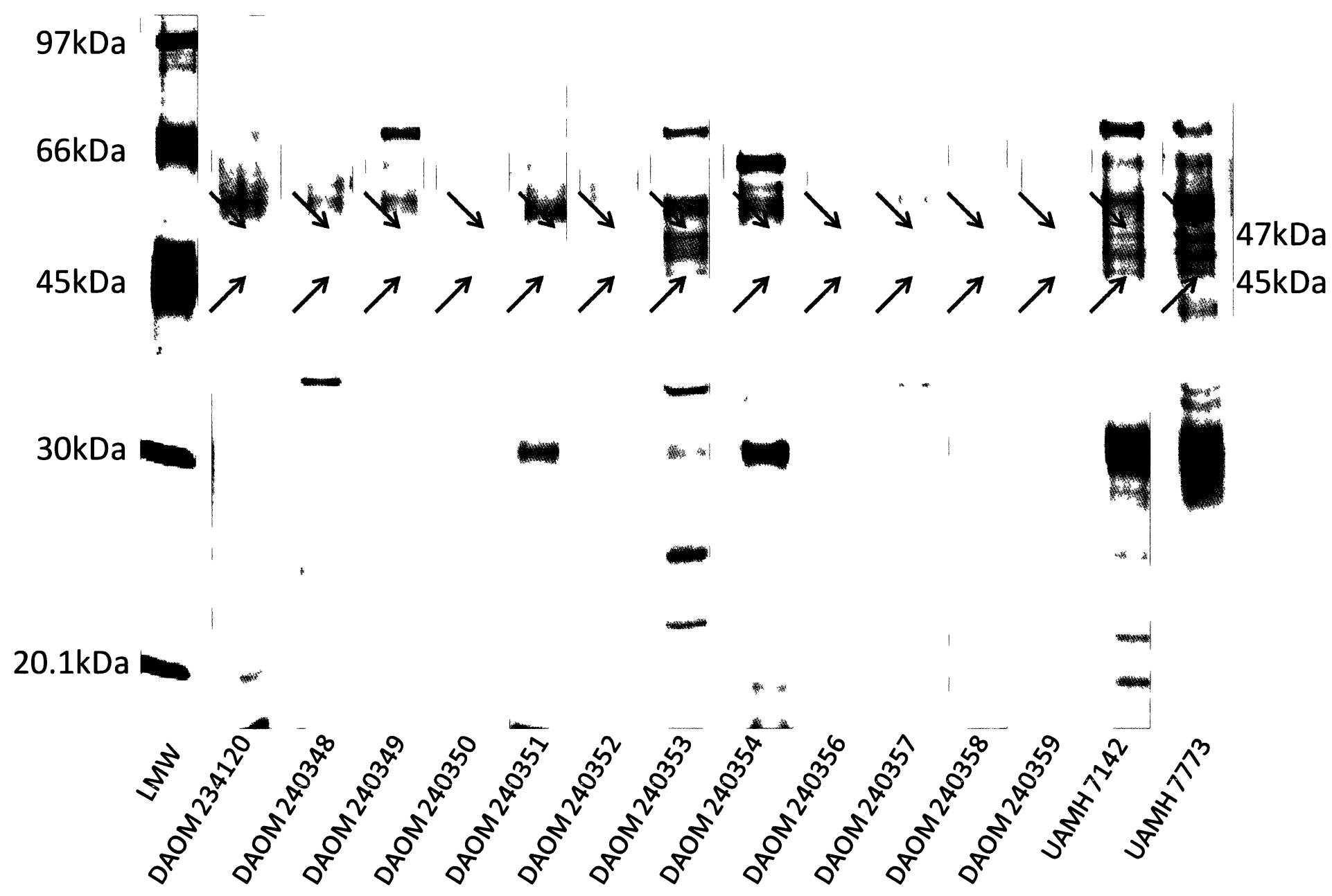

Figurne 12: Snlver stan comparng the amount of the 45 and $47 \mathrm{kDa}$ protens produced in all the $\mathbb{C}$ globosenur s: aris

4 $\mu \mathrm{g} / \mathrm{lane}$ of crude protein

Marker: LMW-SDS marker from GE Healthcare

Arrows indicate the 45 and $47 \mathrm{kDa}$ proteins 
The immunoblots (figures 6 to 10) were performed to determine which strain produced the strongest response to the $45 \mathrm{kDa}$ and $47 \mathrm{kDa}$ target antigens. The activity between the different strains was compared using the HpAbs that reacted the strongest from the ELISA assays. Some of the different proteins, from each strain, that showed activity to the human sera are listed in table 1. The HpAb QC 2797 had the strongest response to the two target proteins and had high optical density values in the ELISA experiments. This serum was then used as the primary antibody for further screening and purification of the 45 and $47 \mathrm{kDa}$ proteins.

The immunoblot response of the 45 and $47 \mathrm{kDa}$ proteins against each human sera were given an arbitrary rate of $1-3$, one being weak and 3 being strong (e.g., + for $1,++$ for 2 and +++ for 3 in table 2). Omission of a serum from the table means that neither the 45 nor the $47 \mathrm{kDa}$ protein reacted to that particular $\mathrm{HpAb}$. 
Table 1: Summary of immunoblot response of some C. globosum proteins to a few HpAbs

\begin{tabular}{|c|c|c|c|c|c|}
\hline $\mathrm{MW}(\mathrm{kDa})$ & QC2797 & QC 3342 & QC3349 & QC 3351 & QC 3352 \\
\hline 66 & & + & + & + & \\
\hline 50 & + & + & + & & + \\
\hline 47 & + & & + & & \\
\hline 45 & & & & + & + \\
\hline 43 & & & & & \\
\hline 40 & & & & + & \\
\hline 30 & + & + & + & & + \\
\hline 27 & & & & & \\
\hline
\end{tabular}

\begin{tabular}{|c|c|c|c|c|c|}
\hline $\mathrm{MW}(\mathrm{kDa})$ & QC 2797 & QC 3342 & QC 3349 & QC 3351 & QC 3352 \\
\hline 66 & & + & + & + & + \\
\hline 50 & + & & + & + & \\
\hline 47 & + & & + & & + \\
\hline 45 & + & + & + & + & + \\
\hline 43 & & & & + & \\
\hline 40 & + & & + & + & + \\
\hline 30 & + & & + & + & + \\
\hline 27 & & & & + & \\
\hline
\end{tabular}

\begin{tabular}{|c|c|c|c|c|c|}
\hline $\mathrm{MW}(\mathrm{kDa})$ & QC2797 & QC3342 & QC3349 & QC 3351 & QC3352 \\
\hline 66 & & + & + & + & + \\
\hline 50 & + & & + & & + \\
\hline 47 & & + & & & \\
\hline 45 & + & & + & + & + \\
\hline 43 & & & & & \\
\hline 40 & & + & + & + & \\
\hline 30 & + & + & + & + & + \\
\hline 27 & & & & & \\
\hline
\end{tabular}

\begin{tabular}{|c|c|c|c|c|c|}
\hline $\mathrm{MW}(\mathrm{kDa})$ & QC2797 & QC 3342 & QC 3349 & QC 3351 & QC 3352 \\
\hline 66 & + & + & + & + & + \\
\hline 50 & + & & + & & + \\
\hline 47 & + & & & + & \\
\hline 45 & & + & + & & + \\
\hline 43 & & & & & \\
\hline 40 & & + & + & + & + \\
\hline 30 & + & + & + & + & + \\
\hline 27 & & + & + & + & \\
\hline
\end{tabular}

\begin{tabular}{|c|c|c|c|c|c|}
\hline $\mathrm{MW}(\mathrm{kDa})$ & QC 2797 & QC 3342 & QC 3349 & QC 3351 & QC 3352 \\
\hline 66 & + & & + & + & + \\
\hline 50 & + & & + & + & + \\
\hline 47 & + & & & & \\
\hline 45 & & + & + & + & + \\
\hline 43 & & & + & & \\
\hline 40 & & + & + & + & \\
\hline 30 & + & + & + & + & + \\
\hline 27 & & & & & \\
\hline
\end{tabular}

\begin{tabular}{|c|c|c|c|c|c|}
\hline $\mathrm{MW}(\mathrm{kDa})$ & QC2797 & QC 3342 & QC 3349 & QC 3351 & QC 3352 \\
\hline 66 & & & + & + & + \\
\hline 50 & + & & + & & + \\
\hline 47 & + & & & & \\
\hline 45 & + & & + & + & + \\
\hline 43 & & & + & & \\
\hline 40 & + & + & + & + & + \\
\hline 30 & + & + & + & + & + \\
\hline 27 & & + & + & + & \\
\hline
\end{tabular}

\begin{tabular}{|c|c|c|c|c|c|}
\hline$M W(k D a)$ & QC2797 & QC 3342 & QC3349 & QC 3351 & QC 3352 \\
\hline 66 & & & + & + & + \\
\hline 50 & + & & & + & + \\
\hline 47 & + & + & + & + & + \\
\hline 45 & & & + & + & + \\
\hline 43 & & & & & \\
\hline 40 & & + & + & + & + \\
\hline 30 & + & + & + & + & + \\
\hline 27 & + & & & + & + \\
\hline
\end{tabular}

\begin{tabular}{|c|c|c|c|c|c|}
\hline $\mathrm{MW}(\mathrm{kDa})$ & QC 2797 & QC 3342 & QC3349 & QC 3351 & QC 3352 \\
\hline 66 & + & + & + & + & + \\
\hline 50 & + & & & & + \\
\hline 47 & + & + & & & + \\
\hline 45 & & + & + & + & + \\
\hline 43 & & + & & & \\
\hline 40 & & + & + & + & + \\
\hline 30 & + & & + & + & + \\
\hline 27 & + & & & & \\
\hline
\end{tabular}




\begin{tabular}{|c|c|c|c|c|c|}
\hline$M W(k D a)$ & QC2797 & QC 3342 & QC3349 & QC 3351 & QC 3352 \\
\hline 66 & + & + & & + & + \\
\hline 50 & + & & + & + & + \\
\hline 47 & + & + & + & + & + \\
\hline 45 & + & + & & + & + \\
\hline 43 & + & & + & + & \\
\hline 40 & & + & & + & \\
\hline 30 & + & + & + & + & + \\
\hline 27 & & & & + & \\
\hline
\end{tabular}

\begin{tabular}{|c|c|c|c|c|c|}
\hline$M W(k D a)$ & QC2797 & QC 3342 & QC 3349 & QC 3351 & $\mathrm{QC} 3352$ \\
\hline 66 & + & & + & + & + \\
\hline 50 & & & + & & \\
\hline 47 & + & & + & + & + \\
\hline 45 & & & & & \\
\hline 43 & & & & & \\
\hline 40 & & & + & + & \\
\hline 30 & + & + & + & + & + \\
\hline 27 & & & & & \\
\hline
\end{tabular}

\begin{tabular}{|c|ccccc|}
\hline $\mathrm{DAOM} 240358$ & \multicolumn{7}{|c|}{} \\
\hline $\mathrm{MW}(\mathrm{kDa})$ & QC2797 & QC3342 & QC3349 & QC3351 & QC3352 \\
\hline 66 & + & + & + & & + \\
50 & + & & & + & \\
47 & + & & & + & + \\
45 & & + & + & + & + \\
43 & & & & & + \\
40 & & & & + & + \\
30 & + & + & + & + & + \\
27 & + & & & + & + \\
\hline
\end{tabular}

\begin{tabular}{|c|c|c|c|c|c|}
\hline $\mathrm{MW}(\mathrm{kDa})$ & QC2797 & QC 3342 & QC 3349 & QC 3351 & QC 3352 \\
\hline 66 & + & + & + & & + \\
\hline 50 & + & & + & + & \\
\hline 47 & + & + & + & + & + \\
\hline 45 & & & & + & \\
\hline 43 & + & & & & + \\
\hline 40 & & & + & + & + \\
\hline 30 & + & & + & + & + \\
\hline 27 & & & + & + & \\
\hline
\end{tabular}

\begin{tabular}{|c|c|c|c|c|c|}
\hline Proteın MW & QC2797 & QC 3342 & QC3349 & QC 3351 & QC3352 \\
\hline 66 & + & + & + & & + \\
\hline 50 & + & + & & & + \\
\hline 47 & + & + & + & + & + \\
\hline 45 & + & + & + & + & + \\
\hline 43 & & & & & + \\
\hline 40 & + & & + & & + \\
\hline 30 & + & + & + & + & + \\
\hline 27 & + & + & & + & + \\
\hline
\end{tabular}

\begin{tabular}{|c|c|c|c|c|c|}
\hline Proteın MW & QC2797 & QC 3342 & QC 3349 & QC 3351 & QC 3352 \\
\hline 66 & + & + & + & + & + \\
\hline 50 & + & + & & + & \\
\hline 47 & + & + & & + & + \\
\hline 45 & + & + & + & & + \\
\hline 43 & + & & & & \\
\hline 40 & & & & + & \\
\hline 30 & + & & + & + & + \\
\hline 27 & & & & & \\
\hline
\end{tabular}


Table 2: Immunoblot response of $C$. globosum target proteins against all HpAbs

\begin{tabular}{cccccccccc} 
DAOM 234120 \\
\hline MW & QC & QC & QC & QC & QC & QC & QC & QC & QC \\
(kDa) & 2797 & 3346 & 3349 & 3350 & 3351 & 3352 & 3357 & 3497 & 3499 \\
\hline 45 & & + & & ++ & ++ & + & + & ++ & + \\
47 & ++ & + & ++ & + & & & + & + & ++ \\
\hline
\end{tabular}

DAOM 240348

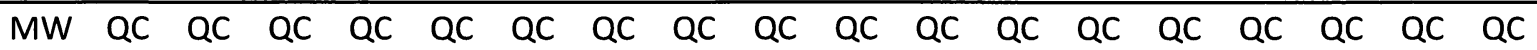
(kDa) 279727983342334633473349335033513352335333543356335733593493349735013502

\begin{tabular}{lllllllllllllllllllllllll}
45 & ++ & + & ++ & + & +++ & ++ & ++ & + & ++ & + & + & ++ & & +++ & ++ & + & + & + \\
47 & +++ & ++ & & & + & +++ & +++ & ++ & & ++ & + & + & + & + & ++ & ++ & + & & ++ \\
\hline
\end{tabular}

DAOM 240349

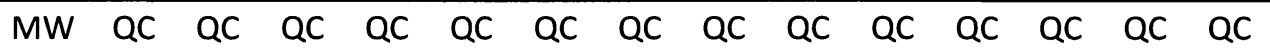

(kDa) 27973346334733493351335233533354335533593490349735013508

\begin{tabular}{llllllllllllllllll}
45 & ++ & + & ++ & + & ++ & ++ & ++ & + & ++ & + & + & + & + & \\
47 & & + & ++ & & & & & ++ & + & + & & & & ++ & + & + \\
\hline
\end{tabular}

DAOM 240350

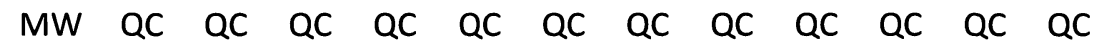

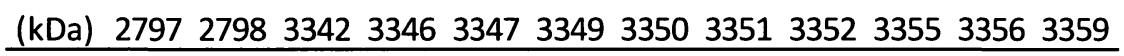

\begin{tabular}{lllllllllllllllll}
45 & & & + & ++ & ++ & + & +++ & + & + & ++ & ++ & ++ & ++ \\
47 & ++ & + & & & + & + & & & ++ & + & & & + & ++ & ++ \\
\hline
\end{tabular}

DAOM 240351

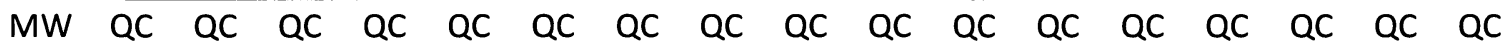
(kDa) 27973342334633473349335033513352335333543355335633573359349734993502

\begin{tabular}{|c|c|c|c|c|c|c|c|c|c|c|c|c|c|c|c|c|c|}
\hline 45 & & +++ & + & +++ & ++ & +++ & + & +++ & + & + & ++ & + & + & & ++ & + & + \\
\hline 47 & +++ & & + & +++ & & +++ & & & + & + & + & + & + & +++ & + & ++ & + \\
\hline
\end{tabular}

DAOM 240352

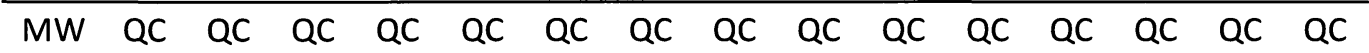

(kDa) $279727983346334733493350335133523353 \quad 335433563357335934933502$

\begin{tabular}{rrrrrrrrrrrrrrrrrrrrr}
45 & + & ++ & + & ++ & +++ & ++ & + & ++ & + & + & ++ & + & +++ & ++ & + \\
47 & + & ++ & + & ++ & & ++ & & & + & + & ++ & ++ & + & +++ & ++ & + \\
\hline
\end{tabular}

DAOM 240353

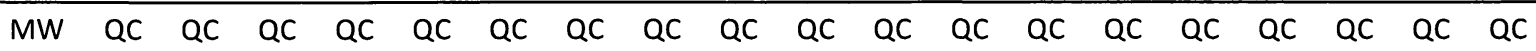
(kDa) 2797279833423346334733493350335133523353335433553356335733593499350235083510

$\begin{array}{llllllllllllllllllllll}45 & & ++ & & & + & + & ++ & + & ++ & ++ & + & + & ++ & + & + & + & + & + & + & ++ \\ 47 & + & ++ & ++ & + & + & ++ & + & ++ & ++ & + & + & ++ & + & + & ++ & + & + & + & + & + & +\end{array}$


DAOM 240354

\begin{tabular}{ccccccccccccccccccccc}
\hline$M W$ & $Q C$ & $Q C$ & $Q C$ & $Q C$ & $Q C$ & $Q C$ & $Q C$ & $Q C$ & $Q C$ & $Q C$ & $Q C$ & $Q C$ & $Q C$ & $Q C$ & $Q C$ & $Q C$ & $Q C$ & $Q C$ & $Q C$ & $Q C$ \\
$(\mathrm{kDa})$ & 2797 & 2798 & 3342 & 3346 & 3347 & 3349 & 3350 & 3351 & 3352 & 3353 & 3354 & 3355 & 3356 & 3358 & 3359 & 3493 & 3497 & 3499 & 3508 & 3510 \\
\hline 45 & & + & ++ & + & + & ++ & + & + & ++ & + & + & ++ & & + & + & ++ & ++ & + & + & + \\
47 & ++ & + & ++ & + & + & & + & & ++ & + & & + & + & + & ++ & + & + & & + & + \\
\hline
\end{tabular}

DAOM 240356

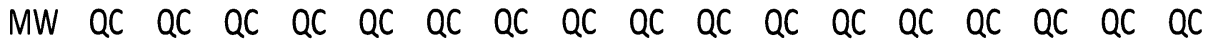

(kDa) 27972798334233463347334933503351335233533355335633573358335934993508

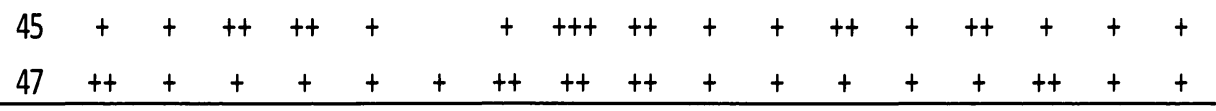

DAOM 240357

MW $\quad Q C \quad Q C \quad Q C \quad Q C \quad Q C \quad Q C \quad Q C \quad Q C$

(kDa) 27972798334633473349335133523494

45

$47++++++++$

DAOM 240358

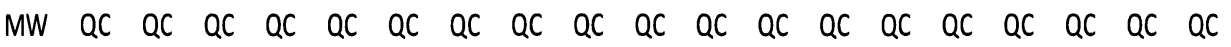

(KDa) 2797279833423346334733493350335133523353335433553356335733583493349935083510

\begin{tabular}{llllllllllllllllllllll}
45 & & ++ & + & + & + & + & ++ & + & ++ & + & + & & + & + & + & + & + & ++ \\
47 & ++ & ++ & & + & ++ & & ++ & ++ & + & + & + & + & + & + & + & ++ & + & ++ \\
\hline
\end{tabular}

DAOM 240359

MW $\quad Q C \quad Q C \quad Q C \quad Q C \quad Q C \quad Q C \quad Q C \quad Q C \quad Q C \quad Q C \quad Q C \quad Q C \quad Q C$

(KDa) 2797279833423346334733493351335233533356349435083510

$45++++\quad+\quad+++++$

$47+++t++t+t+t+4$

UAMH 7142

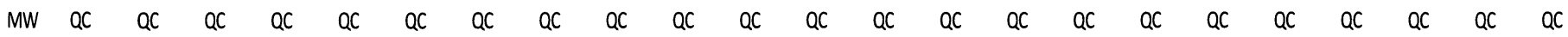

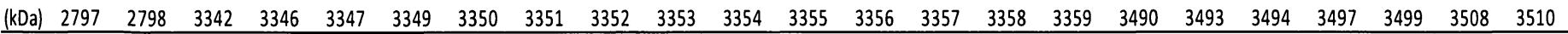

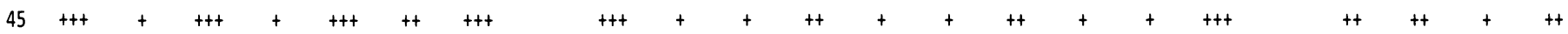

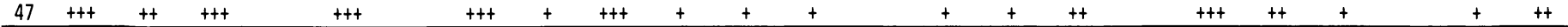

UAMH 7773

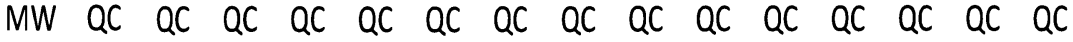

(kDa) 279727983342334633493350335133523353335433553356335934973499

\begin{tabular}{|c|c|c|c|c|c|c|c|c|c|c|c|c|c|c|}
\hline 45 & $++t$ & + & + & $+t$ & + & + & & + & + & + & + & + & & $+t$ \\
\hline$\Delta 7$ & $t+t$ & ++ & + & ++ & & + & ++ & 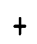 & + & & t+ & + & t+ & $+t$ \\
\hline
\end{tabular}


All 14 C. globosumstrains produce the 45 and $47 \mathrm{kDa}$ proteins but in varying yields. The strain UAMH 7142 was chosen for further isolation, purification and polyclonal antibody production because it produced the highest yields of the target proteins, it had strong response when tested by immunoblotting (figure 13) and showed elevated optical density values on ELISA assays. 


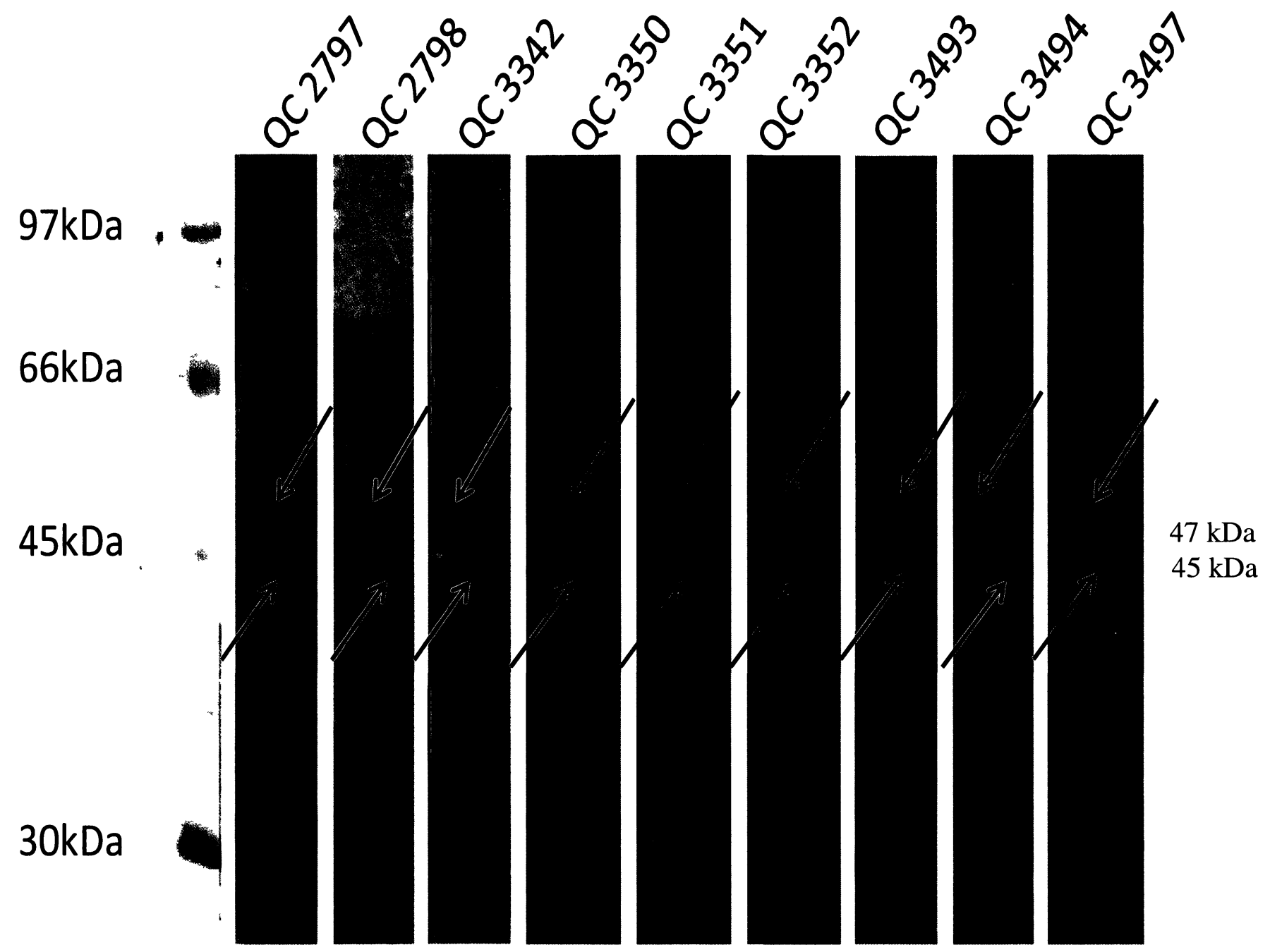

Figure 13: Immunoblot comparing the response of different HpAbs to C. globosum strain UAMH 7142

$8 \mu \mathrm{g} / \mathrm{lane}$ of crude protein

Marker: LMW-SDS marker from GE Healthcare

Arrows indicate the 45 and $47 \mathrm{kDa}$ proteins

$1^{\circ} \mathrm{Ab}$ : HpAb diluted $1 / 2,000$ with $1 \%$ BSA/TBST

$2^{\circ} \mathrm{Ab}$ : AP-anti-human IgG diluted $1 / 2,000$ with $1 \%$ BSA/TBST 


\subsubsection{Verifying the presence of the target antigenic proteins in cells and spores}

Before proceeding to further isolation and purification of the target proteins their presence in cells as well as spores was confirmed. The silver stain in figure 14 displays the presence of proteins with a molecular weight of $45 \mathrm{kDa}$ and $47 \mathrm{kDa}$ both in cells and spores. Immunoblots (figures 15 and 16) were performed to confirm the antigenic activity of the 45 and $47 \mathrm{kDa}$ target proteins with sera that showed a positive response in previous testing with the culture filtrate extracts. The arrows in figures 14-16 highlight the presence of the target antigenic proteins in both the cells and spores. 


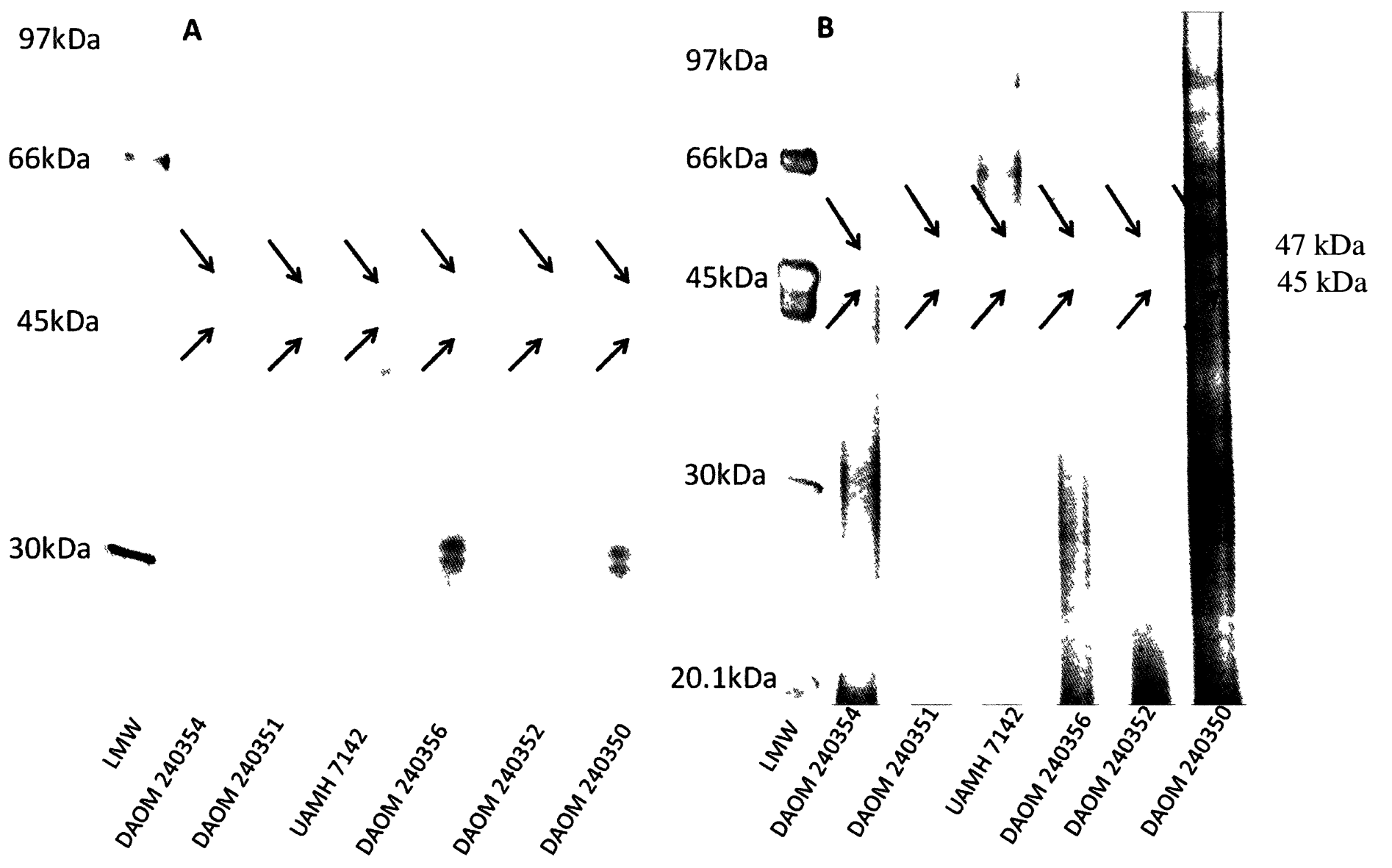

Figure 14: Silver stain displaying the presence of the 45 and $47 \mathrm{kDa}$ proteins in cells (A) and spores (B)

$4 \mu \mathrm{g} / \mathrm{lane}$ of crude protein Marker: LMW-SDS marker from GE Healthcare Arrows indicate the 45 and $47 \mathrm{kDa}$ proteins 


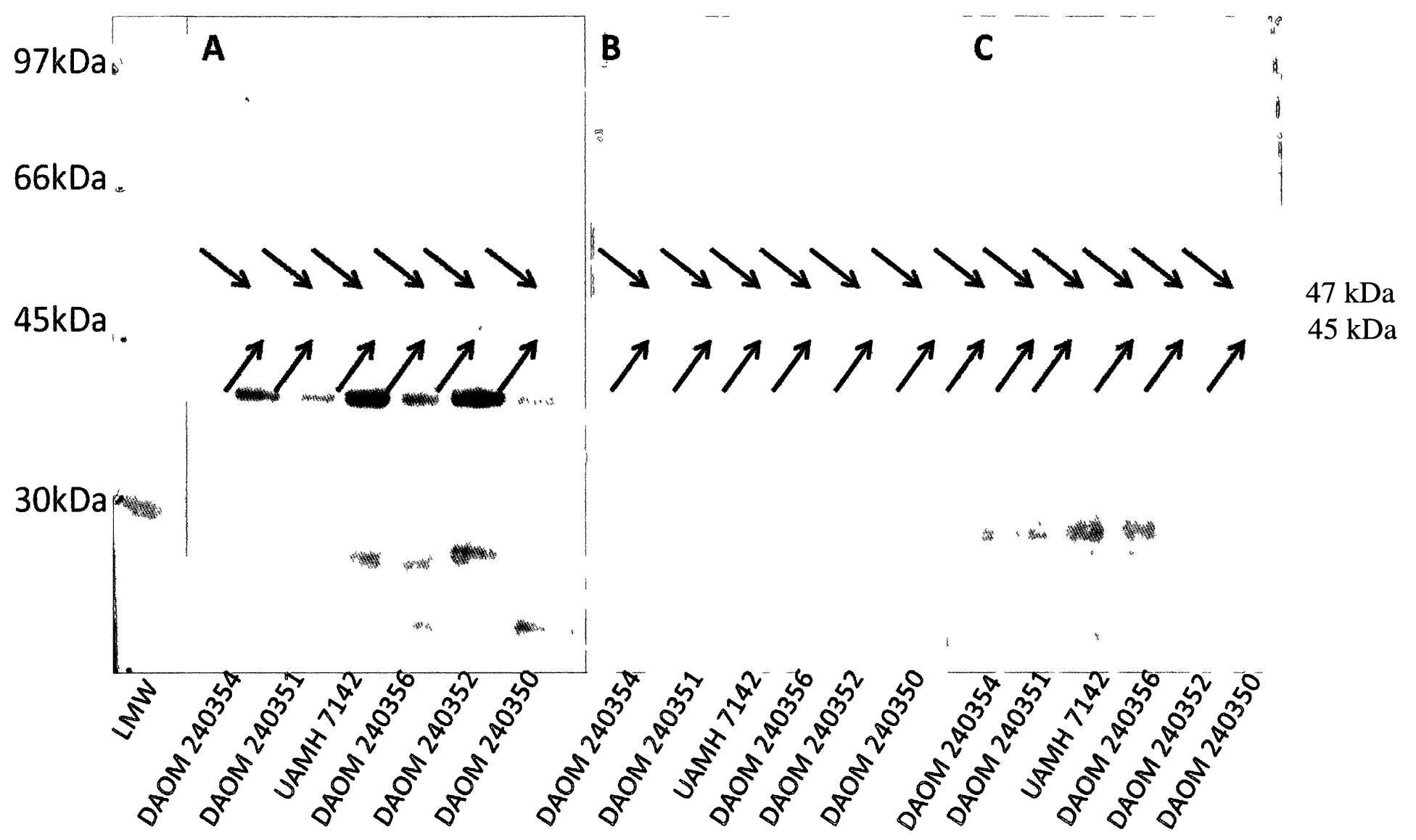

Figure 15: Immunoblots of C. globosum cells against HpAbs QC 3351 (A), QC 3352 (B) and QC 2797 (C).

$8 \mu \mathrm{g} / \mathrm{lane}$ of crude protein

Marker: LMW-SDS marker from GE Healthcare

Arrows indicate the 4.5 and $47 \mathrm{kDa}$ proteins

$1^{\circ} \mathrm{Ab}: \mathbb{H p A b}$ diluted $1 / 2,000$ with $1 \%$ BSA/TBST

$2^{\circ} \mathrm{Ab}$ : AP-anti-human IgG dilluted $1 / 2,000$ with $1 \%$ BSA/TBST 


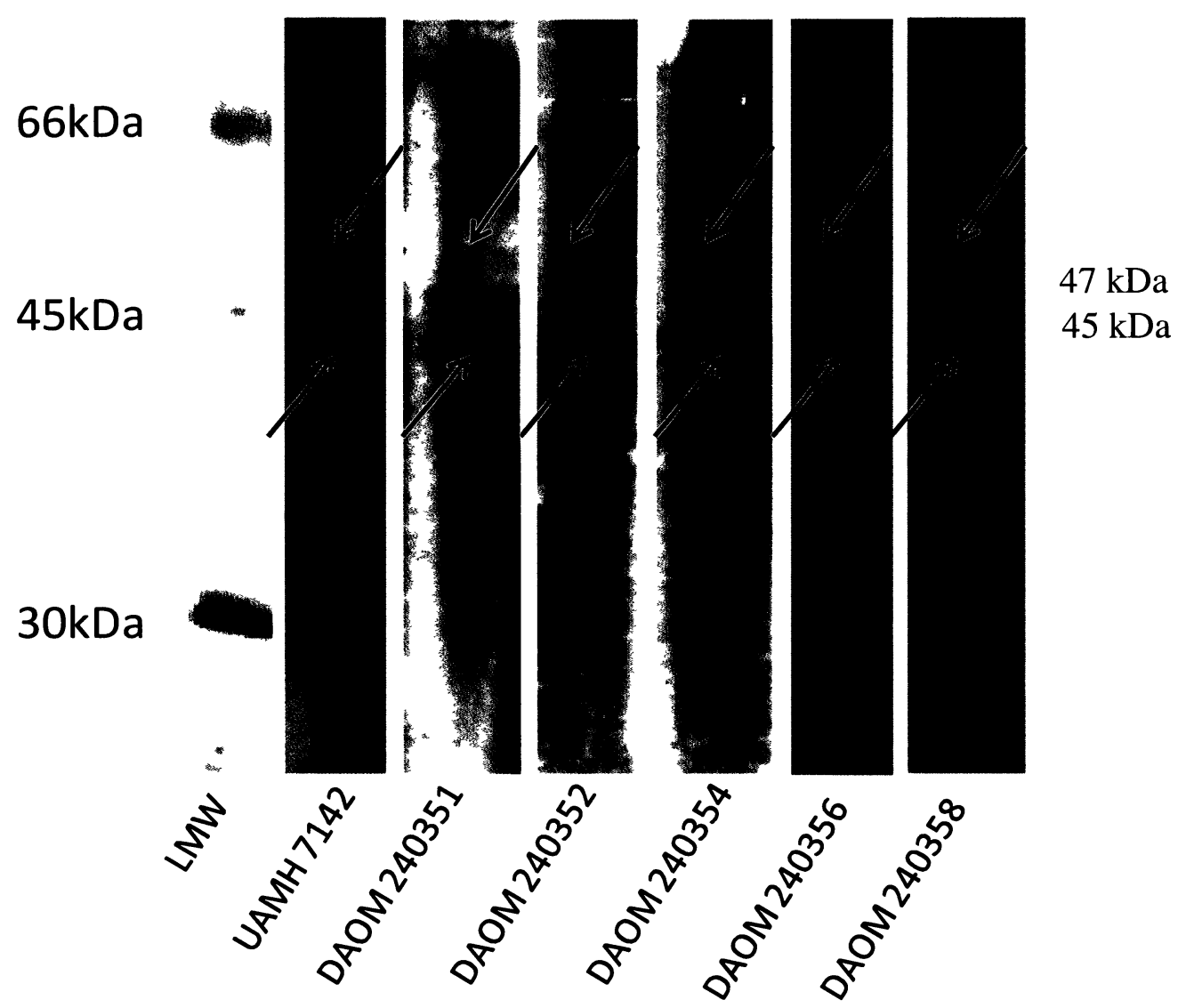

Figure 16: Immunoblot showing the response of the 45 and $47 \mathrm{kDa}$ proteins from spores against HpAbs QC 2797

$20 \mu \mathrm{g} / \mathrm{lane}$ of crude protein

Marker: LMW-SDS marker from GE Healthcare

Arrows indicate the 45 and $47 \mathrm{kDa}$ proteins

$1^{\circ} \mathrm{Ab}$ : HpAb diluted $1 / 2,000$ with $1 \%$ BSA/TBST

$2^{\circ} \mathrm{Ab}$ : AP-anti-human IgG diluted $1 / 2,000$ with $1 \%$ BSA/TBST 


\subsubsection{Cross-reactivity of different fungal species to target antigenic proteins}

Before pursuing any purification or antibody production with the target proteins the possibility of cross-reactivity had to be assessed. The crude protein samples of different fungal species were examined and compared to $C$. globosum by immunoblots. All protein samples were normalized and $5 \mu \mathrm{g}$ of total protein was used per lane. In figure 17, the large arrows indicate fungi that have proteins in the same region as the target proteins from $C$. globosum. These fungi were examined more closely on immunoblot (figure 18). The 45 and $47 \mathrm{kDa}$ target proteins seemed to cross-react with proteins from the fungi Aspergillus versicolor, Eppicoccum nigrum, Penicillium chrysogenum and $P$. expansum (figure 18). But when carefully compared side by side with C. globosum on silver stain (figure 19) the proteins that appeared similar in molecular weights actually possess molecular weights that are above and below the target proteins (identified with arrows in figure 19). 


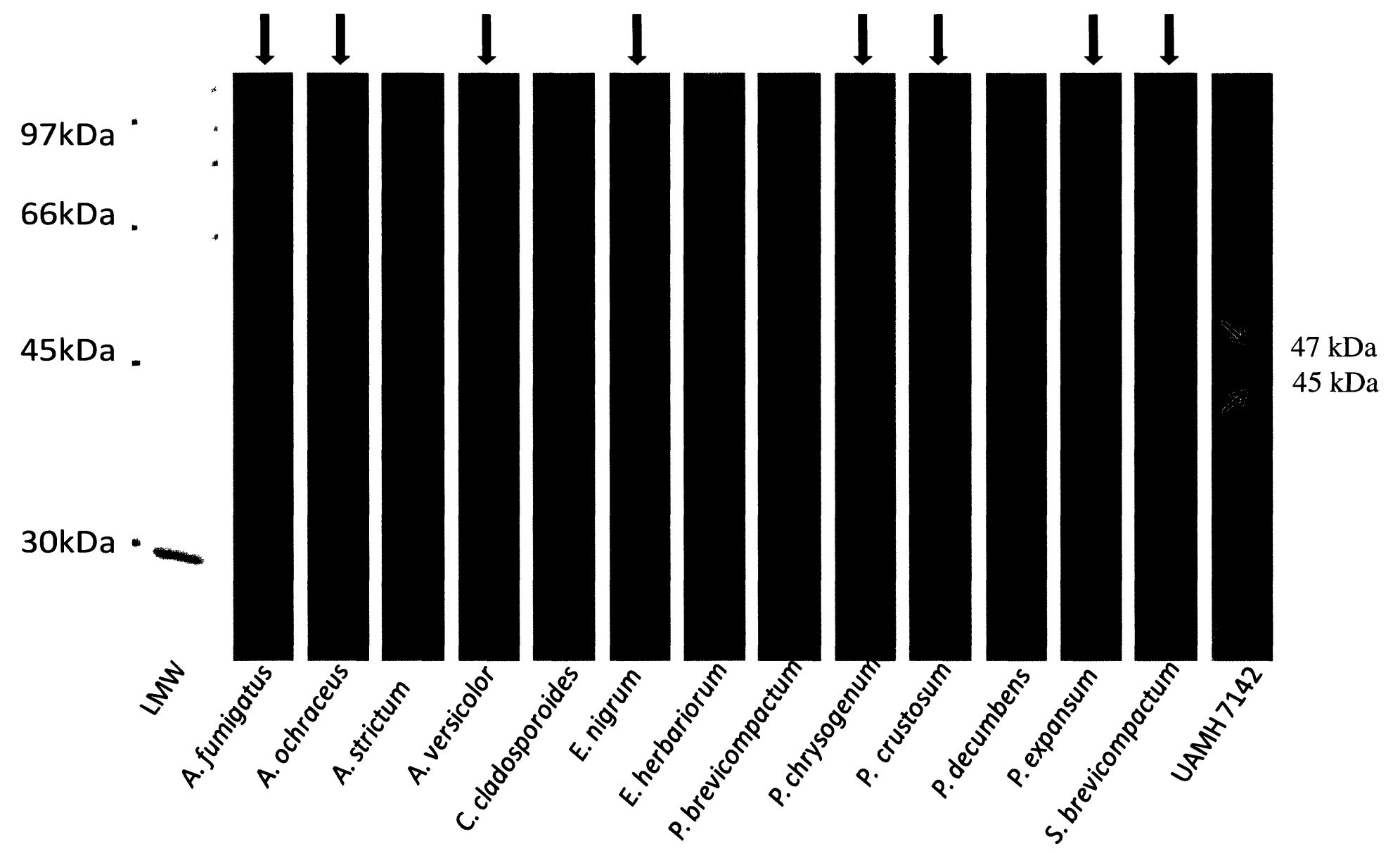

Figure 17: Immunoblot comparing the response of $C$. globosum strain UAMH 7142 to other fungi against $\mathrm{HpAb}$ QC 2797

$5 \mu \mathrm{g} / \mathrm{lane}$ of crude protein

Marker: LMW-SDS marker from GE Healthcare

Arrows indicate the 45 and $47 \mathrm{kDa}$ proteins in C. globosum strain UAMH 7142

$1^{\circ} \mathrm{Ab}: \mathrm{HpAb}$ diluted $1 / 2,000$ with $1 \%$ BSA/TBST

$2^{\circ} \mathrm{Ab}$ : AP-anti-human IgG diluted 1/2,000 with $1 \%$ BSA/TBST 


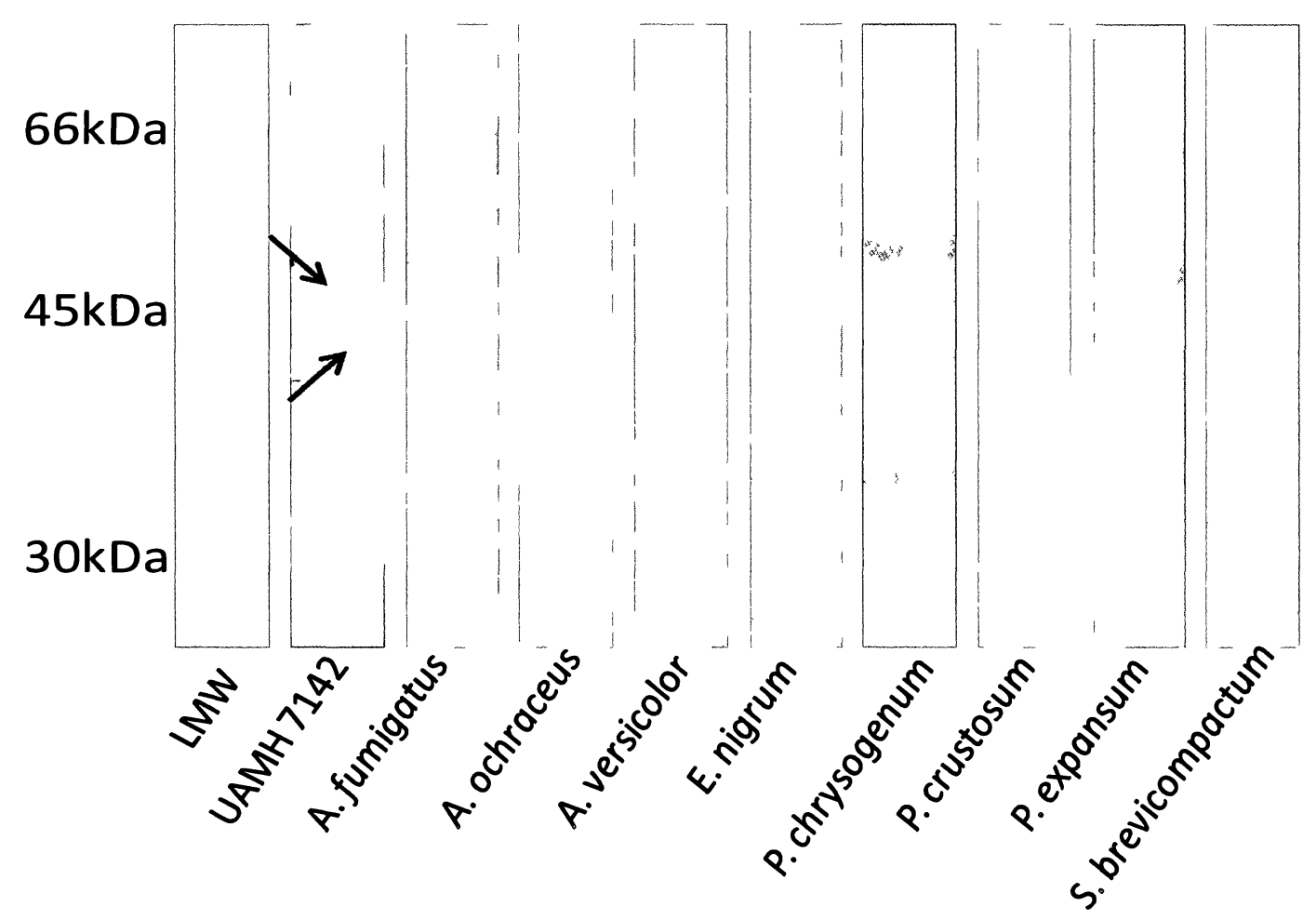

Figure 18: Immunoblot comparing the response of $C$. globosum strain UAMH 7142 to other fungi against HpAb QC 2797

$5 \mu \mathrm{g} /$ lane of crude protein

Marker: LMW-SDS marker from GE Healthcare

Arrows indicate the 45 and $47 \mathrm{kD}$ a proteins in C. globosum strain UAMH 7142

$1^{\circ} \mathrm{Ab}: \mathrm{HpAb}$ diluted $1 / 2,000$ with $1 \% \mathrm{BSA} / \mathrm{TBST}$

$2^{\circ} \mathrm{Ab}$ : AP-anti-human IgG diluted $1 / 2,000$ with $1 \%$ BSA/TBST 


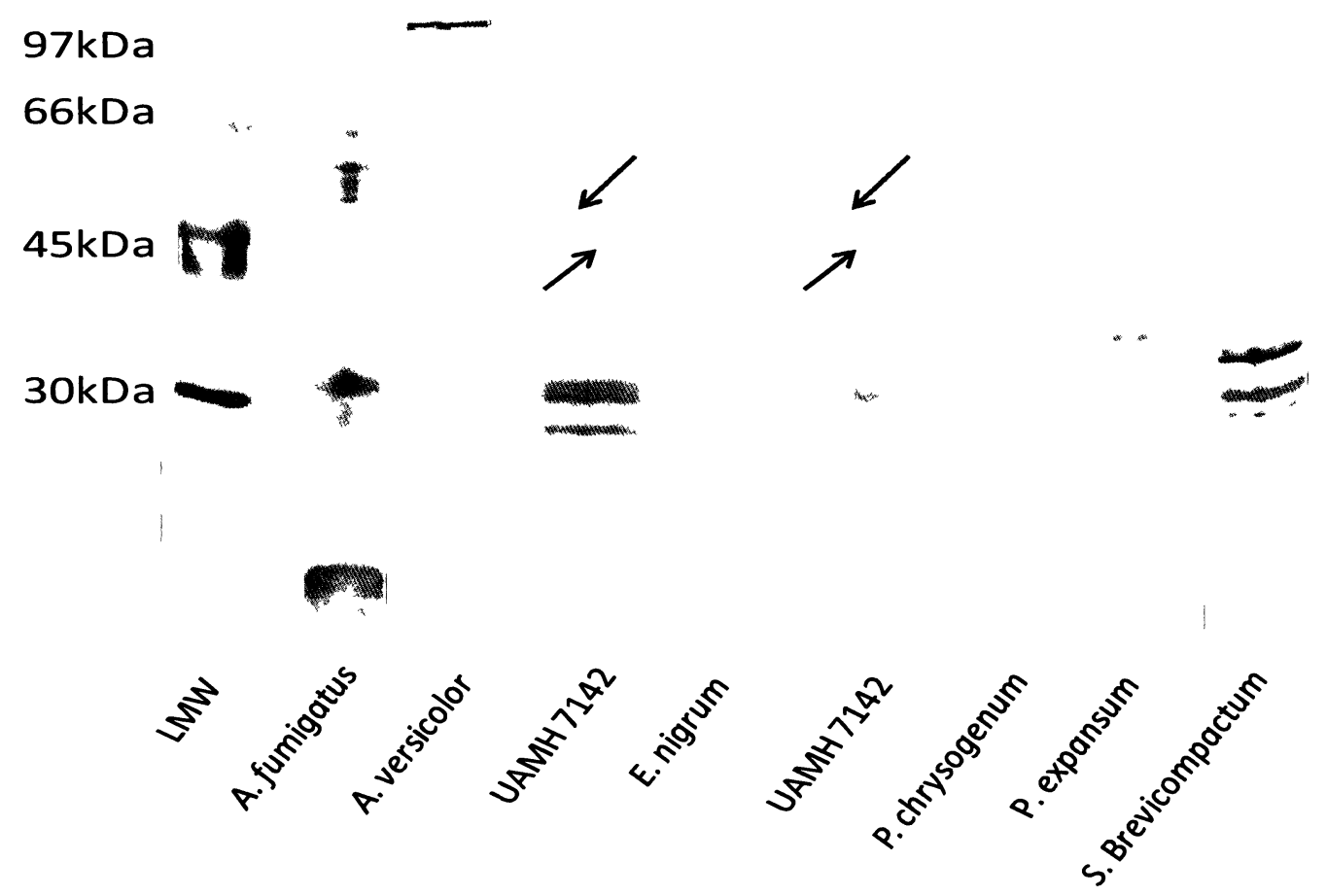

Figure 19: Silver stain demonstrating the presence of proteins in other fungi that have similar molecular weights to $C$. globosum target proteins

$3 \mu \mathrm{g} / \mathrm{lane}$ of crude protein

Marker: I,MW-SDS marker from GIF, Healthcare

Arrows indicate the 45 and $47 \mathrm{kDa}$ proteins in C. globosum strain UAMIH 7142 


\subsection{Purification of $C$. globosum target proteins}

\subsubsection{Ion exchange chromatography}

The $C$. globosum protein samples from the concentrator that contain the 45 and $47 \mathrm{kDa}$ target proteins were purified using anion exchange chromatography. The crude protein samples from the concentrator were used since they produced larger amounts of the target proteins (as seen in figure 20). 


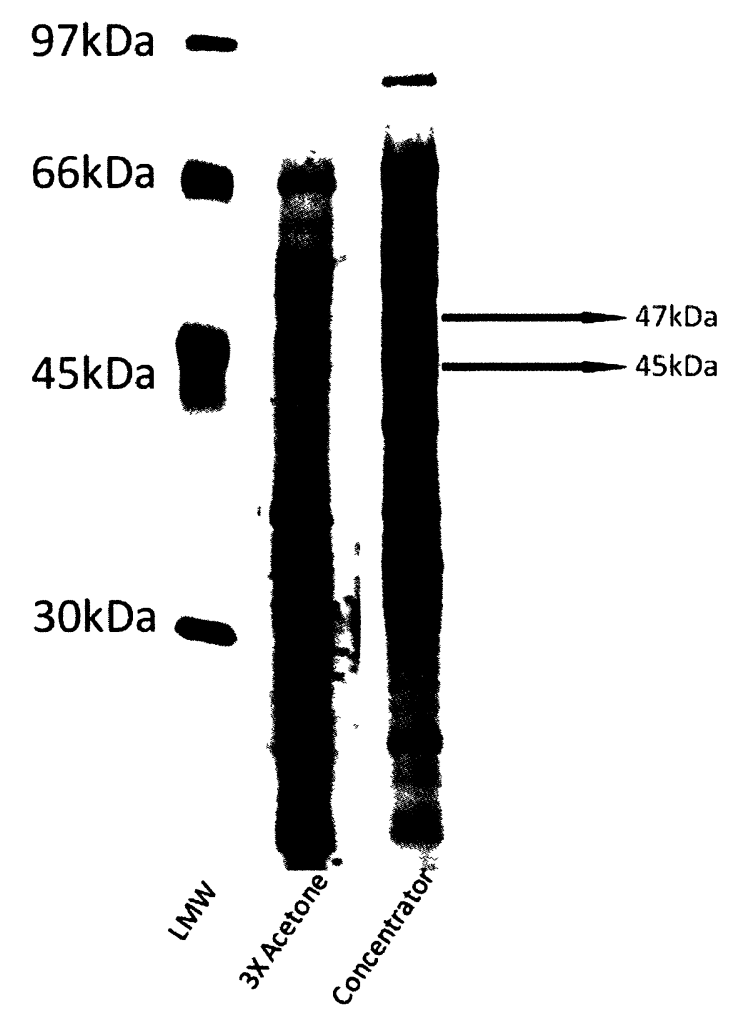

Figure 20: Silver stain comparing the amounts of proteins obtained with the $3 x$ acetone and the concentrator

$4 \mu \mathrm{g} / \mathrm{lane}$ of crude protein

Marker: LMW-SDS marker from GE Healthcare 
Approximately $100 \mathrm{mg}$ of crude proteins was applied to the column for each run. A gradient elution $(0-50 \%, 800 \mathrm{~mL})$ with increasing concentrations of sodium chloride-Tris buffer was used to separate the different proteins in the sample. The silver staining (figure 21) showed the different fractions that contained the target proteins. Fractions 9 to 23 only contained the $45 \mathrm{kDa}$ protein while fractions 34 to 48 only contained the 47 $\mathrm{kDa}$ protein. These fractions were then pooled together and the reactivity was tested by immunoblot (figure 22). The total amount of partially purified $45 \mathrm{kDa}$ was approximately $525 \mu \mathrm{g} / \mathrm{batch}$ and $5 \mathrm{mg} / \mathrm{batch}$ for the $47 \mathrm{kDa}$ protein. This semi-purified protein material was then further purified by gel filtration chromatography. 


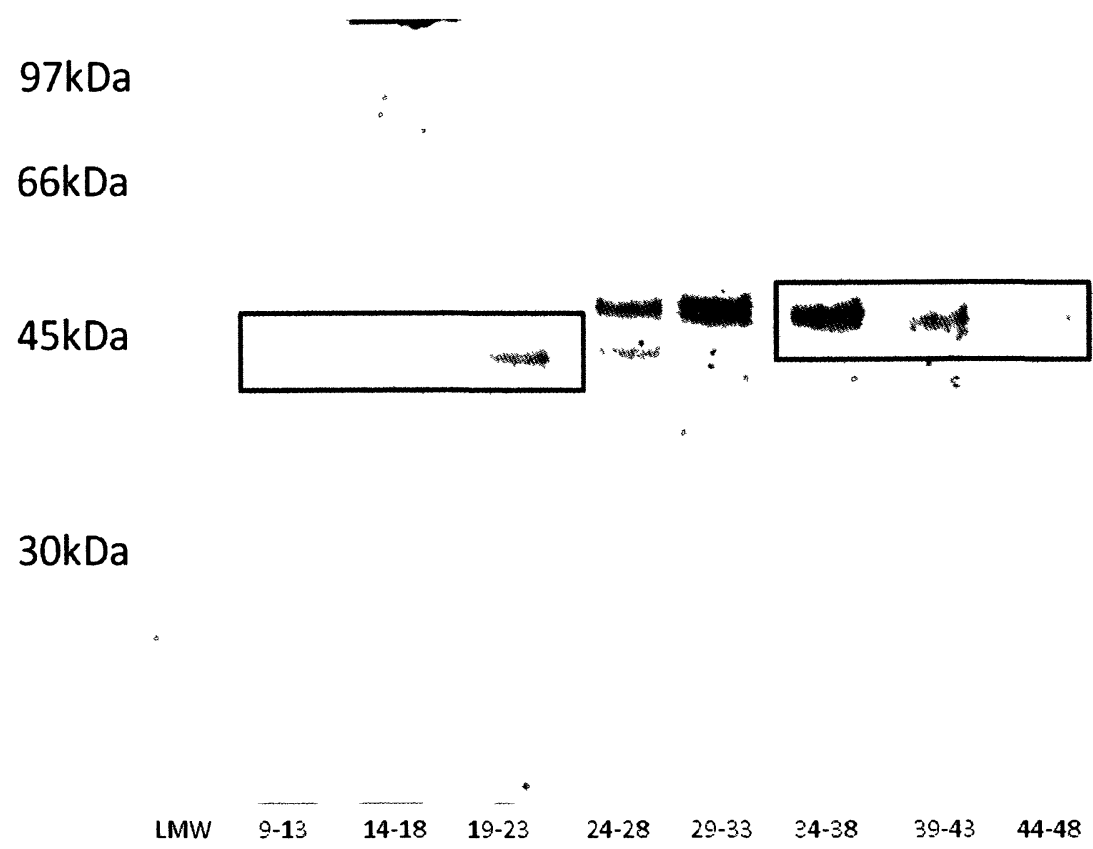

Figure 21: Silver stain of the different fractions eluted from anion exchange column

$4 \mu \mathrm{g} / \mathrm{lane}$ of crude protein

Marker: LMW-SDS marker from GE Healthcare

Fractions 9-28 comprise the $45 \mathrm{kDa}$ protein

Fractions $34-48$ comprise the $47 \mathrm{kDa}$ protein 


\section{$66 \mathrm{kDa}$}

$45 \mathrm{kDa}$

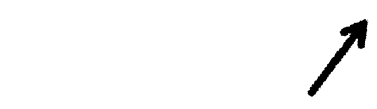

$30 \mathrm{kDa}$

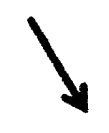

45kDa
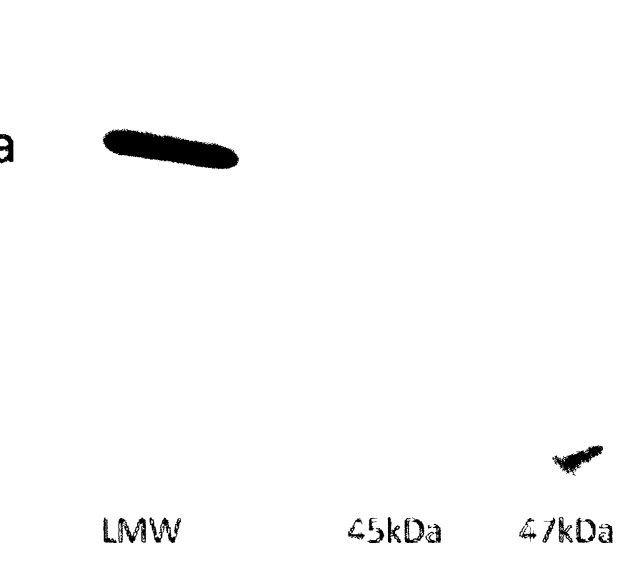

Figure 22: Immunoblot confirming the 45 and $47 \mathrm{kDa}$ proteins eluted from anion exchange column against HpAb QC 2797

$4 \mu \mathrm{g} / \mathrm{lane}$ of crude protein

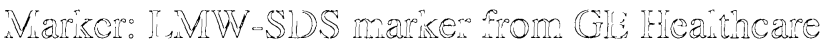

Arrows indicate the 45 and $47 \mathrm{kDa}$ proteins in C. globosum strain UAMH 7142

$1^{\circ} \mathrm{Ab}: \mathrm{HpAb}$ diluted $1 / 2,000$ with $1 \% \mathrm{BSA} / \mathrm{TBST}$

$2^{\circ} \mathrm{Ab}$ : AP-anti-human IgG diluted 1/2,000 with $1 \%$ BSA/TBST 


\subsubsection{Gel filtration chromatography}

The anion exchange protein sample for the $47 \mathrm{kDa}$ antigen was further purified by size exclusion chromatography using a Sephacryl S-300HR gel filtration column. Due to the poor recovery of the $45 \mathrm{kDa}$ protein from anion exchange it could not be purified using gel filtration. Five different protein standards: carbonic anhydrase $(29 \mathrm{kDa})$, albumin $(66 \mathrm{kDa})$, alcohol dehydrogenase $(150 \mathrm{kDa}), \beta$-amylase $(200 \mathrm{kDa})$ and blue dextran $(2,000 \mathrm{kDa})$, were run on the column first. The elution volume of the different standard proteins is presented in figure 23.

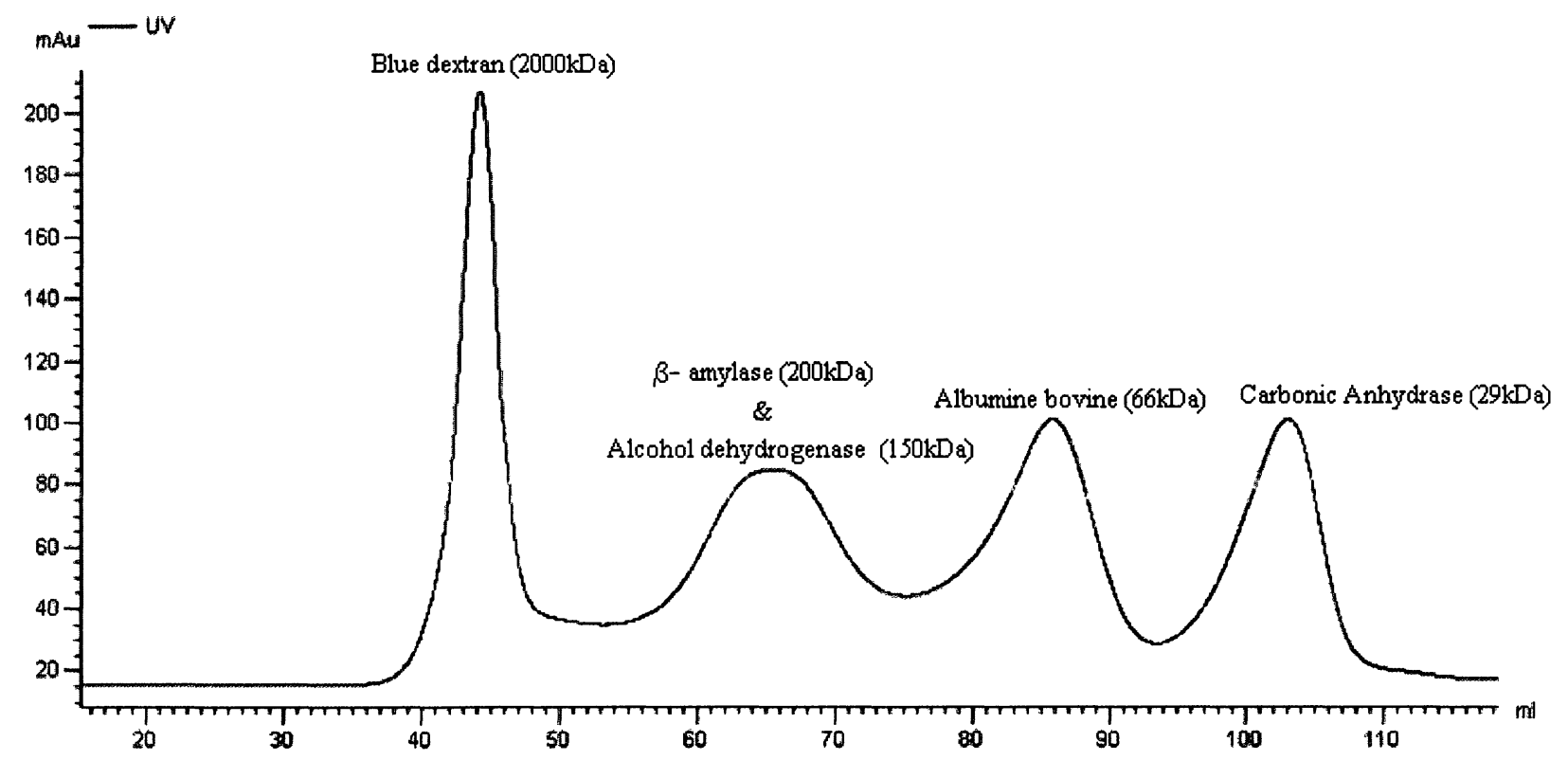

Figure 23: Elution fractions for the protein standards from gel filtration column 
Since gel filtration chromatography separates proteins by size the target protein should be eluted between the albumin $(66 \mathrm{kDa})$ and the carbonic anhydrase $(29 \mathrm{kDa})$ or between 85 and $105 \mathrm{~mL}$. In figure 24 fractions 10 to 16 contain the $47 \mathrm{kDa}$ protein. Another protein was also eluted in fraction 15 and 16 but the target protein still represents greater than $90 \%$ of the total protein while the other protein represents less than $5 \%$. Table 3 reports the protein recovery after each purification step. The target proteins were sufficiently pure for amino acid sequencing and for monoclonal antibody production. 


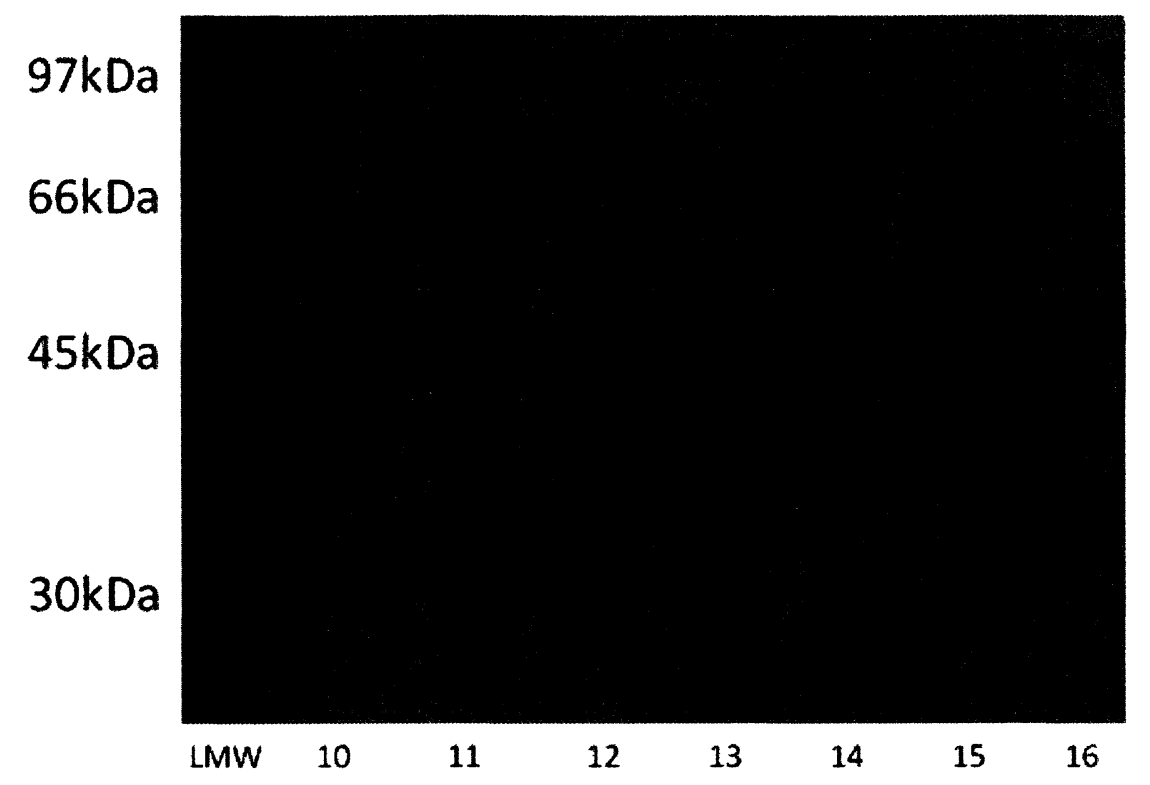

Figure 24: Silver stain of elution fractions of the $47 \mathrm{kDa}$ protein from gel filtration column

$10 \mu \mathrm{g} /$ lane of crude protein

Marker: LMW-SDS marker from GE Healthcare

Fractions 10-16 contain the $47 \mathrm{kDa}$ protein in C. globosum strain UAMH 7142 
Table 3: Protein recovery for each purification step for $C$. globosum

\begin{tabular}{lccccc}
\multicolumn{1}{c}{ Purıfication step } & Total proteın (mg) & 45kDa proteın (mg) & Yield (\%) & 47 kDa proteın (mg) & Yıeld (\%) \\
\hline concentrator (per 8L batch) & 350 & 10 & 3 & 7 & 2 \\
10n exchange chromatography & 125 & 0525 & 525 & 5 & 71 \\
gel filtration chromatography & 5 & N/A & N/A & 1 & 20
\end{tabular}




\subsection{Polyclonal antibody production}

\subsubsection{Polyclonal antibodies produced in rabbits}

The rabbit polyclonal antibodies (RpAbs) were produced by injecting two rabbits with $1 \mathrm{mg}$ of spores from $C$. globosum strain UAMH 7142. The rabbit identified as 305 was then boosted three times following successive 21 days increments with $0.5 \mathrm{mg}$ of $47 \mathrm{kDa}$ pure protein extracts. The other rabbit (675) was injected twice with $0.5 \mathrm{mg}$ of the $45 \mathrm{kDa}$ pure protein extract.

\subsubsection{Analysis of the polyclonal antibodies from test-bleeds}

A test bleed was performed 17 days after the rabbits were injected with the spores. The response of the target proteins to the RpAbs was determined by immunoblot (figure 25); the culture filtrate $(\mathrm{CF})$ and spores $(\mathrm{SP})$ were examined for their response to spore boost (CF1\&SP1) as well as the second antigen boosted (CF2\&SP2) test bleeds. The following image compares the responses of the target proteins for both boost stages. 


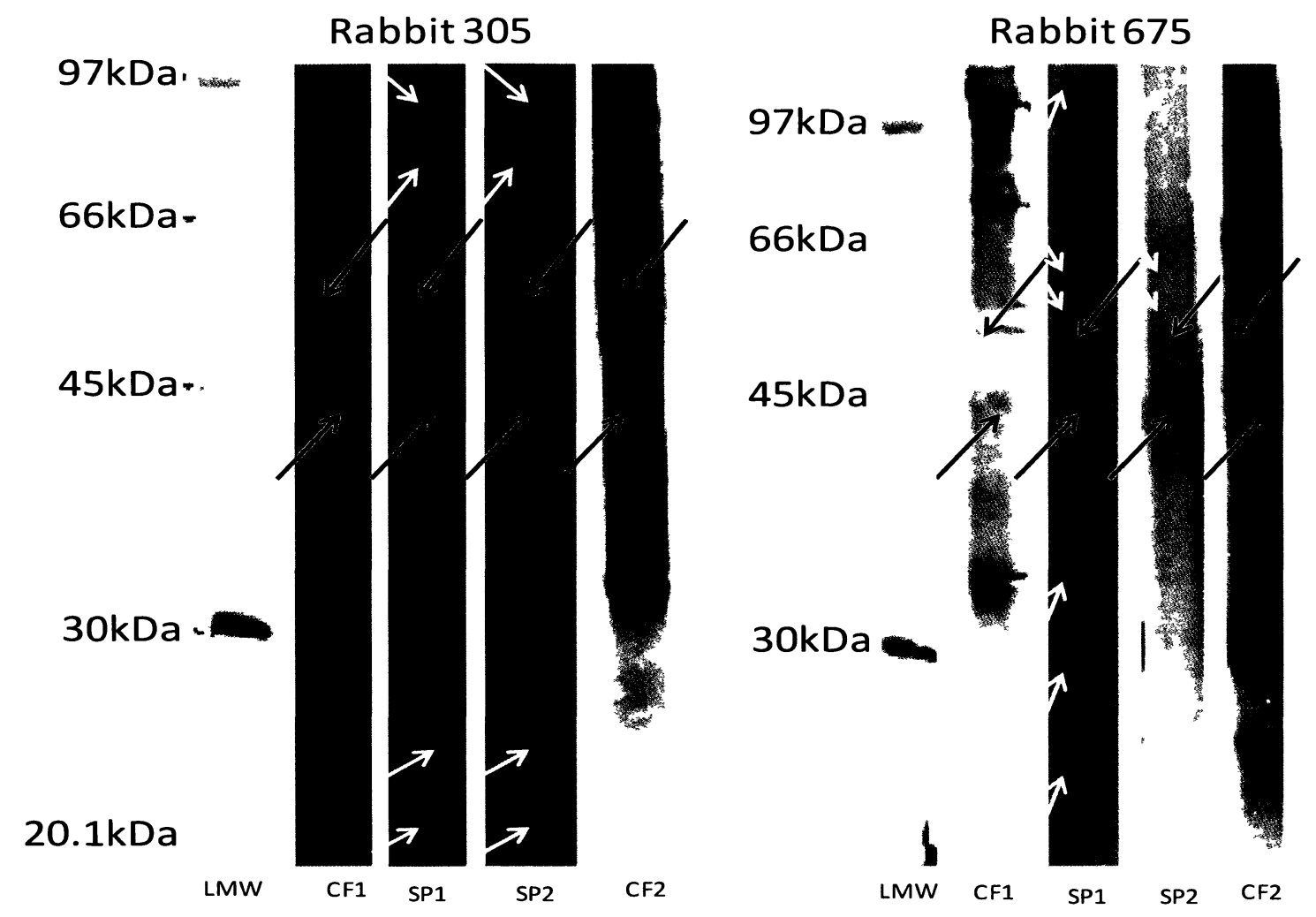

Figure 25: Immunoblots demonstrating the response of the 45 and $47 \mathrm{kDa}$ protein from culture filtrate (CF) and spores (SP) after the rabbits were immunized with spores (CF1 \& SP1) and after the second antigen boost (CF2 \& SP2)

Marker: LMW-SDS marker from GE Healthcare

Black arrows show 45 and $47 \mathrm{kDa}$ proteins

White arrows show other proteins responding proteins in spore samples

$1^{\circ} \mathrm{Ab}: \mathrm{RpAb}$ diluted $1 / 800$ with $1 \% \mathrm{BSA} / \mathrm{TBST}$

$2^{\circ} \mathrm{Ab}$ : AP-anti-rabbit IgG diluted $1 / 30,000$ with $1 \%$ BSA/TBST 


\subsubsection{Purification of polyclonal antibodies}

After the terminal bleed the rabbit polyclonal antibodies were purified using a protein $\mathrm{G}$ column. The purity of both antibodies was observed by CBB (figure 26), the lack of other proteins besides the heavy and light chain proves that the antibody was well purified. The performance of each antibody was evaluated using ELISA (figure 27).

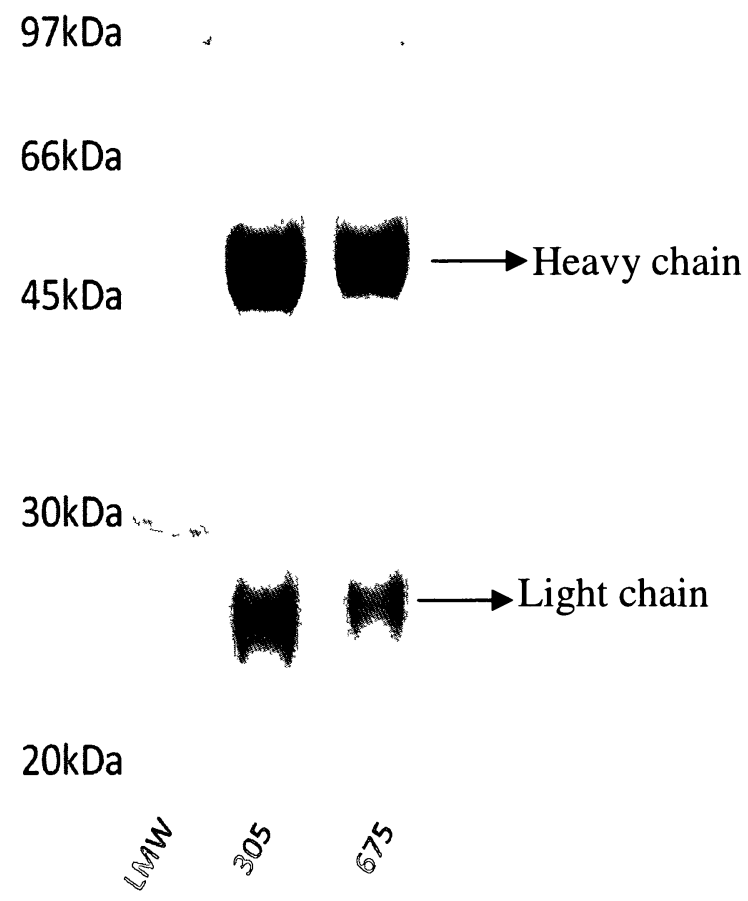

Figure 26: CBB stained gel of the rabbit polyclonal antibody 305 and 675 after a protein $G$ column purification 


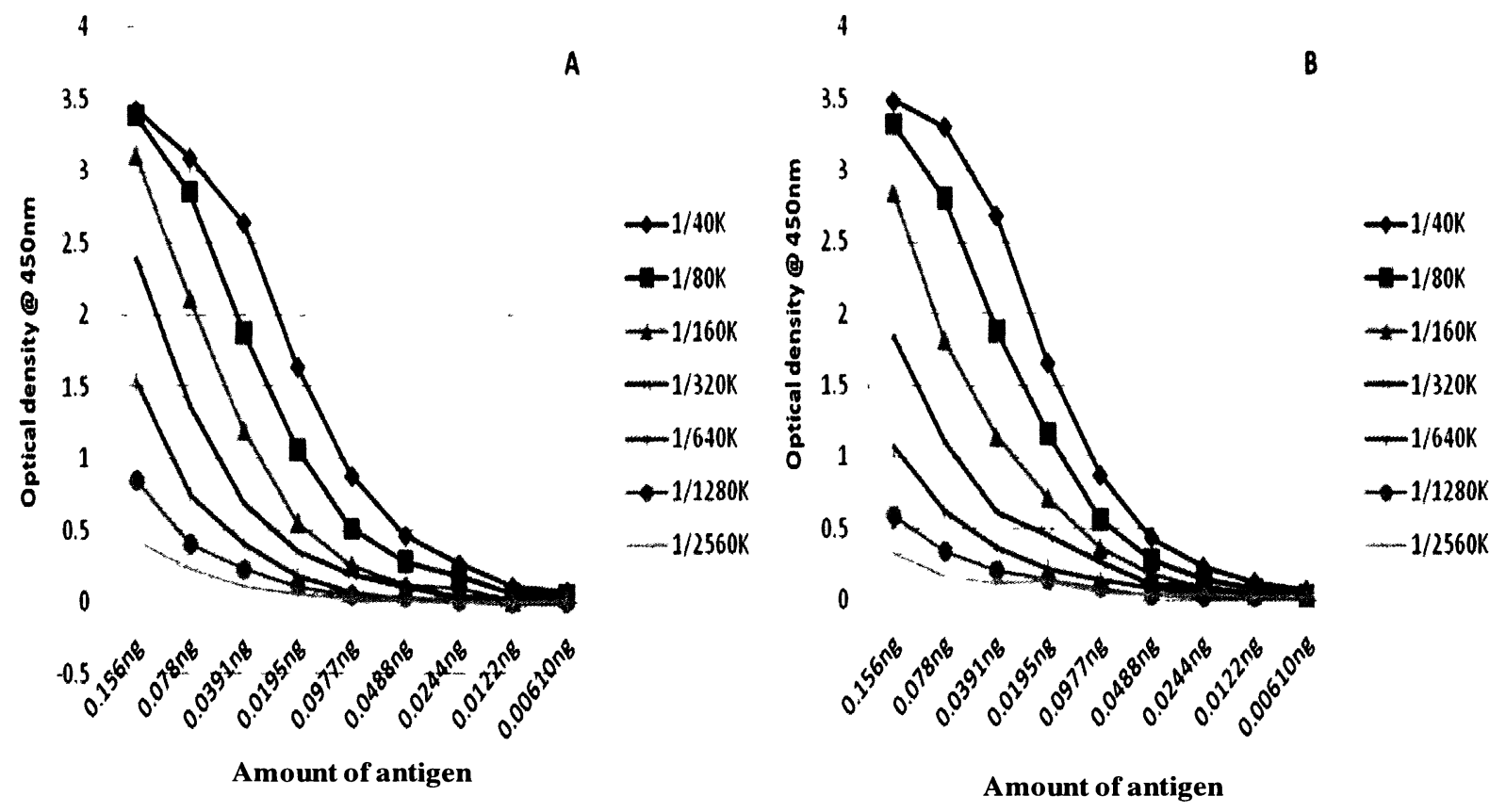

Figure 27: ELISA results demonstrating the activity of the antibody 305 (A) and 675 (B) against the 47 $\mathrm{kDa}$ protein 


\subsubsection{Cross-reactivity testing with the RpAbs}

The immunoblots in figure 28 show the results of the cross-reactivity test of the target proteins to other fungi using the rabbit polyclonal antibodies. The other fungi tested showed limited response to the RpAbs in comparison to C. globosum. The crossreactivity was also assessed using ELISA. The $C$. globosum spores displayed a much better response to the antibody 305 in comparison to other fungi (figure 29). The target proteins from the culture filtrate, the spores as well as the purified extracts reacted when tested against the rabbit polyclonal antibodies, proving their antiginicity (figure 30). These immunoblotting tests and the ELISA results confirm that the target proteins are appropriate for further study. 
Polyclonal 305

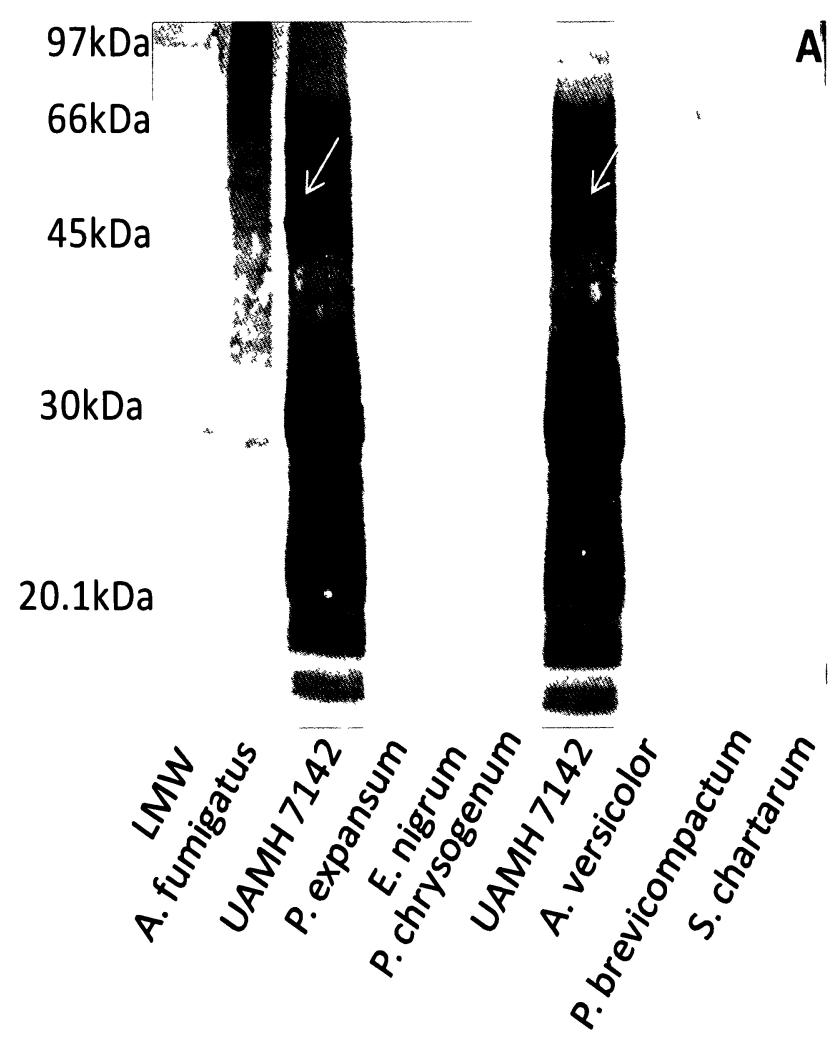

Polyclonal 675

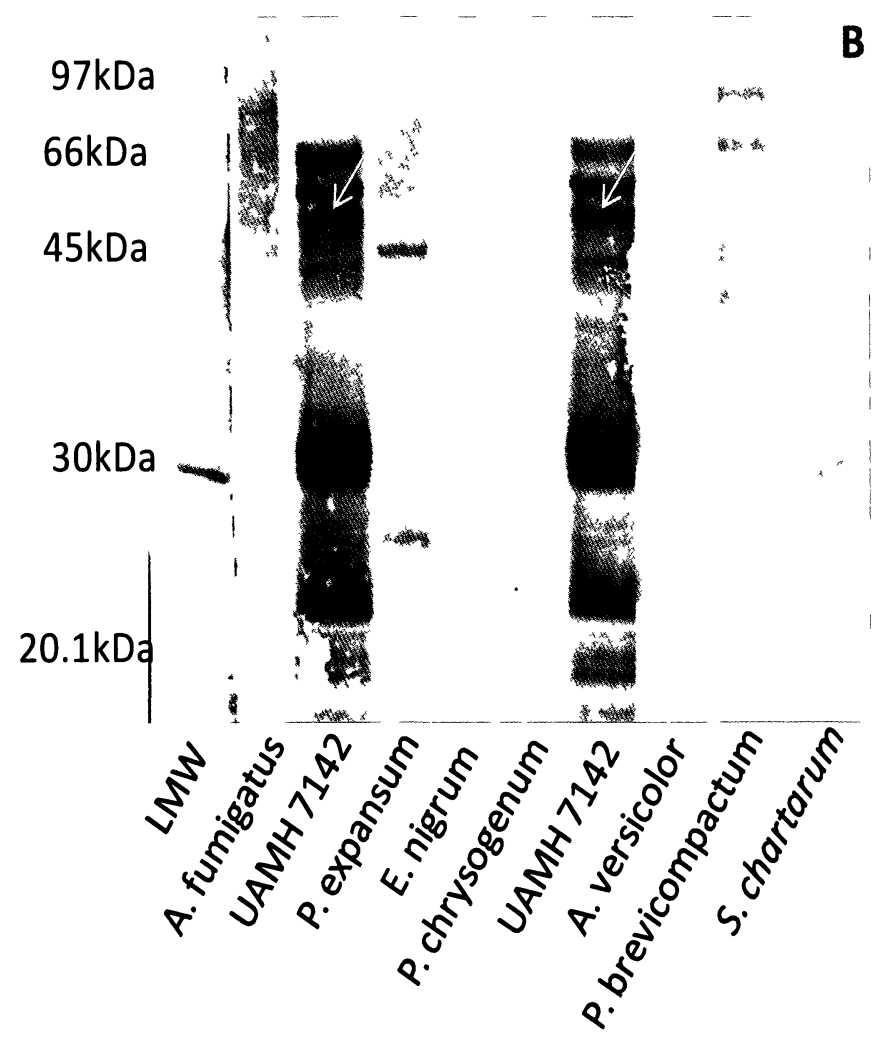

Figure 28: Immunoblots demonstrating the response of $C$. globosum strain UAMH 7142 compared to other fungi using the rabbit polyclonal antibodies 305 (A) and 675 (B)

Marker: LMW-SDS marker from GE Healthcare

Yellow arrows show $47 \mathrm{kDa}$ protein

Red arrows show $45 \mathrm{kDa}$ protein

$1^{\circ} \mathrm{Ab}$ : Purified RpAb diluted 1/10,000 with $1 \%$ BSA/TBST

$2^{\circ} \mathrm{Ab}$ : AP-anti-rabbit IgG diluted $1 / 30,000$ with $1 \%$ BSA/TBST 


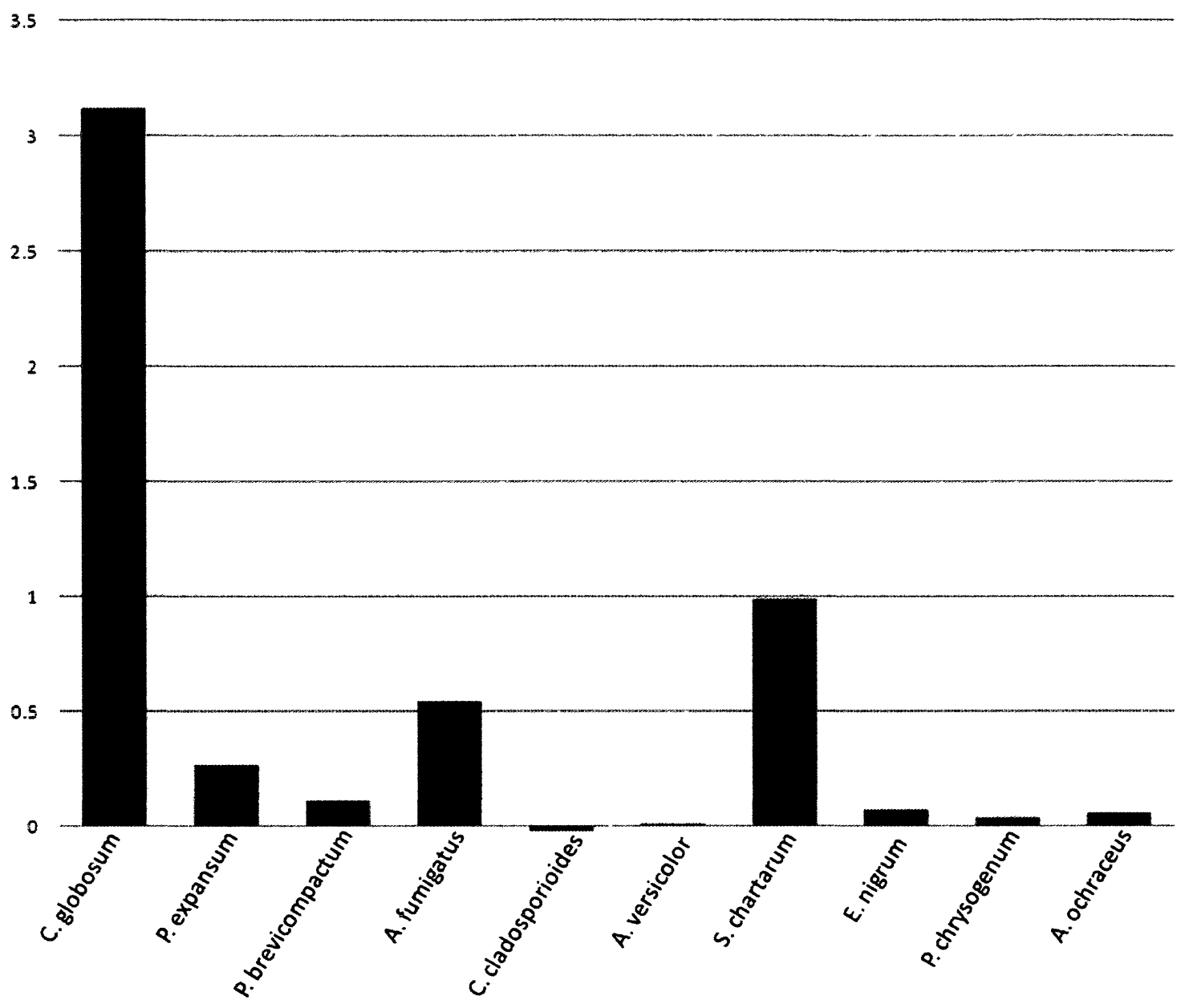

$\cdot 1$

Figure 29: ELISA results demonstrating the response of $C$. globosum and different fungi using the rabbit polyclonal antibody 305

80ng of crude protein from spores

$1^{\circ} \mathrm{Ab}$ : Purified RpAb diluted $1 / 40,000$ with $1 \%$ BSA/PBST

$2^{\circ} \mathrm{Ab}$ : HRP-anti-mouse IgG diluted $1 / 5,000$ with $1 \%$ BSA/PBST 


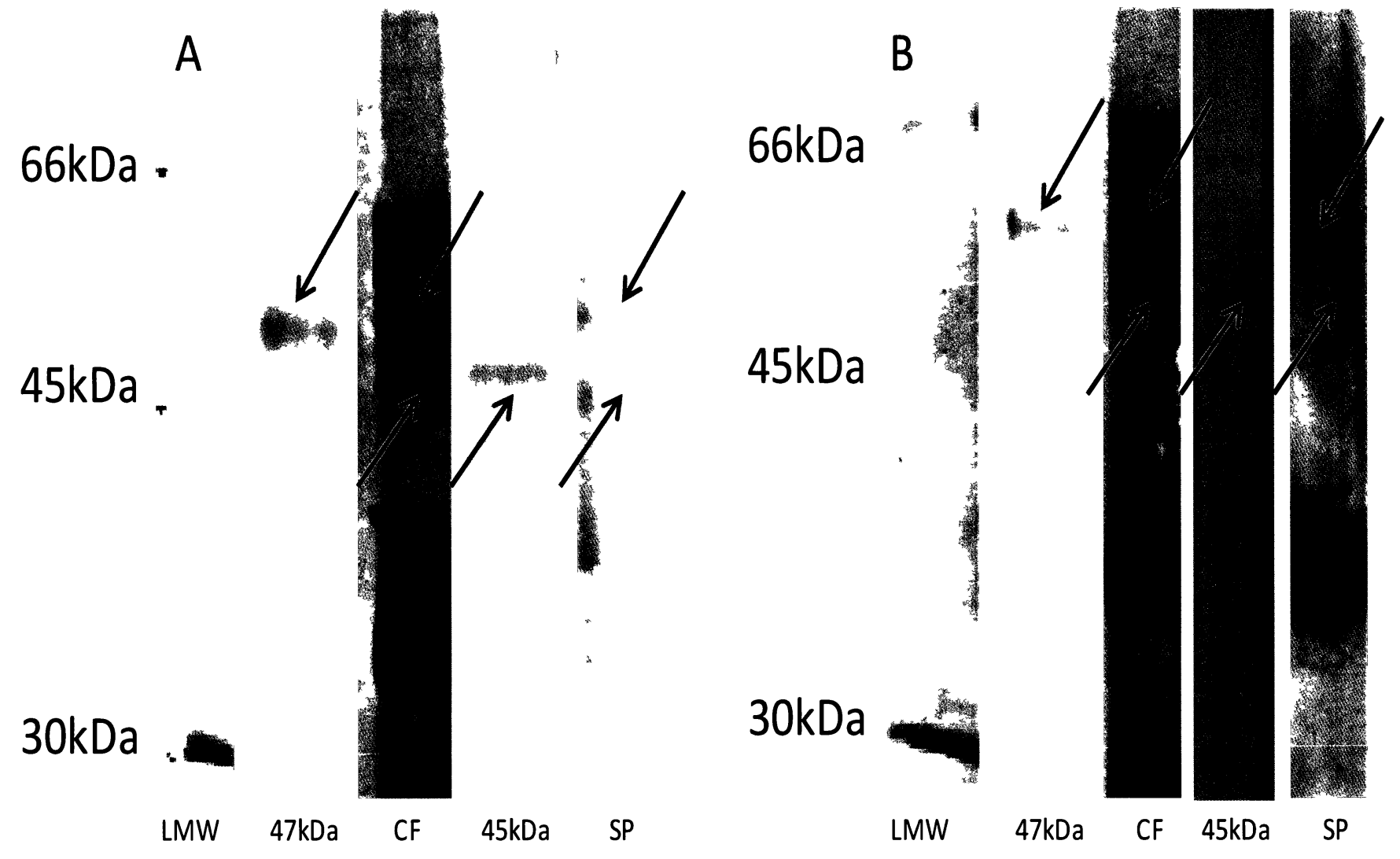

Figure 30: Immunoblots demonstratıng the antıgınicity of the 45 and $47 \mathrm{kDa}$ proteins using the RpAbs 305 (A) and 675 (B)

Marker: LMW-SDS marker from GE Healthcare

CF: Culture filtrate

SP: Spore extract

Black arrows show 45 and $47 \mathrm{kDa}$ proteins

$1^{\circ} \mathrm{Ab}$ : Purified RpAb diluted $1 / 10,000$ with $1 \%$ BSA/TBST

$2^{\circ} \mathrm{Ab}$ : AP-anti-rabbit IgG diluted $1 / 30,000$ with $1 \%$ BSA/TBST 


\subsection{Characterization of the target antigens}

\subsubsection{MS/MS}

The $45 \mathrm{kDa}$ and $47 \mathrm{kDa}$ proteins were cut out of a CBB gel and sent to Health Canada for MS/MS determination. They were digested with trypsin and analyzed by liquid chromatography tandem mass spectrometry (LC-MS/MS) using a Linear Trap Quadrupole Fourier Transform (LTQ-FT). The resulting peptide sequences were BLAST searched with the protein database to characterize the antigenic proteins. The peptide sequences analysis determined that both target proteins are chitosanases. The spectrums for both target proteins $45 \mathrm{kDa}(\mathrm{CHG} 45)$ and $47 \mathrm{kDa}(\mathrm{CHG} 47)$ are displayed in figure 31 , the numbers identify the major and minor mass-to-charge ratios associated to the chitosanase. The alignment of the 45 and $47 \mathrm{kDa}$ proteins spectrum in figure 32 shows the similarity between both target proteins and the peptide sequences correlated to chitosanase. Because of the similarities of the two target proteins and the difficulty of isolating and purifying the $45 \mathrm{kDa}$ protein the $47 \mathrm{kDa}$ was used for any other characterization analyses and monoclonal antibody production. 

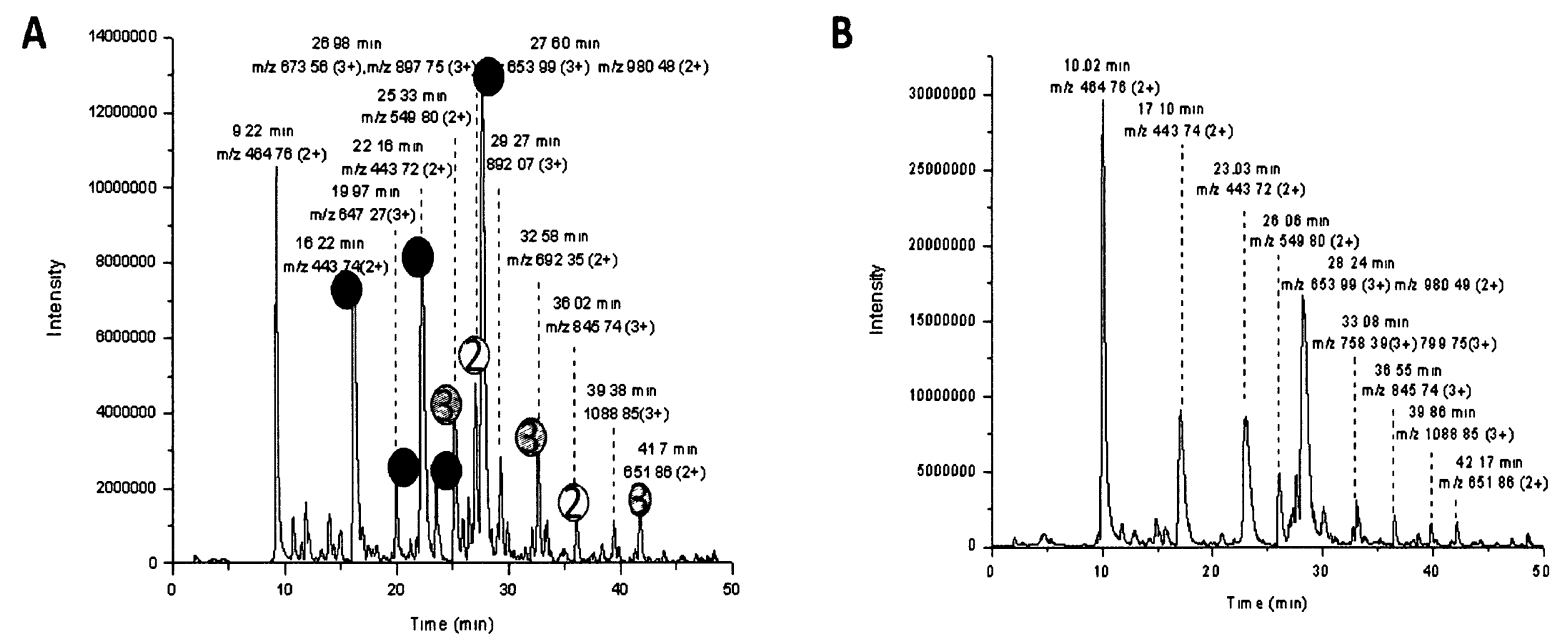

Figure 31: LTQ-FT spectrum of the sample CHG47 (A) and CHG45 (B)

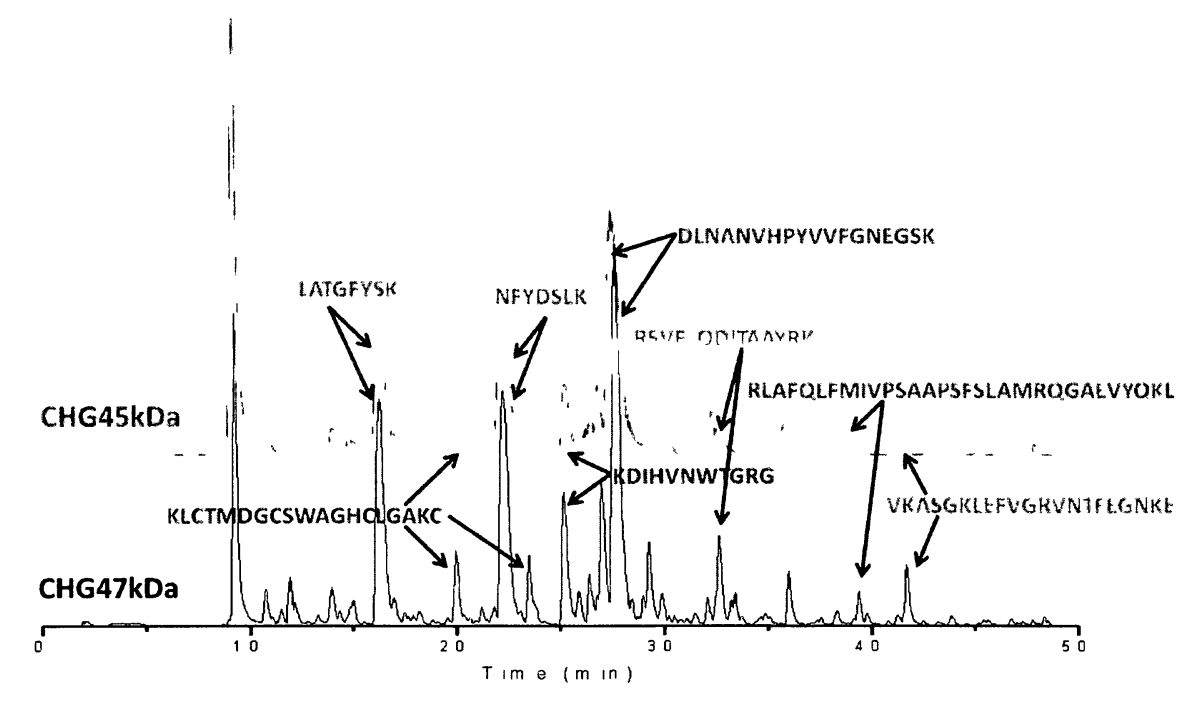

Figure 32: Alignment of the LTQ-FT spectra for the 45 and $47 \mathrm{kDa}$ proteins and the peptide sequences associated 


\subsubsection{Isoelectric point ( $\mathrm{pI})$}

The isoelectric focusing was used to determine the $\mathrm{pH}$ of the $47 \mathrm{kDa}$ protein. The isoelectric focusing uses a $\mathrm{pH}$ gradient to separate the proteins horizontally. Around $8 \mu \mathrm{g}$ of pure extract of the $47 \mathrm{kDa}$ protein was separated on an electric focusing strip with a $\mathrm{pH}$ that ranged from 3 to 10 and 5 to 8 . The calculated $\mathrm{pH}$ was found to be 4.5 (figure 33) indicating that the $47 \mathrm{kDa}$ is an acidic protein. The protein was not present on the strip that ranged from 5 to 8 and the image was therefore omitted.

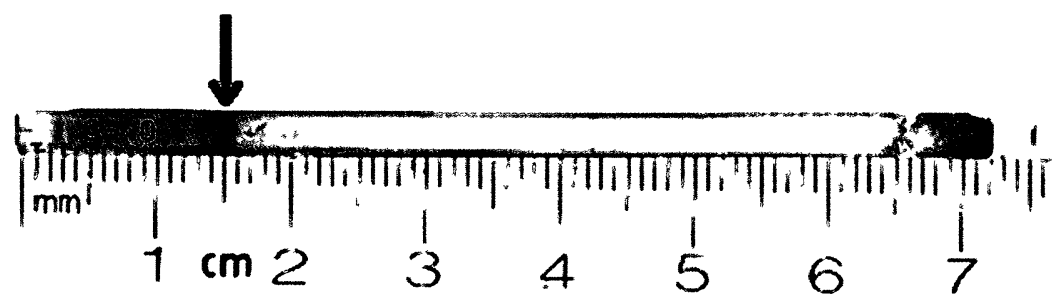

Figure 33: Silver stained isoelectric focusing strip (pH 3-10), arrow indicates a $\mathrm{pI}$ of 4.5 for the $C$. globosum $47 \mathrm{kDa}$ protein

\subsubsection{Glycoprotein assay}

A glycoprotein stain was used to determine whether the $47 \mathrm{kDa}$ protein was glycosylated. The gel was first stained with the glycoprotein staining kit and then with CBB (figure 34). The first lane of the gel consisted of the $47 \mathrm{kDa}$ protein treated with pNGASE, the second lane was the $47 \mathrm{kDa}$ pure target protein, the third lane had the horseradish peroxidase (HRP) as the positive control and the last lane contained the negative control a soybean trypsin inhibitor. The only positive band from the glycoprotein stained gel was the horseradish peroxidase, the $47 \mathrm{kDa}$ protein is not glycosylated. 
$66 \mathrm{kDa}$

A

B

\section{$45 \mathrm{kDa}$}

$30 \mathrm{kDa}$

\section{$20 \mathrm{kDa}$}

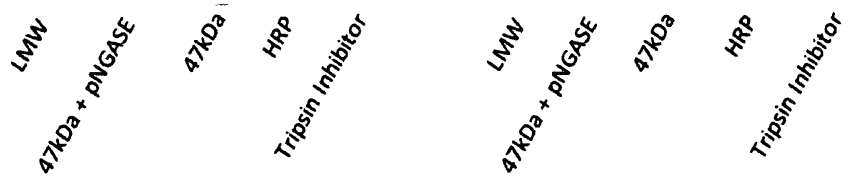

Figure 34: CBB stained gel (A) and glycoprotein stain (B) demonstrating that the $47 \mathrm{kDa}$ target proteins is not glycosylated 


\subsubsection{Chitosanase assay}

The presence of reduced sugar produced by the $47 \mathrm{kDa}$ target protein was performed using a dinitrosalicylic colorimetric method. A calibration curve was first produced using glucose as the standard. Different amounts of glucose ranging from 0.1 to $6.0 \mathrm{mg}$ were tested and the reduced sugar production was measured using a spectrophotometer at $575 \mathrm{~nm}$ (figure 35). The target protein was mixed with $20 \mu \mathrm{g}$ of chitosan and dinitrosalicylic acid reagent and the amount of reduced sugar was measure at different temperatures. Figure 36 shows that a superior activity of the chitosanase enzyme was observed at a temperature of $50^{\circ} \mathrm{C}$. The activity of the enzyme increased as the temperature increased but if the temperature was above $50^{\circ} \mathrm{C}$ a decline in the ability to produce reduced sugar was observed. Different incubation times were tested as well. The production of reduced sugar was time dependant as displayed in figure 37 . With a longer incubation time a higher production of reduced sugar is perceived but after 4hours it reached a plateau. 


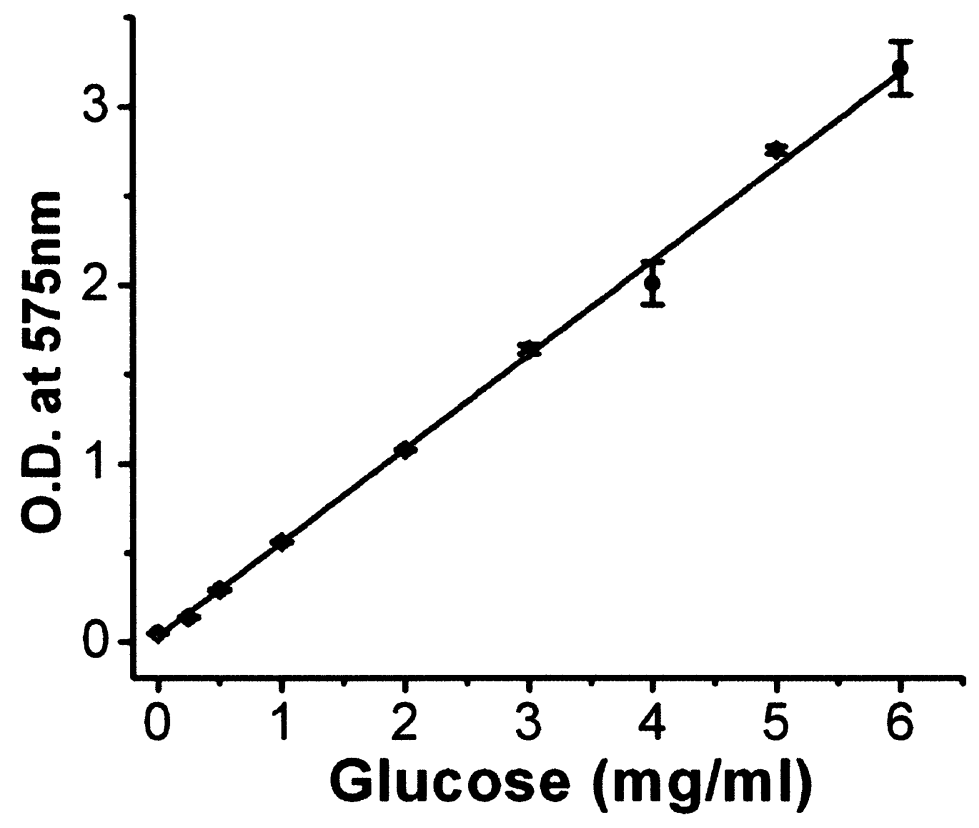

Figure 35: Calibration curve of the optical densities of reduced sugar produced when glucose is treated with dinitrosalicylic acid reagent 


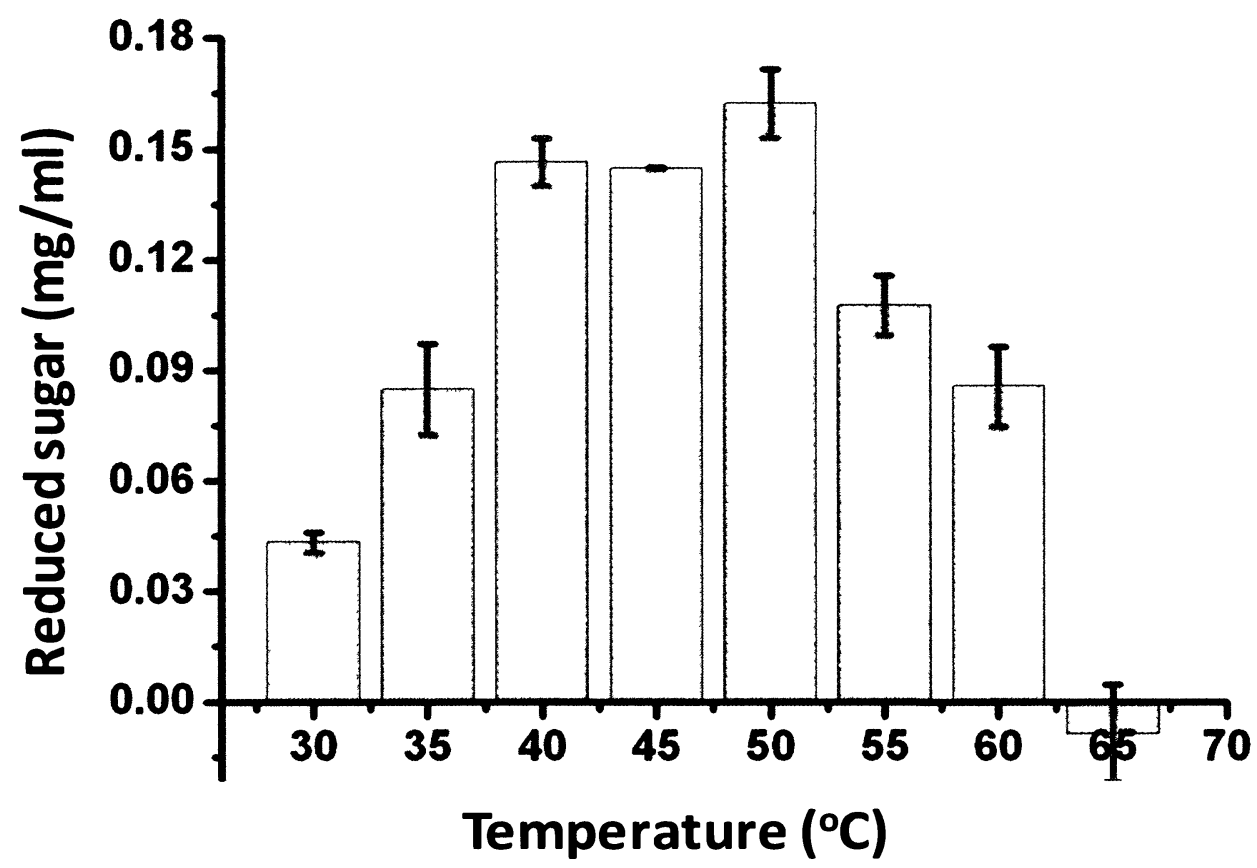

Figure 36: Reduced sugar produced when $47 \mathrm{kDa}$ protein and chitosan are incubated at different temperatures with dinitrosalicylic acid reagent 


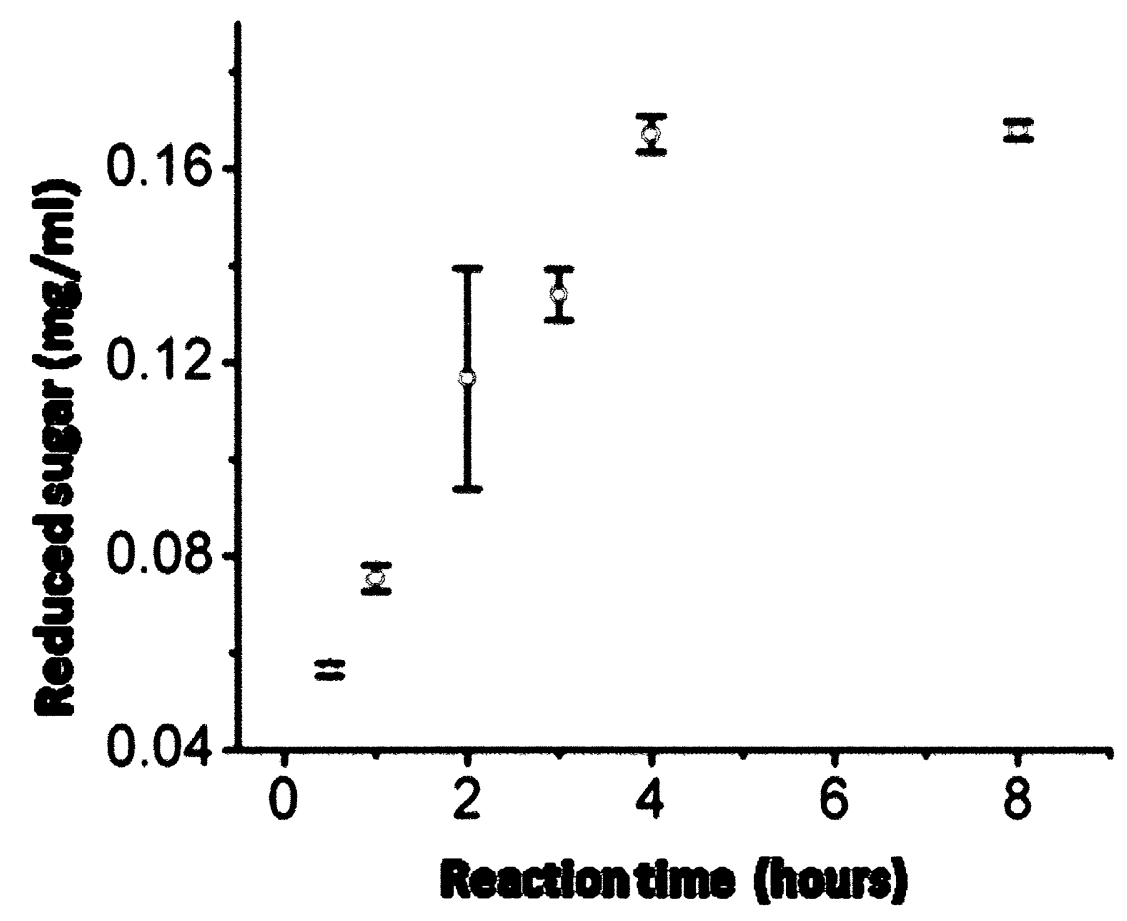

Figure 37: Reduced sugar produced when $47 \mathrm{kDa}$ protein and chitosan are incubated for different amounts of time with dinitrosalicylic acid reagent (reaction done at $50^{\circ} \mathrm{C}$ ) 


\subsection{Monoclonal antibody production}

\subsubsection{Monoclonal antibodies produced in mice}

The mouse monoclonal antibodies (MmAbs) were produced by injecting $5 \mathrm{mg}$ of the 47 $\mathrm{kDa}$ purified protein extract from gel filtration into four different mice. After three weeks, the mouse sera were screened using ELISA (done by ImmunoPrecise) for their antibody titre response. The ELISA tested the $\operatorname{IgG}$ and $\operatorname{IgM}$ antibody response to the 47 $\mathrm{kDa}$ antigenic protein. The optical density is higher for mouse \#1 and \#4 and the antibody isotype IgG had an overall higher response then the IgM (table 4). The antibody dilution used in the ELISA was $500 \times$ and the amount of antigen varied from $1 \mu \mathrm{g}$ to 7.8 ng.

Table 4: ELISA results (done by Immunoprecıse) for IgG and IgM antıbody response to $47 \mathrm{kDa}$ antigen

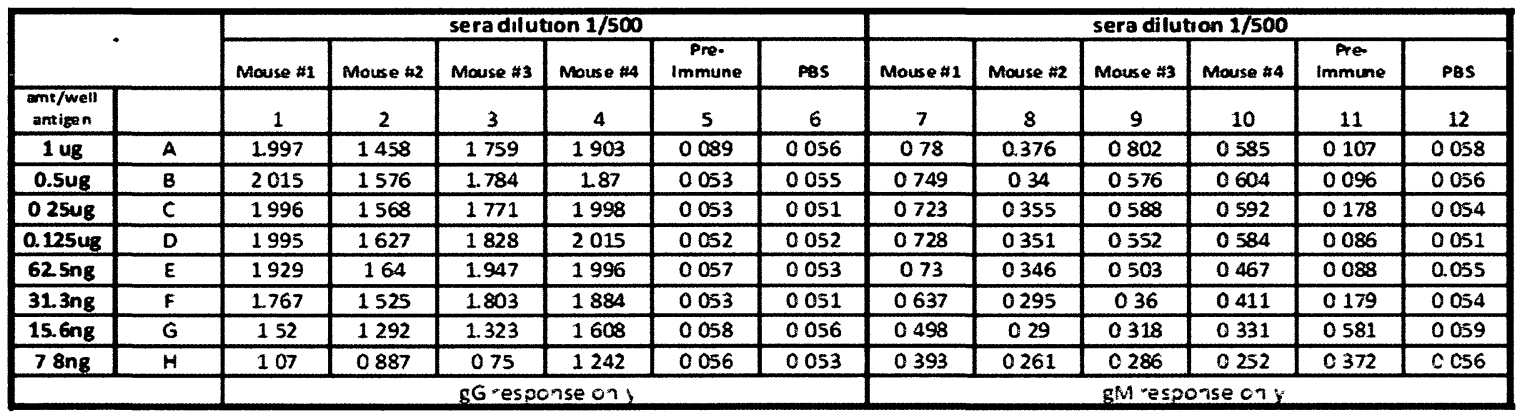

The antigenicity of the $47 \mathrm{kDa}$ protein was further analyzed by conducting immunoblots with the mouse sera. The dilutions used were 1/800 for all four serum samples. The following immunoblot demonstrates the response to the $47 \mathrm{kDa}$ protein to every mouse sera. Since the antigenic protein responded highly on immunoblot to mouse \#1 and \#4 and they also had the highest optical density values on ELISA they were selected for the hybridoma production. 


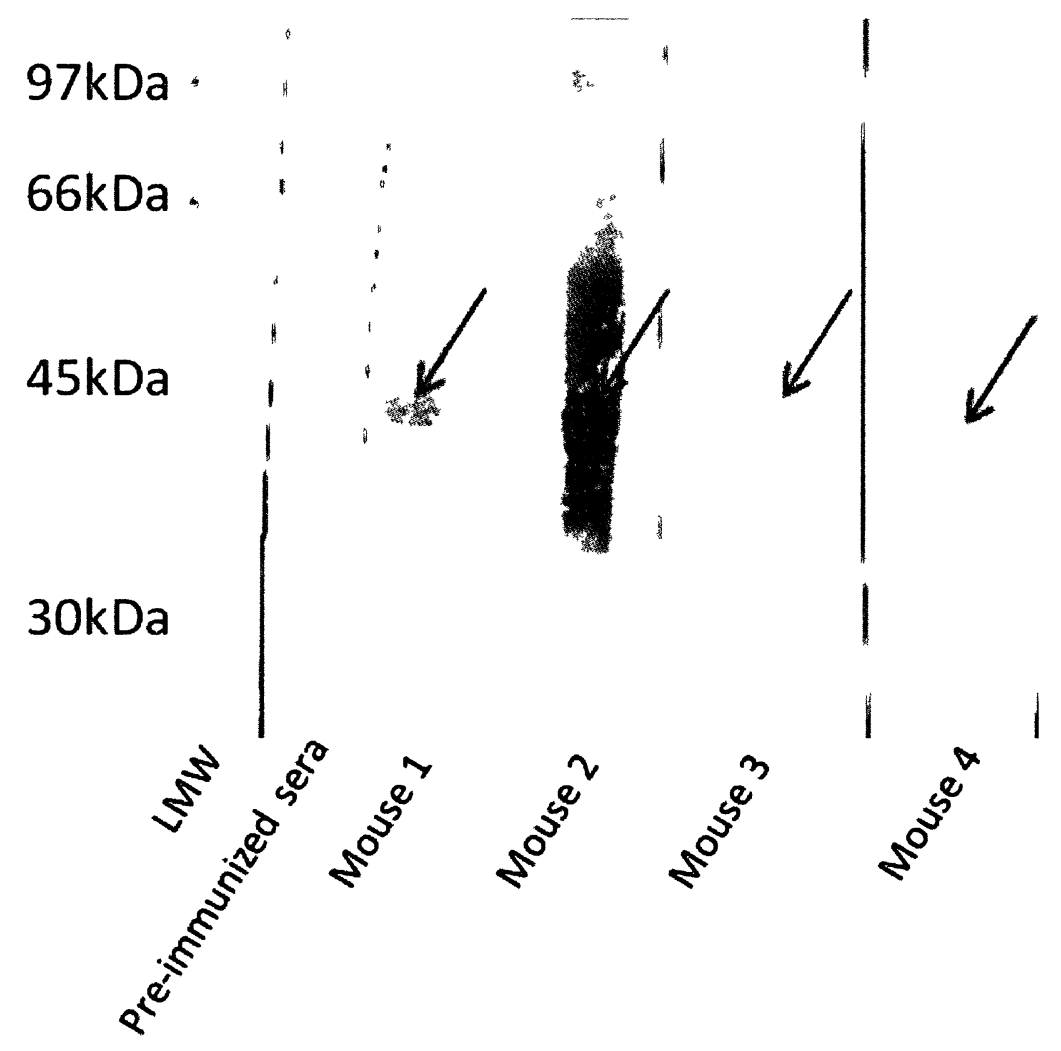

Figure 38: Immunoblot performed on culture filtrate from C. globosum against pre-ımmunized sera and serum from mouse 1 to 4

Marker: LMW-SDS marker from GE Healthcare

Black arrows show $47 \mathrm{kDa}$ protein

$1^{\circ} \mathrm{Ab}: \mathrm{MmAb}$ diluted $1 / 800$ with $1 \% \mathrm{BSA} / \mathrm{TBST}$

$2^{\circ} \mathrm{Ab}$ : AP-anti-mouse IgG diluted $1 / 25,000$ with $1 \% \mathrm{BSA} / \mathrm{TBST}$ 


\section{DISCUSSION}

There exists a large number of fungal species that can colonize the indoor environment, however, these can vary by geographic area, climate, seasons and other factors. The nutrients and the temperature required for fungal growth are usually present indoors making the moisture availability the primary controlling factor for mold growth (NAS, 2004). Several studies have been conducted to demonstrate that many respiratory diseases are related to fungal exposure. It was determined that sufficient evidence exists to prove that an association between indoor fungi and the exacerbation of asthma in sensitive individuals exists. However, there is insufficient evidence to determine whether fungi are directly associated with the development of asthma (NAS, 2000).

Asthma represents one of the most prevalent respiratory diseases in Canada. Based on US data the cases attributed to dampness and mold exposure are estimated to cost between $\$ 230$ to $\$ 530$ million (Mudarri and Fisk, 2007). This cost appears to continue to rise as more Canadians are becoming asthmatic every year. For example, in 1998/1999 asthma in Canada affected $7.5 \%$ of adults and $10.7 \%$ of children, these numbers increased to $8.4 \%$ and $13.4 \%$ respectively in 2009 , representing a total of 2.3 million Canadians being affected by asthma (Health Canada 2001; Statistics Canada, 2009). Additionally, asthma accounts for $20 \%$ of absenteeism from work and school (Health Canada, 2001).

Considering that fungi are associated with respiratory illnesses, it has become evident that controlling the presence of these organisms in indoor environments is crucial. 
Without including floods there are 4 main sources attributed to mold growth indoors; leaks in building fabrics, condensation, unattended plumbing leaks and household mold (e.g., mold growth on kitchen and bathroom surfaces, garbages and defrost pans; Dales et al., 2008). The implementation of housing interventions that eliminate moisture intrusion can help prevent health outcomes (Krieger et al., 2010). Some examples of interventions are: directing falling rain away from exterior building materials, plumbing lines should be easy to access and inspected for leaks regularly and fixed immediately if leaking, condensation should be controlled with dehumidification if humidity is high or increasing insulation when surfaces are too cold and ventilation with outdoor air can control water vapor in the building (Pezant et al., 2008a).

The Allergen Nomenclature Sub-Committee of the World Health Organization (WHO) and the International Union of Immunological Societies (IUIS) has accepted 101 allergens from fungi (www.allergen.org, 2010). Even though several methods are used to detect fungi from damp indoor environments, the quantitative exposure assessment methods are lacking making the correlations to asthma and allergies challenging. It has become evident that research for rapid analysis of indoor fungi that give immediate evaluation of potential health risks should be of high-priority (NAS, 2004). The development of "standardized methods for assessing exposure to fungal allergens are essential, preferably based on the measurements of allergens rather than culturable or countable fungi" (NAS, 2000). 
In the US and Canada, $C$. globosum was the most prevalent species isolated from moldy wallboard (Miller, 2010), it was also one of the top 12 species isolated from exposed cotton fabrics (Miller, 2010 after Siu, 1951). A wide variety of filamentous fungi can grow on different damp building substrates, C. globosum is commonly isolated from gypsum wallboard, wood, textiles and fabrics and frequently isolated from ceiling tiles, insulation and manufactured wood (Miller, 2010). The presence of C. globosum indoors should be further investigated since the inhalation of their spores has been known to elicit IgE-mediated allergies such as pneumonia and sinusitis (Huppert et al., 1978; Aru et al., 1997; Nielson et al., 1999; Yu et al., 2006). The methods involving the production of antibodies that were developed in this research are expected to be useful to assess C. globosum indoors.

It is important when determining exposure assessments to a particular fungal allergen that the protein antigenic to humans is common to strains across a broad geographic area. Each strain may produce different proteins that are antigenic to humans or the same antigens but in varying amounts. One of the determining factors in isolating fungal antigens is the growth conditions of the cultures (e.g., temperature, oxygen content, growth time and nutrients). These conditions need to be carefully monitored in order to reproduce consistent protein yields (Esch, 2004). Proteins that are accumulated and released in culture are relevant for detection methods. From previous studies (Xu et al., 2007), several media were compared for high protein yields from culture which led to the choice of medium used. The first step of this research consisted of screening the $C$. globosum proteins from culture filtrate extracts against HpAbs with ELISA and 
immunoblotting. The ELISA results would give insight on the reactivity between $C$. globosum and HpAbs while the immunoblots would provide visual identification of reacting proteins common to all strains tested.

Preliminary ELISA tests were performed to optimize the detection signal. This was necessary to have the proper amount of antigen and primary antibody to maximize the signal while maintaining low background. If too much primary antibody is used, it can lead to non-specific binding that will increase the background noise but if too little of the antibody is used it can leave some epitopes undetected leading to a reduced signal. The checkerboard ELISA gave insight to the concentration of antibody and antigen suitable for decent detection.

All the C. globosum strains had an antigenic response to the HpAbs with the ELISA testing. Some strains had lower response to the HpAbs but most had comparable reactivity (figure 4). Several variations were observed in the average response of each $\mathrm{HpAb}$ to the different strains (figure A1.3 and figure 5), some were very responsive (e.g., QC 2797), others were hardly responsive (e.g., QC 2798 and QC 3347) and some appeared to react in similar fashion (e.g., QC 3497 and QC 3359; QC 3499 and QC 3502; QC 3350, QC 3510 and QC 3355). A hypothesis that could explain these variations is that the response is proportional to the exposure levels of the individual; meaning that the longer an individual was exposed to fungal propagules, the higher its titre of responding antibodies leading to increased immune responses (e.g., high ELISA values). Moreover, the shorter the length of exposure of the individual or the longer amount of time since the 
exposure would be associated with lower ELISA responses because of respectively low or decreasing titre of the responding antibodies. The strains produced different antigenic proteins, or the same ones but produced in varying concentrations (figure 12). It is very likely that the patients would exhibit a wide range of responses to the different strains analyzed.

The immunoblotting tests (figures 6 to 10) displayed similar results to the ELISAs, a varied response of the HpAbs to each strain was observed, but the different antigenic proteins could be visualized. Many proteins from each C. globosum strain reacted with the human serum. Each immunoblot was analyzed and the various proteins that demonstrated an antigenic response were noted. A brief overview of these proteins are listed in table 1; some proteins (e.g., 30 and $40 \mathrm{kDa}$ ) were present in all the strains and reacted with almost every serum tested, while some proteins (e.g., 27kDa) were only present in a few strains and responded poorly to only a few sera. The proteins at 45 and $47 \mathrm{kDa}$ were present within all the strains tested and showed a response to several HpAbs and therefore were considered the best choice for antibody production but other parameters had to be verified (e.g., their presence in spores and mycelia had to be confirmed and cross-reactivity tests had to be performed). The intensity of the bands on immunoblots was rated on a scale of 1 to 3 to the target proteins. In table $2, a+$ corresponds to 1 , a weak signal, ++ corresponds to 2 , a moderate signal, and +++ corresponds to 3 , a strong signal. When each strain is compared similar responses to the two target proteins were generally present. C. globosum DAOM 234120, DAOM 240349, DAOM 240350, DAOM 240357 and DAOM 240359 reacted with fewer HpAbs 
than the rest of the strains tested. They had an average response to around $35 \%$ of the human sera and the remaining strains reacted to around $65 \%$ of the human sera. For the most part when the $45 \mathrm{kDa}$ protein was observed as was the $47 \mathrm{kDa}$ protein. The strain UAMH 7142 was the most responsive from the immunoblot tests; the $45 \mathrm{kDa}$ protein reacted to 21 out of 25 sera while the $47 \mathrm{kDa}$ protein reacted to 18 . The variations observed with the different strains could be attributed to each strain producing different yields of the 45 and $47 \mathrm{kDa}$ proteins. The strain UAMH 7142 was chosen for purification and antibody production because it had the highest response to both the 45 and $47 \mathrm{kDa}$ proteins on immunoblots and the total activity determined by ELISA was also high.

To visualize the combined results from ELISA and immunoblot testing more easily a three-dimensional graph was created (figure 11). It consists of (1) ELISA response of culture filtrate extracts of 14 strains of $C$. globosum (X axis), (2) immunoblot response graded on a scale of 1-3 to the target protein (Y axis) and (3) 23 individual human sera ( $\mathrm{Z}$ axis). The different colors in the image represent where these combinations overlap. The patients response falls into three general groups. The first group represents patients that are allergic to several fungi. The strain/antibody combinations had uniformly low immunoblot responses and varied ELISA responses (i.e., the ELISA responses vary from high to weak but the corresponding immunoblot results to the antigenic proteins are low). The second group combines patients that are allergic to $C$. globosum but to other fungi as well. The strain/antibody combinations had variable immunoblots and ELISA responses (i.e., some immunoblots react strongly to the target antigens while others have a weaker 
responses due to their absence; the ELISA signal varies from faint to elevated in relation to the target antigens being absent or present, respectively). This happens because many different proteins are present in the $C$. globosum culture filtrate extracts and can crossreact with proteins produced from other fungi. The third group represents the patients that are mostly allergic to $C$. globosum. The strain/antibody combinations had proportionate ELISA and IgG responses to the target antigens (i.e., the immunoblots to the target antigens are high and the ELISA results are also high but mostly due to the target antigens).

The spores, spore fragments and mycelium are usually the carriers of antigenic proteins therefore immunoblots on the spores and mycelium were performed to confirm the presence of the selected antigenic proteins (figures 15 and 16). The 45 and $47 \mathrm{kDa}$ proteins were present both in spores and mycelium but in lower concentrations. A plausible explanation for this observation would be that the antigens are exported out of the cells into the culture filtrate. For these reasons, the liquid culture was used over spores and mycelium for protein production and further isolation of the target proteins.

The target proteins were extracted from liquid culture using two different techniques; acetone precipitation and concentration through a 10,000 Da cut-off membrane. The acetone precipitation extracts the protein out of solution. The water molecules in culture filtrate form around the proteins and favor their dissolution. The addition of acetone to the culture filtrate lowers the dissolvent power of the water molecules since they are being displaced by the solvent molecules. This decrease in solubility results in 
aggregation and precipitation of the proteins (Rosenberg, 2005). This process is usually carried out with ice-cold acetone $\left(0^{\circ} \mathrm{C}\right.$ or below) to avoid protein denaturation because this reaction is exothermic, it releases heat as the entropy of the system increases. Acetone is widely used for this purpose because of its availability, purity, low cost and it does not usually harm the protein. The $50 \%$ acetone precipitation got rid of carbohydrates and other non-protein material while the $75 \%$ acetone precipitation resulted in very high protein yields. This is consistent with other findings in literature (e.g., Xu et al., 2007, Wilson et al., 2009).

The other method tested for protein extraction from culture filtrate consisted of using a concentrator with a 10,000 Da cut-off membrane. The culture filtrate was concentrated about 50X, reducing the amount of water available to dissolve the proteins and in turn creating a more concentrated protein sample. This process reduces a complex protein sample to a more manageable fraction with minimal protein loss. When the two methods were compared the concentrator was more effective in producing larger amounts of the target antigens (figure 20). It was then utilized as the extraction method prior to purification. The 45 and $47 \mathrm{kDa}$ proteins represented respectively $3 \%$ and $2 \%$ of the total protein yield (table 3$)$.

Before purification the cross-reactivity of the target antigens had to be assessed using the HpAbs. Some fungi showed a response to proteins with similar molecular weights as the target antigens (figure 17, large arrows). Although, after careful examination (figure 18 and 19) the proteins from other fungi (e.g., Aspergillus fumigatus, A. versicolor, 
Epicocum nigrum, Penicillium chrysogenum and $P$. expansum) that reacted were always higher or lower in molecular weight then the 45 and $47 \mathrm{kDa}$ proteins. These low crossreactivity results of proteins from other fungi to the target proteins allowed their purification to take place.

The first purification for the 45 and $47 \mathrm{kDa}$ proteins was done using anion exchange chromatography. This technique separates the different proteins in a sample using their net charges. It is often used because it is effective, simple and rapid. In anion exchange chromatography, the stationary phase is positively charged and interacts with the negatively charged amino groups on the proteins. The addition of salt, $\mathrm{NaCl}$ in the present study, was used for the elution of the proteins. It is an anion that has a strong affinity to the column. It competes with the already bound proteins and facilitates their elution. If the protein has a net negative charge that is weak it will be eluted more easily. The fractions 9 to 23 enclosed the $45 \mathrm{kDa}$ protein, fractions 24 to 33 co-eluted the two target antigens while fractions 34 to 48 only contained the $47 \mathrm{kDa}$ protein (figure 21). These results make evident that the $47 \mathrm{kDa}$ protein was slightly more negatively charged, eluted later, than the $45 \mathrm{kDa}$ protein.

After this purification step, the protein fractions containing the target antigens were pooled together and their activity was confirmed by immunoblotting (figure 22). They were further purified using gel filtration chromatography however the $45 \mathrm{kDa}$ protein was excluded from this step because of its poor recovery, $0.525 \mathrm{mg}$ compared to $5 \mathrm{mg}$ for the $47 \mathrm{kDa}$ protein. 
The last purification step was gel filtration chromatography, it separates proteins based on size. Protein standards used in this experiment indicated that the target protein should be eluted between 85 and $105 \mathrm{~mL}$ (figure 23). The actual elution volumes were between 60 and $90 \mathrm{~mL}$, the $47 \mathrm{kDa}$ protein is an oligomeric protein in its native state. The target protein represents greater than $90 \%$ of the total protein recovered (figure 24). This final purification step yielded around $1 \mathrm{mg}$ of the $47 \mathrm{kDa}$ protein. The pure protein was used for amino acid sequencing and antibody production.

The RpAbs were produced by first injecting two rabbits with $C$. globosum spores and then boosting them with the partially purified $45 \mathrm{kDa}$ and purified $47 \mathrm{kDa}$ proteins. The injection of spores was performed to confirm that the target antigens were present. The test bleed from the spore boost was tested by immunoblotting (figure 25), against spore extract (SP1) and culture filtrate extracts (CF1). The target proteins were present in both extracts, however their responses were weak probably due to their low concentration in spore samples. The partially purified $45 \mathrm{kDa}$ antigen was boosted twice in rabbit identified as 675 and the purified $47 \mathrm{kDa}$ protein was boosted three times in the rabbit labeled 305 .

The test bleeds after the second boost of the antigens were used on immunoblots (figure 25; CF2 \& SP2) and demonstrate an increased response to both target antigens in each rabbit. Although, the rabbit 675 and 305 demonstrated an elevated response to the 45 and $47 \mathrm{kDa}$ proteins, respectively. This result is expected since the $45 \mathrm{kDa}$ protein was 
injected in the rabbit 675 and the $47 \mathrm{kDa}$ protein in the rabbit 305 . A decrease in the titre response, or even elimination of the other spore proteins was also observed in both rabbits (identified with smaller white arrows in figure 24; SP1 \&SP2). This ensured that the RpAbs could possibly be used as a capture antibody, if minimal cross-reactivity was determined. The terminal test bleed (figure 30) showed an increased specificity to the target antigens. This confirmed that the 45 and $47 \mathrm{kDa}$ proteins were antigenic to rabbits, as well as human, that these proteins were in fact produced by the fungi and not an artifact of isolation and that the antibodies could possibly be used in detection methods for C. globosum.

The activity of the purified RpAbs was first verified by ELISA (figure 27). Both RpAb 675 and 305 reacted in proportionally at every dilution tested. They were then tested for cross-reactivity against several fungi using immunoblotting and ELISA. The immunoblotting reactivity of the RpAbs (figure 28) when compared to the HpAbs (figure 18) showed a much weaker response to proteins from other fungi. The later cross-reacted with more fungi and with some proteins similar in molecular weight as the target antigens (figures 18 and 28). This is expected since some patients (HpAbs) are more likely to have been exposed to many indoor fungi thus showing higher cross-reactivity to multiple fungi. A. versicolor, E. nigrum and P. chrysogenum showed a weak response against the RpAbs, especially in the molecular weight region of the target antigens. The rabbits were first immunized with spores that contain several proteins, this could explain the immunogenic response of a few proteins from other fungi. It is also possible that these 
proteins have similar epitopes as the target antigens and can therefore be recognized by the antibody on immunoblot.

The cross-reactivity results of the RpAbs done with ELISA (figure 29) showed similar trends in response; a very high response to $C$. globosum with some minor responses from other fungi with the exception of $S$. chartarum. This fungus had a slightly higher response than the other tested fungi on ELISA but when verified on immunoblots there are no proteins that reacted in the same molecular weight range as the target antigens. Additionally, it is necessary to note that the ELISA OD response is a log based response meaning that an OD of 3.1 for $C$. globosum is ca. $110 \mathrm{X}$ greater than the OD of 0.99 for $S$. chartarum. The ELISA and immunoblot results demonstrate that the RpAbs could potentially be used as a marker for identifying exposure to C. globosum in the indoor environment. The $47 \mathrm{kDa}$ target antigen was then used for the production of mouse monoclonal antibodies (MmAbs).

Multiple experiments to characterize the 45 and $47 \mathrm{kDa}$ proteins were carried out. Mass spectrometry analysis of proteins is widely used because it is rapid, accurate and the cost is reasonable. The target antigens were digested using the protease trypsin and the resulting peptides were analyzed by liquid chromatography tandem mass spectrometry (LC-MS/MS) using a Linear Trap Quadrupole Fourier Transform (LTQ-FT) at Health Canada. The peptide sequences were queried utilizing NCBI/BLAST and the two target proteins were determined to be chitosanases. Chitosanase degrades chitosan, a fungal 
cell wall polysaccharide, playing a crucial role in the defense of the organism against invading pathogens (Somashekar, D. and Joseph, 1996).

The alignment of the protein spectrums (figure 32) shows the similarity between the two proteins. There is a possibility that the two proteins are the same but have undergone slightly different modifications during culture production. One of these differences could be associated to different hydrophobic characters of the proteins. This hypothesis is supported by the ion chromatography results. The proteins were not co-elluted in all fractions collected meaning that the $47 \mathrm{kDa}$ is more negatively charged and therefore eluted less easily (later fractions) than the $45 \mathrm{kDa}$ protein.

Chitosanases have been isolated from different fungi; Aspergillus fumigatus, Apergillus oryzae, Fusarium solani and Penicillium chrysogenum (Zhang et al., 2001; RodríguezMartín, 2010) and in this project from C. globosum. When the amino acid sequences of these different fungi were searched on the NCBI/BLAST database and compared to $C$. globosum their homology was weak for the exception of F. solani. C. globosum had highest coverage $95 \%$ with a chitosanase isolated from $F$. solani and the identity was $35 \%(107 / 305)$. The chitosanase from A. oryzae had a moderate coverage, 49\%, with the C. globosum chitosanase and was $35 \%$ identical (58/162). The molecular weights of the chitosanases from these two species were respectively 27 and $30 \mathrm{kDa}$ and their pIs were undetermined. A low coverage, $29 \%$, was observed with the chitosanase from $P$. chrysogenum, and it was 50\% (26/52) identical to the $C$. globosum chitosanase. The $P$. chrysogenum chitosanase had a molecular weight of $37 \mathrm{kDa}$ and a $\mathrm{pI}$ of 5 . The lowest 
coverage, $21 \%$, was observed with the chitosanase from A. fumigatus and the identity was $57 \%(36 / 63)$. The pI of this chitosanase was determined to be 5.5 and it has a molecular weight of $23 \mathrm{kDa}$. With these results, the $C$. globosum chitosanase seems to be different than the ones isolated from these different fungi.

It is important to note that even though chitosanases have been isolated from different fungi there are still no chitosanase that have been reported as allergens by the Allergen Nomenclature Sub-Committee of the World Health Organization (WHO) and the International Union of Immunological Societies (IUIS; www.allergen.org; www.allergome.org, 2010).

Because of the similarities between the two target antigens and the difficulty in isolating the $45 \mathrm{kDa}$ protein, only the $47 \mathrm{kDa}$ was the protein used for additional analysis and for the monoclonal antibody production.

A chitosanase activity assay was performed to help confirm that the $47 \mathrm{kDa}$ protein was in fact a chitosanase. This enzyme hydrolyses the $\mathrm{B}-1,4$ glycosidic bond between $\mathrm{N}$-acetyl glucosamine and glucosamine in chitosan, a deacetylated chitin and between two glucosamines of a fully deacetylated chitosan (figure 39; Marcotte et al., 1996; Fukamizo and Brzezinski, 1997). 


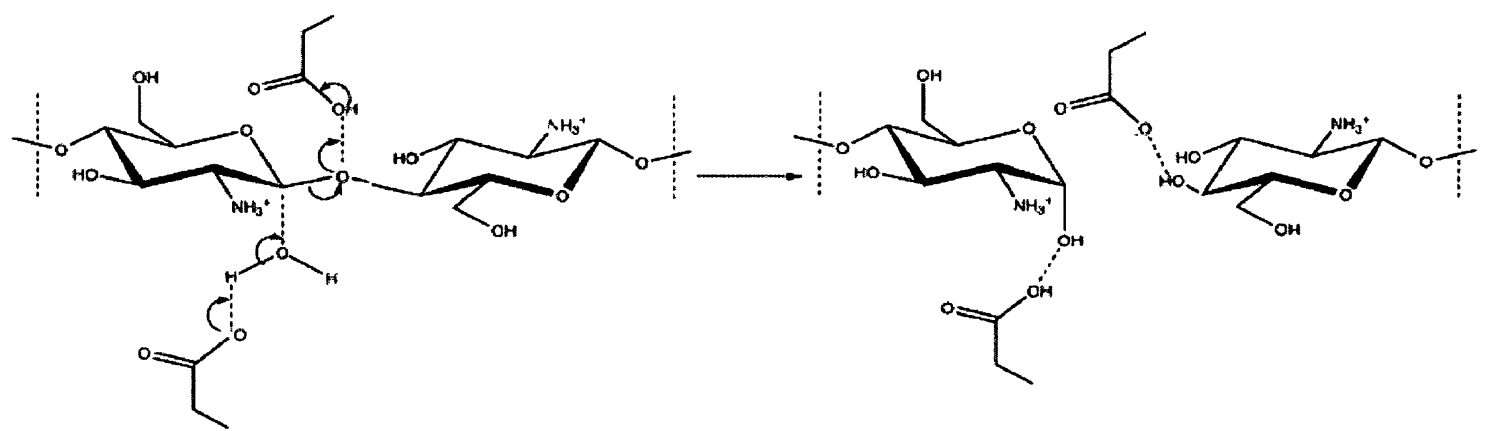

Figure 39: Catalytic mechanism (hydrolysis of $\beta-1,4$ glycosidic bond between two glucosamine) by chitosanase (Adapted from Jollès and Muzzarelli, 1999)

The chitosanase activity measure the amount of reduced sugar produced when the enzyme was in the presence of chitosan. The activity of the enzyme increased when the temperature was elevated (figure 36 ). The maximum activity was observed at $50^{\circ} \mathrm{C}$, a decline in production of reduced sugar was observed at higher temperatures. This is because at higher temperature a partial denaturation of the enzyme is observed. At a temperature of $65^{\circ} \mathrm{C}$ or higher the enzyme was completely denatured explaining the absence of activity. Different incubation times were also tested for this activity assay (figure 37). The production of reduced sugar was time dependent but reached a plateau after 4 hrs. This is attributed to saturation of the method used for the amount of reduced sugar produced.

A glycoprotein assay was also carried out on the $47 \mathrm{kDa}$ protein, it was determined that this protein is not glycosylated. The pI of this protein was also investigated and 
determined to be 4.5 which is acidic (figure 33). This supports the statement above; the $47 \mathrm{kDa}$ antigen was eluted in later fractions using anion chromatography; meaning that because this protein is acidic, negatively charged, it has a good affinity with the positively charge column surface. When the $\mathrm{pI}$ from the $C$. globosum chitosanase is compared to ones produced by other fungi, they are all very similar and in the acidic range.

The mouse monoclonal antibodies are produce by hybridoma cells and the antibodies created can recognize a single epitope on specific proteins, in this case the $47 \mathrm{kDa}$ antigen, leading to enhanced specificity. Four mice were injected with the purified target antigen and their serum was analyzed by ELISA and immunoblot for antibody titre response. The ELISA results showed a high IgG response to C. globosum (table 4) and the $47 \mathrm{kDa}$ antigen had a high immunoblot response with each mouse serum (figure 38 ). Mouse \#1 and \#4 were selected for the production of the hybridomas because they had highest titre response both on ELISA and immunoblot.

In summary, two related proteins with molecular weights of 45 and $47 \mathrm{kDa}$ were isolated from C. globosum and were antigenic to humans and rabbits. The $47 \mathrm{kDa}$ protein is also antigenic to mice. Both proteins were characterized as chitosanases; the larger protein was unglycosylated and had an acidic pI. The $47 \mathrm{kDa}$ antigen was present in spores, mycelium and culture filtrate and RpAbs were successfully produced. The combination of these outcomes appears to make this antigen a useful biomarker for the detection of $C$. globosum in the built environment. Nonetheless, future research could be accomplished 
to determine the actual relationship between the two target antigens. For example, an Edman degradation could be performed to discover information on the $\mathrm{N}$-terminus sequences of these target antigens. Also the cell supernatant of the different clones produced during mAb production will have to be tested on immunoblots, the clones with the highest titre response will then be selected for ascites production. Further experiments are needed to characterize the mAbs. A capture ELISA could then be developed that would be even more sensitive and specific for the detection of $C$. globosum indoors. 


\section{REFERENCES:}

Abbott, S. P., L. Sigler, R. McAleer, D. A. McGough, M. G. Rinaldi, and G. Mizell. Fatal cerebral mycoses caused by the ascomycete Chaetomium strumarium. J Clin Microbiol 33:2692-2698. 1995.

Amman, H.M. Mycotoxins in Indoor Environments. Mycotoxin Res. 21(3): 157-163. 2005

Andersen, B., and Nissen, A.T. Evaluation of media for detection of Stachybotrys and Chaetomium species associated with water-damaged buildings. Int. Biodeterior. Biodegrad. 46: 111-116. 2000.

Aribandi, M., C. Bazan III, and M. G. Rinaldi. Magnetic resonance imaging findings in fatal primary cerebral infection due to Chaetomium strumarium. Australas Radiol 49:166-169. 2005.

Aru A., Munk-Nielsen, L. and Federspiel, B. H. The soil fungus Chaetomium in the human paranasal sinuses. Eur Arch Otorhino-laryngol. 254: 350-352. 1997.

Barron, M.A, Sutton, D.A., Veve, R., Guarro, J., Renaldi, M., Thompson, E., Cagnoni, P.J., Moultney, K. and Madinger, N.E. Invasive Mycotic Infections caused by Chaetomium perlucidum, a New Agent of Carebral Phaeohyphomycosis. Journal of Clinical Microbiology. 41(11): 5302-5307. 2003.

Beezhold, D. H., Green, B., Blachere, F. M., et al. Prevalence of allergic sensitization to indoor fungi in West Virginia. Allergy and Asthma Proceedings. 29:29-34. 2008.

Binder, M. and Tamm, C. The Cytochalasans: A New Class of Biological Active Microbial Metabolites. Angew. Chem. Internat. Edit. 12(5): 370-380. 1973.

Brewer, D., and A. Taylor. The production of toxic metabolites by Chaetomium spp. isolated from soils of permanent pasture. Can J Microbiol 24:1082-1086. 1978.

Brewer, D., Duncan, J.M., Jerram, W.A., Leach, C.K., Safe, S., Taylor, A. and Vining, L.C., Ovine-ill thrift in Nova-Scotia. 5. The production and toxicology of chetomin, a metabolite of Chaetomium spp. Canadian Journal of Microbiology. 18:1130-1137. 1972.

Bossio RE, Marshall AG. Baseline resolution of isobaric phosphorylated and sulfated peptides and nucleotides by electrospray ionization FTICR MS: Another step toward mass spectrometry-based proteomics. Anal Chem. 74:1674-1679. 2002.

Carlile, M. J., Watkinson, S. C. and Gooday G.W. The Fungi. Academic Press. Second Edition. 2001. 
Carrer, P., Marconi, M., Alcini, D. and Cavallo, D. Allergens in indoor air: environmental assessment and health effects. The science of the Total Environment. 270: 33-42. 2001.

Chapman, M. D., Pomes, A., Breiteneder, H. et al. Nomenclature and structural biology of allergens. J. Allergy. Clin. Immunol. 119: 414-420. 2007.

Chapman, M.D., Smith, A.M., Vailes, L.D., Arudau, K.L., Dhanaraj, V. and Pomés, A. Recombinant allergens for diagnosis and therapy of allergic disease. Journal of Allergy and Clinical Immunology. 106(3): 409-418. 2000.

Chapman, M. D, Tsay, A. and Vailes, L. D. Home allergen monitoring and controlimproving clinical practice and patient benefits. Allergy. 56: 604-610. 2001.

Cooke, R.C. Fungi, man and his environment. Longman Group Limited. London. 1977.

Costa, A. R., E. Porto, S. Lacaz, N. T. de Melo, J. F. Calux, and N. Y. S. Valente. Cutaneous and ungual phaeohyphomycosis caused by species of Chaetomium Kunze (1817) ex Fresenius, 1829. J Med Vet Mycol 26:261-268. 1988.

Dales, R., Liu, L., Wheeler, A.J. and Gilbert, N.L. Quality of indoor residential air and health. Can Med Assoc J. 179(2):147-152. 2008.

Day, H. and Ellis, A.K. Allergenic microorganisms and hypersensitivity. In: Flannigan, B., Samson, R.A.and Miller J.D. (eds) Microorganisms in home and indoor work environments: Taylor \& Francis, London. 101-128. 2001.

Deacon, J.W. Fungal Biology. Blackwell Publishing LTD. Oxford. 2006.

Dekker C, Dales R, Bartlett S, Zwanenburg H. Childhood asthma and the indoor environment. Chest. 100: 222-226. 1991.

de la Campa R, Seifert K, Miller JD. Toxins from strains of Penicillium chrysogenum isolated from buildings and other sources. Mycopathologia, 163(3):161-8. 2007.

Deshmukh, S.K., Rai, M.K., Biodiversity of Fungi: Their Role in Human Life. Science Publishers Inc. Enfield. 2005.

Dillon, H. K., Boling, D. K. and Miller, J. D. Comparison of detection methods for Aspergillus fumigatus in environmental air samples in an occupational environment. J. Occup. Environ. Hyg. 4(7): 509-513. 2007.

Dillon, H. K., Miller, J. D., Sorenson, W. G., Douwes, J. and Jacobs, R. R. Review of methods applicable to the assessment of mold exposure to children. Environ. Health Perspect. 107 Suppl 3: 473-480. 1999. 
Domsch, K.H., Gams, W. and Anderson, T-H. Compendium of soil fungi. Volume 1. Academic Press. London, UK. 1999.

Douwes, J., Thorne, P., Pearce, N. and Heederik, D. Bioaerosol Health Effects and Exposure Assessment: Progress and Prospects. Ann. Occup. Hyg. 47(3): 187-200. 2003.

Eder, W., Klimecki, W., Yu, L. et al. Tool-like recptor 2 as a major gene for asthma in children of European farmers. J. Allergy Clin. Immunol. 113: 482-488. 2004.

Esch, R. E. Manufacturing and standardizing fungal allergen products. J. Allergy Clin. Immunol. 113(2): 210-215. 2004.

Fedorov, A.A., Ball, T., Mahoney, N.M. et al. The molecular basis for allergen crossreactivity: crystal structure and IgE-epitotpe mapping of birch pollen profilin. Structure. 5: 33-45. 1997.

Flannigan, B. and Miller, J.D. Microbial growth in indoor environments. In: Flannigan, B., Samson, R.A. and Miller J.D. (eds) Microorganisms in home and indoor work environments: Taylor \& Francis, London. p35-67. 2001.

Fogle, M. (2007). Growth and mycotoxin production by Chaetomium globosum. A Ph.D. dissertation in medical microbiology, The Graduate Faculty of Texas Tech University Health Sciences Center.

Fogle, M.R., Douglas, D.R., Jumper, C.A., and Straus, D.C. Growth and mycotoxin production by Chaetomium globosum. Mycopathologia. 164: 49-56. 2007.

Foto, M. , Plett, J. , Berghout, J. and Miller, J. D. Modification of the Limulus Amebocyte Lysate Assay for the Analysis of Glucan in Indoor Environments. Anal. Bioanal. Chem. 379:156-162. 2004.

Foto, M., Vrijmoed, L.L.P, Miller, J.D., Ruest, K., Lawton, M., Dales, R.E. Comparison of airborne ergosterol, glucan and Air-O-Cell data in relation to physical assessments of mold damage and some other parameters. Indoor Air 15: 257-266. 2005.

Fukamizo, T and Brzezinski, R. Chitosanase from Streptomyces sp. strain N174: a comparative review of its structure and function. Biochemistry and cell biology 75(6):687-96. 1997.

Gould, H. J., Sutton, B. J., Beavil, A. J. et al. The biology of IgE and the basis of allergic disease. Annu. Rev. Immunol. 21: 579-628. 2003.

Gravesen S., Larsen, L., Gyntelberg, F. and Skov, P. Demonstration of microorganisms and dust in schools and offices. Allergy 41: 520-5. 1986.

Green, B.J., Tovey, E.R., Sercombe, J.K., Blachere, F.M., Beezhold, D.H. and 
Schmechel, D. Airborne fungal fragments and allergenicity. Medical Mycology. 44: S245-S255. 2006a.

Green, B.J., Yli-Panula, E. and Tovey, E.R. Sercombe JK, Blachere FM, Beezhold DH, Schmechel D. Halogen Immunoassay, a New method for the Detection of Sensitization to Fungal Allergens; Comparisons with Conventional Techniques. Allergology International. 55: 131-139. 2006b.

Guarro, J., Gené, J. and Stchigel, M., Developments in fungal taxonomy. Clin Micro Rev. 12(3): 454-500. 1999

Guarro, J., Soler, L. and Rinaldi, M.G. Pathogenicity and antifungal susceptibility of Chaetomium species. Eur J Clin Microbiol Infect Dis 14:613- 618. 1995.

Hattori, N., M. Adachi, T. Kaneko, M. Shimozuma, M. Ichinohe, and K. Iozumi. Case report. Onychomycosis due to Chaetomium globosum successfully treated with itraconazole. Mycoses 43:89-92. 2000.

Hawker, L.E. Ecological factors and the survival of fungi. In: Microbial Ecology. eds. Williams R.E.O and Spicer C.C. pp. 238-58. 1975.

Health Canada. Fungal Contamination in Public Buildings: Health Effects and Investigation Methods. 2004.

Hodgson, M.J. and Flannigan B. Occupational respiratory disease - hypersensitivity pneumonitis. In: Flannigan, B., Samson, R.A.and Miller J.D. (eds) Microorganisms in home and indoor work environments: Taylor \& Francis, London. 129-142. 2001.

Horner, W. E., and J. D. Miller. Microbial volatile organic compounds with emphasis on those arising from filamentous fungal contaminants of buildings. ASHRAE Transactions. 109(1): 215-31. 2003.

Horner, W. E., Helbling, A., Salvaggio, J. E. and Lehrer, S. B. Fungal allergens. Clin. Microbiol. Rev. 8(2): 161-179. 1995.

Hung, L-L., Miller, J.D and Dillion, H.K. Field Guide for the Determination of Biological Contaminants in Environmental Samples, Second Edition. AIHA. Fairfax. 2005.

Huppert, M., D. J. Oliver, and S. H. Sun. Combined methenamine-silver nitrate and hematoxylin \& eosin stain for fungi in tissues. J. Clin. Microbiol. 8:598-603. 1978.

Ingold, C.T. The Biology of Fungi. Hutchinson Educational. London. 1961. 
Iossifova, Y., Reponen, T., Daines, M., Levin, L. and Hershey, G. K. K. Comparison of Two Analytical Methods for Detecting (1-3)-beta-D-Glucan in Pure Fungal Cultures and in Home Dust Samples. The Open Allergy Journal. 1:26-34. 2008.

Jackola, D. R., Basu, S., Liebeler, C.L. et al. CD14 promoter polymorphisms in atopic families: implications for modulated allergen-specific immunoglobulin $\mathrm{E}$ and $\mathrm{G} 1$ responses. Int. Arch. Allergy. Immunol. 139: 217-224. 2006.

Janeway, C.A., Travers, P., Walport, M. and Shlomchik, M. J. Immunobiology: the immune system in health and disease. Sixth ed. Garland Science Publishing. New York. 2005.

Jarvis, B.B. and Miller, D.J. Mycotoxins as harmful indoor air contaminants. Applied Microbiology and Biotechnology. 66(4): 367-372. 2005.

Jollès, P. and Muzzarelli, R.A.A. Chitin and chitinases. Birkhäuser Basel. 1999.

Kabesch, M., Haseman, K., Schickinger, V. et al. A promoter polymorphism in the D14 gene is associated with elevated levels of soluble CD14 but not with IgE or atopic diseases. Allergy. 59: 520-525. 2004.

Kendric, B. Fifth Kingdom, Third Edition. Mycologue Publications, Sidney, BC. 2001.

Krieger, J.K., Jacobs, D.E., Ashley, P. and Beader, A. and al. Housing Interventions and Control of Asthma-Related Indoor Biologic Agents: A Review of the Evidence. J Public Health Management Practice. 16(5): S11-S20. 2010.

Kurup, V.P., Shen, H.D. and Vijay, H. Immunobiology of Fungal Allergens. International Archives of Allergy and Immunology 129: 181-188. 2002.

Larone, D.H. Medically important fungi: a guide to identification. ASM Press. Washington, D.C. Fourth Edition. pp. 227. 2002.

Lesire, V., E. Hazouard, P. F. Dequin, M. Delain, M. Therizol-Ferly, and A. Legras. Possible role of Chaetomium globosum in infection after autologous bone marrow transplantation. Intensive Care Med 25:124-125. 1999.

Lockey, R. and Ledford, D. K. Mammalian Allergens. Allergens and Allergen Immunotherapy. Volume 21 of Clinical allergy and immunology. Informa Health Care. pp. 201-218. 2008.

Marcotte, E.D., Monzingo, A.F., Ernst, S.R., Brzezinski, R. and Robertus., J.D. X-ray structure of an anti-fungal chitosanase from Streptomyces N174. Nature structural biology. 3(2): 155-162. 1996.

Miller, J.D. Mycological investigations of indoor environments. In: Flannigan, B., 
Samson, R.A.and Miller J.D. (eds) Microorganisms in home and indoor work environments: Taylor \& Francis, London. 231-246. 2001.

Miller, J.D., Mycological investigations of indoor environments. In: Flannigan B, Samson RA, Miller JD (eds) Microorganisms in home and indoor work environments: Diversity, Health Impacts, Investigation and Control, second edition. CRC Press, Boca Raton, FL (in press). 2010.

Miller, J.D. and Young, J. C. The use of Ergosterol to Measure Exposure to Fungal Propagules in Indoor Air. AIHA Journal. 58: 39-43. 1997.

Miller J.D., Day JD. Indoor mold exposure: epidemiology, consequences and immunothapy. Canadian Journal of Allergy \& Clinical Immunology 2: 25-32. 1997.

Miller, J. D., Laflamme, A. M., Sobol, Y., Lafontaine, P. and Greenhalgh, R. Fungi and fungal products in some Canadian houses. International Biodeterioration. 24(2): 103-120. 1988.

Miller, J. D, Pezant, B. and Weekes, D. In: Mold Ecology: Recovery of Fungi from Certain Moldy Building Materials Anonymous (eds). Recognition, Evaluation, \& Control of Indoor Mold. 2008.

Miller, J. D, Sun, M., Gilyan, A., Roy, J. and Rand, T.G. Inflammation-associated gene transcription and expression in mouse lungs induced by low molecular weight compounds from fungi from the built environment. Chemico-Biological Interraction. 183: 113-124. 2010.

Mudarri, D. and Fisk W.J. Public health and economic impact of dampness and mold. Indoor Air. 17(3):226-235. 2007.

Murad, Y. M, Lewis, C.W., Anderson, J.G. et al. Preparation of fungal spores for mycotoxin detection. Inter Bioter Biodeg. 32: 228-229. 1993.

Naidu, J., S. M. Singh, and M. Pouranik. Onychomycosis caused by Chaetomium globosum Kunze. Mycopathologia 113:31-34. 1991.

NAS. Clearing the air: asthma and indoor air exposures. National Academy of Sciences Institute of Medecine, Division of Health Promotion and Disease Prevention.

Washington DC: National Acadamy Press. 2000.

NAS. Damp Indoor Spaces and Health. National Academy of Sciences Institute of Medecine, Division of Health Promotion and Disease Prevention. Washington DC: National Acadamy Press. 2004.

Nielsen, K. F., S. Gravesen, P. A. Nielsen, B. Andersen, U. Thrane, and J. C. Frisvad. Production of mycotoxins on artificially and naturally infested building materials. 
Mycopathologia 145:43-56. 1999.

Pate, A.D., Hamilton, R.G., Ashley, P.J., Zeldin, D.C. and Halsey, J.F. Proficiency testing of allergen measurements in residential dust. Journal of Allergy and Clinical Immunology. 116(4): 844-850. 2005.

Pieckova, E. In vitro toxicity of indoor Chaetomium Kunze ex Fr. Ann. Agric. Environ. Med. 10(1):9-14. 2003.

Pitt, J.I., Hocking, A.D. Fungi and Food Spoilage. Elsevier. New York. 2009.

Pezant, B. et al. Science and Buildings. Mold Ecology: Recovery of Fungi from Certain Moldy Building Materials Anonymous (eds). Recognition, Evaluation, \& Control of Indoor Mold. pp.55-60. 2008a.

Pezant, B. et al. Laboratory Analytical Methods. Mold Ecology: Recovery of Fungi from Certain Moldy Building Materials Anonymous (eds). Recognition, Evaluation, \& Control of Indoor Mold. pp.153-167. 2008b.

Rand, T.G., Sun, M., Gilyan, A., Downey, J. and Miller, J.D. Dectin-1 and inflammationassociated gene transcription and expression in mouse lungs by a toxic $(1,3)-\beta-D$ glucan. Arch Toxicol. 84: 205-220. 2010.

Rodríguez-Martín, A., Acosta, R., Liddell, S., Núñez, F., Benito, M.J. and Asensio, M.A. Characterization of the novel antifungal chitosanase $\mathrm{PgChP}$ and the encoding gene from Penicillium chrysogenum.Appl Microbiol Biotechnol. 88: 519-528. 2010.

Rosenberg, I. A. Protein Analysis and Purification: Bench top procedures. Birkhauser. Boston. pp. 145-146. 2005.

Salares, V.R., Hinde, C.A. and Miller, J.D. Analysis of settled dust in homes and fungal glucan in air particulate collected during HEPA vacuuming. Indoor Built Environment. 18:485-491. 2009.

Samson, R.A., Hoekstra, E.S. and Frisvad, J.C. Mycological media in: Introduction to food and airborne fungi. ASM Press. $6^{\text {th }}$ edition. pp.308-32. 2002.

Schaub, B., Lauener, R. and von Mutius, E. The many faces of the hygiene hypothesis. J. Allergy. Clin. Immunol. 117: 969-77; quiz 978. 2006.

Scott J, Untereiner WA, Wong B, Straus NA, Malloch D. Genotypic variation in Penicillium chrysogenum from indoor environments. Mycologia, 96(5) : 1095-1105. 2004.

Seifert, K.A. Progress towards DNA barcoding of fungi. Molecular Ecology Resources. 9(s1): 83-89. 2009. 
Seifert, K.A. and Lévesque, A. Phylogeny and molecular diagnosis of mycotoxigenic fungi. European Jornal of Plant Pathology. 110: 449-471. 2004.

Sekita, S., K. Yoshihira, and S. Natori. Structures of chaetoglobosins C, D, E, F, cytotoxic indol-yl-[13] cytochalasans from Chaetomium globosum. Tetrahedron Letters 17:1351-1354. 1976.

Seth, H.K. Amonograph of the genus Chaetomium. Nova Hedwigia. 37: 1-133. 1970.

Shelton, B., Kirkland, K., Flanders, W.D. and Morris, G.K. Profiles of airborne fungi in buildings and outdoor environments in the United States. Appl. Environ. Microbiol., 68: 1743-53. 2002.

Simon-Nobbe, B., Denk, U., Poll, V., Rid, R. and Breitenbach, M. The spectrum of fungal allergy. Int Arch Allergy Immunol. 145:58-86. 2008.

Simoni M, Lombardi E, Berti G, Rusconi F, La Grutta S, Piffer S, Petronio MG, Galassi C, Forastiere F, Viegi G, the SIDRIA-2 Collaborative Group. Mold/dampness exposure at home is associated with respiratory disorders in Italian children and adolescents: the SIDRIA-2 Study. Occupational Environmental Medicine. 62: pp 616-622. 2007.

Singh, J. Building Mycology: Management of decay and health in buildings, First Edition. E \& FN Spon. London. 1994.

Somashekar, D. and Joseph, R. Chitosanases-Properties and applications: a review. Biores.Tech. 55: 35-45. 1996.

Sporik, R. B., Arruda, L. K., Woodfolk, J. et al. Environmental exposure to Aspergillus fumigatus allergen (Asp f I). Clin. Exp. Allergy. 23: 326-331. 1993.

Stachan, D. P. Hay fever, hygiene, and household size. BMJ. 299: 1259-1260. 1989.

Statistic Canada. Respiratory Disease in Canada. 2009.

Stiller, M. J., S. Rosenthal, R. C. Summerbell, J. Pollack, and A. Chan. Onchomycosis of the toenails caused by Chaetomium globosum. J Amer Acad Dermatol 26:775-776. 1992.

Strom, G.J., Hellstrom, B. and Kumlin, A. The sick building syndrome: An effect of microbial growth in building constructions. Indoor Air. 90(1): 173-185. 1990.

Teixeira, A. B. A., P. Trabasso, M. L. Moretti-Branchini, F. H. Aoki, A. C. Vigorito, M. Miyaji, Y. Mikami, M. Takada, and A. Z. Schreiber. Phaeohyphomycosis caused by Chaetomium globosum in an allogeneic bone marrow transplant recipient. Mycopathologia 156:309-312. 2003.

Traber, R., Hofmann, H. and Kobel, H. Cyclosporins--new analogues by precursor 
directed biosynthesis. J. Antibiot. (Tokyo). 42(4): 591-597. 1989.

Towbin, H., Staehelin, T. and Gordon, J. Electrophoretic transfer of proteins from polyacrylamide gels to nitrocellulose sheets: procedure and applications. Proc. Natl. Acad. Sci. USA. 76, p. 4350. 1979.

Udagawa, S., Muroi, T., Kurata, H., Sekita, S., Yoshihira, K., Natori, S., Umeda, M. The production of chaetoglobosins, sterigmatocystin, o-methylsterigmatocystin, and chaetocin by Chaetomium spp. and related fungi. Can J Microbiol. 25, 170-177. 1979.

Ueno, Y. and Hsieh, D. P. H. The Toxicology of Mycotoxins. Critical Reviews in Toxicology 14(2): 99-132. 1985.

Von Mutius, E. Environmental factors influencing the development and prograssion of pediatric asthma. J. Allergy Clin. Immunol. 109: S525-32. 2002.

Watling, R. Fungi. The Natural History Museum. London. 2003.

Wilson, A., Luo, W. and Miller, J. D. Using human Sera to Identify a 52-kDa Exoantigen of Penicillium chrysogenum and Implications of Polyphasic Taxonomy of Anamorphic Ascomycetes in the Study of Antigenic Proteins. Mycopathologia. 168: 213-226. 2009.

Wolf, J., O'Neil, N.R., Rogers, C.A., Muilenberg, M.L. and Ziska, L.H. Elevated Atmospheric Carbon Dioxide Concentrations Amplify Alternaria alternata Sporulation and Total Antigen production. Envioronmental Health Perspectives. doi:10.1289/ehp.0901867. 2010.

Xu, J., Liang, Y., Belilise, D. and Miller, J.D. Characterization of monoclonal antibodies to an antigenic protein from Stachybotrys chartarum and its measurement in house dust. J. Immunol. Methods. 2008.

Xu, J., Jensen, J.T., Liang, Y., Belilise, D. and Miller, J.D. The biology and immunogenicity of a 34-kDa antigen of Stachybotrys chartarum sensu lato. J. Immunol. Methods. 2007.

Yeghen, T., L. Fenelon, C. K. Campbell, D. W. Warnok, A. V. Hoffbrand, H. G. Prentice, and C. C. Kibbler. Chaetomium pneumonia in a patient with acute myeloid leukaemia. J Clin Pathol 49:184-186. 1996.

Yu, J., S. Yang, and R. Li. A case of subcutaneous phaeohyphomycosis caused by Chaetomium globosum and the sequences analysis of C. globosum. Med Mycol 44:541545. 2006.

Zhang, X-Y., Dai, A-L., Kuroiwa, K., Kodaira, R., et al. Cloning and Characterization of a Chitosanase Gene from the Koji Mold Aspergillus oryzae Strain IAM 2660. Biosc Biotechnol Biochem. 65(4): 977-981. 2001. 


\section{APPENDIX}

Table A1.1 - List of the different Chaetomium globosum strains

\begin{tabular}{|l|l|l|l|}
\hline $\begin{array}{c}\text { Deposited } \\
\text { accession } \\
\text { number }\end{array}$ & $\begin{array}{l}\text { Paracel } \\
\text { number }\end{array}$ & Location & Sampling material \\
\hline DAOM 234120 & N/A & Guelph, ON & Swab (ceilings and walls) \\
\hline DAOM 240348 & $0801041-7$ & Ottawa, ON & rcs-indoor \\
\hline DAOM 240349 & $0803032-32$ & Ottawa, ON & rcs-indoor \\
\hline DAOM 240350 & $0803084-30$ & Ottawa, ON & rcs-indoor \\
\hline DAOM 240351 & $0808038-4$ & Ottawa, ON & rcs-indoor \\
\hline DAOM 240352 & $0808083-2$ & Halifax, NS & rcs-indoor \\
\hline DAOM 240353 & $0809144-9$ & Ottawa, ON & rcs-indoor \\
\hline DAOM 240354 & $6220100-10$ & Ottawa, ON & rcs-indoor \\
\hline DAOM 240356 & $6250047-2$ & Ottawa, ON & rcs-indoor \\
\hline DAOM 240357 & $6250047-8$ & Ottawa, ON & rcs-indoor \\
\hline DAOM 240358 & L5744-1 & Ottawa, ON & rcs-indoor \\
\hline DAOM 240359 & L6114-6 & Ottawa, ON & rcs-indoor \\
\hline UAMH 7142 & N/A & Edmonton, AB & rcs-indoor \\
\hline UAMH 7773 & N/A & Grimshaw, AB & rcs-indoor \\
\hline & & & \\
\hline
\end{tabular}

Table A1.2 - ITS sequences of $C$. globosumstrains

\begin{tabular}{|l|l|}
\hline $\begin{array}{l}\text { DAOM } \\
\text { number }\end{array}$ & ITS Sequences \\
\hline 240348 & $\begin{array}{l}\text { CATTACTTATCGCATTTCGCTGCGTTCTTCATCGATGCCAGAACCAAGAGA } \\
\text { TCGTTGTTGAAAGTTTGACTTATTCAGTACAGAAGACTCAGAGAGGCCA } \\
\text { TAAATTATCAAGAGTTTGGTGACTCCGGCGGGCGCCCGCGGTGGGGCCCA } \\
\text { GGGGCGCCCGGGGGTAAACCCCGGGGCGCCCGCAAAGCAACGGTATA } \\
\text { GGTAACGTTCACAATGGTTTAGGGAGTTTGCAACTCTGTAATGATCCCTCC } \\
\text { GCTGGTTCACCAACGGAGACCTTGTTACGACTTTTACTTCCTCTAAATGACC } \\
\text { AAG }\end{array}$ \\
\hline 240349 & $\begin{array}{l}\text { CATTACAGAGTTGCAAAACTCCCTAAACCATTGTGCCCCTTACCTATACCGT } \\
\text { TGCTTCGGCGGGCGGCCCCGGGGTTACCCCCCGGGCGCCCCTGGGCCCCA } \\
\text { CCGCGGGCGCCCGCCGGAGGTCACCAAACTCTTGATAATTTATGGCCTCTCT } \\
\text { GAGTCTTCTGTACTGAATAAGTCAAAACTTTCAACAACGGATCTCTTGGTTC } \\
\text { TGGCATCGATGAAGAACGCAGCGAAATGCGATAAGTAATGTGAATTGCAGA }\end{array}$ \\
\hline
\end{tabular}




\begin{tabular}{|c|c|}
\hline & $\begin{array}{l}\text { ATTCAGTGAATCATCGAATCTTTGAACGCACATTGCGCCCGCCAGCATTCTG } \\
\text { GCGGGCATGCCTGTTCGAGCGTCATTTCAACCATCAAGCCCCCGGGCTTGTG } \\
\text { TTGGGGACCTGCGGCTGCCGCAGGCCCTGAAAAGCAGTGGCGGGCTCGCTG } \\
\text { TCGCACCGAGCGTAGAAAAATACATCTCGCTCTGGTCGCGCCGCGGGTTCC } \\
\text { GGCCGTTAAACCACCTTTTAACCCAAGGTTGACCTCGGATCAGGTAGGAAG } \\
\text { ACCCGCTGAACTTAAGCATATCAATAAGCGGAGGAAACCCCCTTTTTTTTTT } \\
\text { TTTTTTTTTTTTTTTTTTCCCCCTTTTTCTT }\end{array}$ \\
\hline 240350 & $\begin{array}{l}\text { CATTACAGAGTTGCAAAACTCCCTAAACCATTGTGACCCTTACCTATACCGT } \\
\text { TGCTTCGGCGGGCGGCCCCGGGGTTTACCCCCCGGGCGCCCCTGGGCCCCA } \\
\text { CCGCGGGCGCCCGCCGGAGGTCACCAAACTCTTGATAATTTATGGCCTCTCT } \\
\text { GAGTCTTCTGTACTGAATAAGTCAAAACTTTCAACAACGGATCTCTTGGTTC } \\
\text { TGGCATCGATGAAGAACGCAGCGAAATGCGATAAGTAATGTGAATTGCAGA } \\
\text { ATTCAGTGAATCATCGAATCTTTGAACGCACATTGCGCCCGCCAGCATTCTG } \\
\text { GCGGGCATGCCTGTTCGAGCGTCATTTCAACCATCAAGCCCCGGGCTTGTG } \\
\text { TTGGGGACCTGCGGCTGCCGCAGGCCCTGAAAAGCAGTGGCGGGCTCGCTG } \\
\text { TCGCACCGAGCGTAATAAAAAAAATCTCGCTCTGGTCGCGCCGCGGGTTCC } \\
\text { GGCCGTTAAACCACCTTTTAACCCAAGGTTGACCTCGGATCAGGTAGGAAG } \\
\text { ACCCGCTGAACTTAAGCATATCAATAAGCGGAGGAA }\end{array}$ \\
\hline 240 & $\begin{array}{l}\text { CATTACAGAGTTGCAAAACTCCCTAAACCATTGTGAACCTTACCTATACCGT } \\
\text { TGCTTCGGCGGGCGGCCCCGGGGTTTACCCCCCGGGCGCCCCTGGGCCCCA } \\
\text { CCGCGGGCGCCCGCCGGAGGTCACCAAACTCTTGATAATTTATGGCCTCTCT } \\
\text { GAGTCTTCTGTACTGAATAAGTCAAAACTTTCAACAACGGATCTCTTGGTTC } \\
\text { TGGCATCGATGAAGAACGCAGCGAAATGCGATAAGTAATGTGAATTGCAGA } \\
\text { ATTCAGTGAATCATCGAATCTTTGAACGCACATTGCGCCCGCCAGCATTCTG } \\
\text { GCGGGCATGCCTGTTCGAGCGTCATTTCAACCATCAAGCCCCCGGCTTGTG } \\
\text { TTGGGGACCTGCGGCTGCCGCAGGCCCTGAAAAGCAGTGGCGGGCTCGCTG } \\
\text { TCGCACCGAGCGTAATAACATACATCTCGCTCTGGTCGCGCCGCGGGTTCCG } \\
\text { GCCGTTAAACCACCTTTTTAACCCAAGGTTGACCTCGGATCAGGTAGGAAG } \\
\text { ACCCGCTGAACTTAAGCATATCAATAAGCGGAGGAA }\end{array}$ \\
\hline 240 & $\begin{array}{l}\text { CATTACAGAGTTGCAAAACTCCCTAAACCATTGTGCCCCTTACCTATACCGT } \\
\text { TGCTTCGGCGGGCGGCCCCGGGGTTTACCCCCCGGGCGCCCCTGGGCCCCA } \\
\text { CCGCGGGCGCCCGCCGGAGGTCACCAAACTCTTGATAATTTATGGCCTCTCT } \\
\text { GAGTCTTCTGTACTGAATAAGTCAAAACTTTCAACAACGGATCTCTTGGTTC } \\
\text { TGGCATCGATGAAGAACGCAGCGAAATGCGATAAGTAATGTGAATTGCAGA } \\
\text { ATTCAGTGAATCATCGAATCTTTGAACGCACATTGCGCCCGCCAGCATTCTG } \\
\text { GCGGGCATGCCTGTTCGAGCGTCATTTCAACCATCAAGCCCCCGGGCTTGTG } \\
\text { TTGGGGACCTGCGGCTGCCGCAGGCCCTGAAAAGCAGTGGCGGGCTCGCTG } \\
\text { TCGCACCGAGCGTAGTAAAATAAATCTCGCTCTGGTCGCGCCGCGGGTTCC }\end{array}$ \\
\hline
\end{tabular}




\begin{tabular}{|c|c|}
\hline & $\begin{array}{l}\text { GGCCGTTAAACCACCTTTTAACCCAAGGTTGACCTCGGATCAGGTAGGAAG } \\
\text { ACCCGCTGAACTTAAGCATATCAATAAGCGGAGGA }\end{array}$ \\
\hline 240353 & $\begin{array}{l}\text { CATTACAGAGTTGCAAAACTCCCTAAACCATTGTGACCTTTACCTATACCGT } \\
\text { TGCTTCGGCGGGCGGCCCCGGGGTCCACCCCCCGGGCGCCCCTGGGCCCCA } \\
\text { CCGCGGGCGCCCGCCGGAGGTCACCAAACTCTTGATAATTTATGGCCTCTCT } \\
\text { GAGTCTTCTGTACTGAATAAGTCAAAACTTTCAACAACGGATCTCTTGGTTC } \\
\text { TGGCATCGATGAAGAACGCAGCGAAATGCGATAAGTAATGTGAATTGCAGA } \\
\text { ATTCAGTGAATCATCGAATCTTTGAACGCACATTGCGCCCGCCAGCATTCTG } \\
\text { GCGGGCATGCCTGTTCGAGCGTCATTTCAACCATCAAGCCCCGGGCTTGTG } \\
\text { TTGGGGACCTGCGGCTGCCGCAGGCCCTGAAAAGCAGTGGCGGGCTCGCTG } \\
\text { TCGCACCGAGCGTAAAAACATACATCTCGCTCTGGTCGCGCCGCGGGTTCC } \\
\text { GGCCGTTAAACCACCTTTTAACCCAAGGTTGACCTCGGATCAGGTAGGAAG } \\
\text { ACCCGCTGAACTTAAGCATATCAATAAGCGGAGGA }\end{array}$ \\
\hline 240354 & $\begin{array}{l}\text { CATTACAGAGTTGCAAAACTCCCTAAACCATTGTGAACGTTACCTATACCGT } \\
\text { TGCTTCGGCGGGCGGCCCCGGGGTTTACCCCCCGGGCGCCCCTGGGCCCCA } \\
\text { CCGCGGGCGCCCGCCGGAGGTCACCAAACTCTTGATAATTTATGGCCTCTCT } \\
\text { GAGTCTTCTGTACTGAATAAGTCAAAACTTTCAACAACGGATCTCTTGGTTC } \\
\text { TGGCATCGATGAAGAACGCAGCGAAATGCGATAAGTAATGTGAATTGCAGA } \\
\text { ATTCAGTGAATCATCGAATCTTTGAACGCACATTGCGCCCGCCAGCATTCTG } \\
\text { GGGGGCATGCCTGTTCGAGCGTCATTTCAACCATCAAGCCCCGGGCTTGTG } \\
\text { TTGGGGACCTGCGGCTGCCGCAGGCCCTGAAAAGCAGTGGCGGGCTCGCTG } \\
\text { TCGCACCGAGCGTAGTAACATACATCTCGCTCTGGTCGCGCCGCGGGTTCCG } \\
\text { GCCGTTAAACCACCTTTTAACCCAAGGTTGACCTCGGATCAGGTAGGAAGA } \\
\text { CCCGCTGAACTTAAGCATATCAATAAGCGGAGGAA }\end{array}$ \\
\hline 240356 & $\begin{array}{l}\text { CATTACAGAGTTGCAAAACTCCCTAAACCATTGTGAACGTTACCTATACCGT } \\
\text { TGCTTCGGCGGGCGGCCCCGGGGTTTACCCCCCGGGCGCCCCTGGGCCCCA } \\
\text { CCGCGGGCGCCCGCCGGAGGTCACCAAACTCTTGATAATTTATGGCCTCTCT } \\
\text { GAGTCTTCTGTACTGAATAAGTCAAAACTTTCAACAACGGATCTCTTGGTTC } \\
\text { TGGCATCGATGAAGAACGCAGCGAAATGCGATAAGTAATGTGAATTGCAGA } \\
\text { ATTCAGTGAATCATCGAATCTTTGAACGCACATTGCGCCCGCCAGCATTCTG } \\
\text { GCGGGCATGCCTGTTCGAGCGTCATTTCAACCATCAAGCCCCGGGCTTGTG } \\
\text { TTGGGGACCTGCGGCTGCCGCAGGCCCTGAAAAGCAGTGGCGGGCTCGCTG } \\
\text { TCGCACCGAGCGTAATAAAATACATCTCGCTCTGGTCGCGCCGCGGGTTCC } \\
\text { GGCCGTTAAACCACCTTTTTAACCCAAGGTTGACCTCGGATCAGGTAGGAA } \\
\text { GACCCGCTGAACTTAAGCATATCAATAAGCGGAGGA }\end{array}$ \\
\hline
\end{tabular}




\begin{tabular}{|c|c|}
\hline 240357 & $\begin{array}{l}\text { CATTATCACCTGTGGGTTAAAGGTGGTTTAACGGCCGGAACCCGCGGCGCG } \\
\text { ACCAGAGCGAGATGTATGCTACTACGCTCGGTGCGACAGCGAGCCCGCCAC } \\
\text { TGCTTTTCAGGGCCTGCGGCAGCCGCAGGTCCCCAACACAAGCCCGGGGGC } \\
\text { TTGATGGTTGAAATGACGCTCGAACAGGCATGCCCGCCAGAATGCTGGCGG } \\
\text { GCGCAATGTGCGTTCAAAGATTCGATGATTCACTGAATTTGCAATTCACAT } \\
\text { TACTTATCGCATTTCGCTGCGTTCTTCATCGATGCCAGAACCAAGAGATCCG } \\
\text { TTGTTGAAAGTTTTGACTTATTCAGTACAGAAGACTCAGAGAGGCCATAAA } \\
\text { TTATCAAGAGTTGGTGACCTCCGGCGGGCGCCCGCGGTGGGGCCCAGGGG } \\
\text { CGCCCGGGGGGTAAACCCCGGGGCCGCCCGCCGAAGCAACGGTATAGGTA } \\
\text { ACGTTCACAATGGTTTAGGGAGTTTTGCAACTCTGTAATGATCCCTCCGCTG } \\
\text { TTCACCAACGGAGACCTTGTTACGACTTTTACTTCCTCTAAATGACCAAGAA } \\
\text { GGAGGATGAGGATTTCCTCAGAAGGAGGACCTCTCCGCAAATTGAGCGTG } \\
\text { TCGCCTCACTAGGAGACTAGCAGCCGGGGCTGCTGTGGTAGGCAAGACTTG } \\
\text { ACCTACGGAAACCTTGTTACGACTTTTACTTCCTCTAAATGACC }\end{array}$ \\
\hline 240358 & $\begin{array}{l}\text { CATTACCGAGTTGCAAAACTCCCTAAACCATTGTGCCCCCTTACCTATACCG } \\
\text { TTGCTTCGGCGGGCGGCCCCGGGGTTCCCCCCCCGGGCGCCCCTGGGCCCC } \\
\text { ACCGCGGGCGCCCGCCGGAGGTCACCAAACTCTTGATAATTTATGGCCTCTC } \\
\text { TGAGTCTTCTGTACTGAATAAGTCAAAACTTTCAACAACGGATCTCTTGGTT } \\
\text { CTGGCATCGATGAAAAACGCAGCGAAATGCGATAAGTAATGTGAATTGCAG } \\
\text { AATTCAGTGAATCATCGAATCTTTGAACGCACATTGCGCCCGCCAGCATTCT } \\
\text { GGCGGGCATGCCTGTTCGAGCGTCATTTCAACCATCAAGCCCCGGGCTTG } \\
\text { GTTGGGGACCTGCGGCTGCCGCAGGCCCTGAAAAGCAGTGGCGGGCTCGCT } \\
\text { GTCGCACCGAGCGTAAAAAAATACATCTCGCTCTGGTCGCGCCGCGGGTTC } \\
\text { CGGCCGTTAAACCACCTTTTAACCCAAGGTTGACCTCGGATCAGGTAGGAA } \\
\text { GACCCGCTGAACTTAAGCATATCAATAAGCGGAGGA }\end{array}$ \\
\hline 240359 & $\begin{array}{l}\text { CATTACTTATCGCATTTCGCTGCGTTCTTCATCGATGCCAGAACCAAGAGAT } \\
\text { CCGTTGTTGAAAGTTTTGACTTATTCAGTACAGAAGACTCAGAGAGGCCAT } \\
\text { AAATTATCAAGAGTTTGGTGACCTCCGGCGGGCGCCCGCGGTGGGGCCCAG } \\
\text { GGGCGCCCGGGGGGTAAACCCCGGGGCCGCCCGCCAAAACAACGGTATAG } \\
\text { GTAACGTTCACAATGGTTTAGGGAGTTTTGCAACTCTGTAATGATCCCTCCG } \\
\text { CTGGTTCACCAACGGAGACCTTGTTACGACTTTTACTTCCTCTAAATGACCA } \\
\text { AGA }\end{array}$ \\
\hline
\end{tabular}


Table A1.3 - List of the identification number for the human sera (HpAbs)

\begin{tabular}{|l|l|l|l|l|l|}
\hline 1 & QC 2797 & 12 & QC 3355 & 23 & QC 3502 \\
\hline 2 & QC 2798 & 13 & QC 3356 & 24 & QC 3508 \\
\hline 3 & QC 3342 & 14 & QC 3357 & 25 & QC 3510 \\
\hline 4 & QC 3346 & 15 & QC 3358 & & \\
\hline 5 & QC 3347 & 16 & QC 3359 & & \\
\hline 6 & QC 3349 & 17 & QC 3490 & & \\
\hline 7 & QC 3350 & 18 & QC 3493 & & \\
\hline 8 & QC 3351 & 19 & QC 3494 & & \\
\hline 9 & QC 3352 & 20 & QC 3497 & & \\
\hline 10 & QC 3333 & 21 & QC 3499 & & \\
\hline 11 & QC 3354 & 22 & QC 3501 & & \\
\hline
\end{tabular}

Table A1.4 - Optical density values measured @ 450nm for C. globosumELISA against human sera QC 2797 to QC 3356

\begin{tabular}{|c|c|c|c|c|c|c|c|c|c|c|c|c|c|}
\hline Strain \# & $\begin{array}{c}\text { QC } \\
2797 \\
\end{array}$ & $\begin{array}{c}\mathrm{QC} \\
2798 \\
\end{array}$ & $\begin{array}{c}\mathrm{QC} \\
\mathbf{3 3 4 2} \\
\end{array}$ & $\begin{array}{c}\mathrm{QC} \\
3346\end{array}$ & $\begin{array}{c}\mathrm{QC} \\
3347 \\
\end{array}$ & $\begin{array}{c}\mathrm{QC} \\
3349 \\
\end{array}$ & $\begin{array}{c}\mathrm{QC} \\
\mathbf{3 3 5 0}\end{array}$ & $\begin{array}{c}\mathrm{QC} \\
3351 \\
\end{array}$ & $\begin{array}{c}\mathrm{QC} \\
\mathbf{3 3 5 2} \\
\end{array}$ & $\begin{array}{c}\text { QC } \\
\mathbf{3 3 5 3} \\
\end{array}$ & $\begin{array}{c}\mathbf{Q C} \\
\mathbf{3 3 5 4}\end{array}$ & $\begin{array}{c}\mathrm{QC} \\
\mathbf{3 3 5 5} \\
\end{array}$ & $\begin{array}{c}\mathrm{QC} \\
\mathbf{3 3 5 6} \\
\end{array}$ \\
\hline $\begin{array}{l}\text { DAOM } \\
240348\end{array}$ & 1.8225 & 0.0607 & 1.4141 & 0.9784 & 0.4042 & 0.4129 & 0.7150 & 1.4430 & 0.1737 & 0.0241 & 0.01585 & 0.7477 & 0.1207 \\
\hline $\begin{array}{l}\text { DAOM } \\
240349 \\
\end{array}$ & 3497 & 0.1658 & 1.8545 & 1.2323 & .5196 & 0.5144 & 1.4742 & 1.9012 & 1.1372 & 0.4092 & 0.6289 & 0.9886 & 0.3296 \\
\hline $\begin{array}{l}\text { DAOM } \\
240350 \\
\end{array}$ & 2.1391 & 0.2130 & 0.8133 & 0.6907 & 0.5873 & 1.0108 & 0.6615 & 1.1638 & 1.2120 & 1.1171 & 0.5555 & 1.0787 & 0.3701 \\
\hline $\begin{array}{l}\text { DAOM } \\
240351 \\
\end{array}$ & 1.3801 & 0.2286 & 0.6630 & 0.6327 & 0.4967 & 0.8931 & 0.4302 & 0.7904 & 0.9008 & 0.3473 & 0.3198 & 0.9226 & 0.2949 \\
\hline $\begin{array}{l}\text { DAOM } \\
240352 \\
\end{array}$ & 2.2431 & 0.2276 & 0.6895 & 0.5059 & 0.4674 & 0.7446 & 0.4329 & 0.8552 & 0.9440 & 0.4420 & 0.3629 & 0.9628 & 0.3601 \\
\hline $\begin{array}{l}\text { DAOM } \\
240353 \\
\end{array}$ & 2.1565 & 0.1477 & 0.7749 & 0.5889 & 0.4533 & 0.8850 & 0.6001 & 1.0245 & 1.2044 & 0.4698 & 0.5145 & 0.9258 & 0.2834 \\
\hline $\begin{array}{l}\text { DAOM } \\
240354 \\
\end{array}$ & 2.1412 & 0.3760 & 1.1324 & 1.3347 & 0.5407 & 0.5713 & 1.3453 & 2.0197 & 1.4732 & 0.3440 & 0.6201 & 0.8494 & 0.2356 \\
\hline $\begin{array}{l}\text { DAOM } \\
240355 \\
\end{array}$ & 1.3597 & 0.2140 & 1.2151 & 1.0087 & 0.4380 & 0.3701 & 1.1908 & 1.8220 & 1.2456 & 0.3543 & 0.56775 & 0.7148 & 0.0397 \\
\hline $\begin{array}{l}\text { DAOM } \\
240356 \\
\end{array}$ & 2.3550 & 0.2141 & 0.6490 & 1.6380 & 5540 & 3210 & 1.8200 & 0.6510 & 1450 & .1140 & 0.472 & 1.0250 & 0.9236 \\
\hline $\begin{array}{l}\text { DAOM } \\
240357 \\
\end{array}$ & 1.2010 & 0.0785 & 0.8502 & 0.9162 & 0.1262 & 0.2277 & 1.4187 & 1.8375 & 1.4121 & 0.1451 & 0.39955 & 0.5542 & 0.0094 \\
\hline $\begin{array}{l}\text { DAOM } \\
240358 \\
\end{array}$ & 2.2680 & 0.0916 & 0.8601 & 1.1891 & 0.4795 & 0.4272 & 1.4499 & 2.0341 & 1.0480 & 0.3518 & 0.37205 & 0.8921 & 0.2248 \\
\hline $\begin{array}{l}\text { DAOM } \\
240359 \\
\end{array}$ & 2.1485 & 0.2224 & 0.9862 & 0.5384 & 0.3531 & 0.7882 & 0.9998 & 1.1808 & 1.3561 & 0.5328 & 0.61385 & 0.9854 & 0.3368 \\
\hline $\begin{array}{c}\text { UAMH } \\
7142 \\
\end{array}$ & 2.9620 & 0.8926 & 0.9594 & 1.9516 & 0.4697 & 0.8260 & 0.6983 & 1.3475 & 2.2465 & 0.3995 & 1.8981 & 0.3201 & 1.9179 \\
\hline $\begin{array}{c}\text { UAMH } \\
7773 \\
\end{array}$ & 2.2680 & 0.7030 & 2.1998 & 1.9683 & 0.7827 & 0.7571 & 1.9170 & 2.6888 & 2.7211 & 0.3284 & 1.11855 & 1.2143 & 1.0591 \\
\hline
\end{tabular}




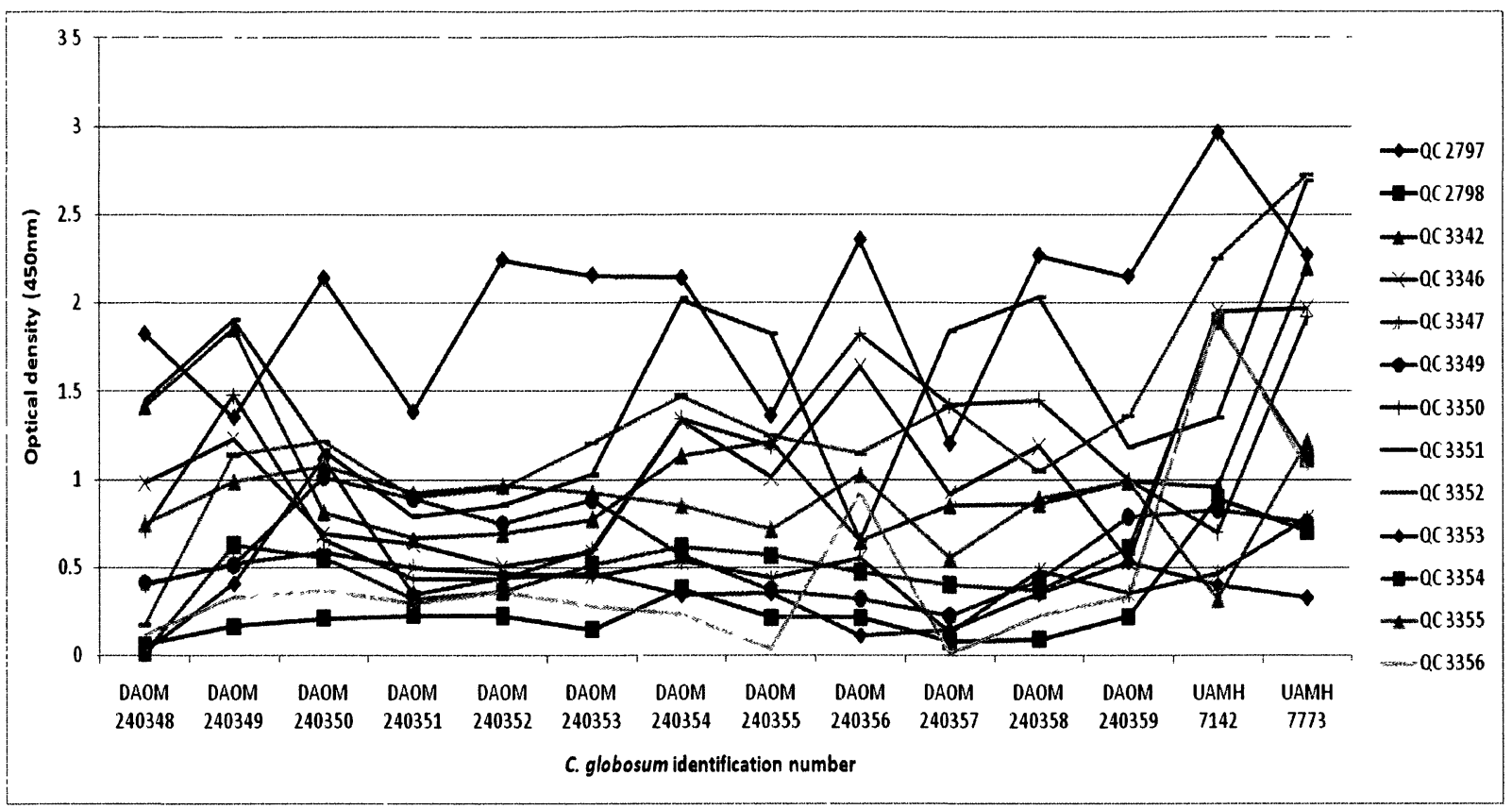

Figure A1.1 - ELISA response of C. globosumstrains against HpAbs QC 2797 to QC 3356 
Table A1.5 - Optical density values measured @ 450nm for $C$. globosumELISA against human sera QC 3357 to QC 3510

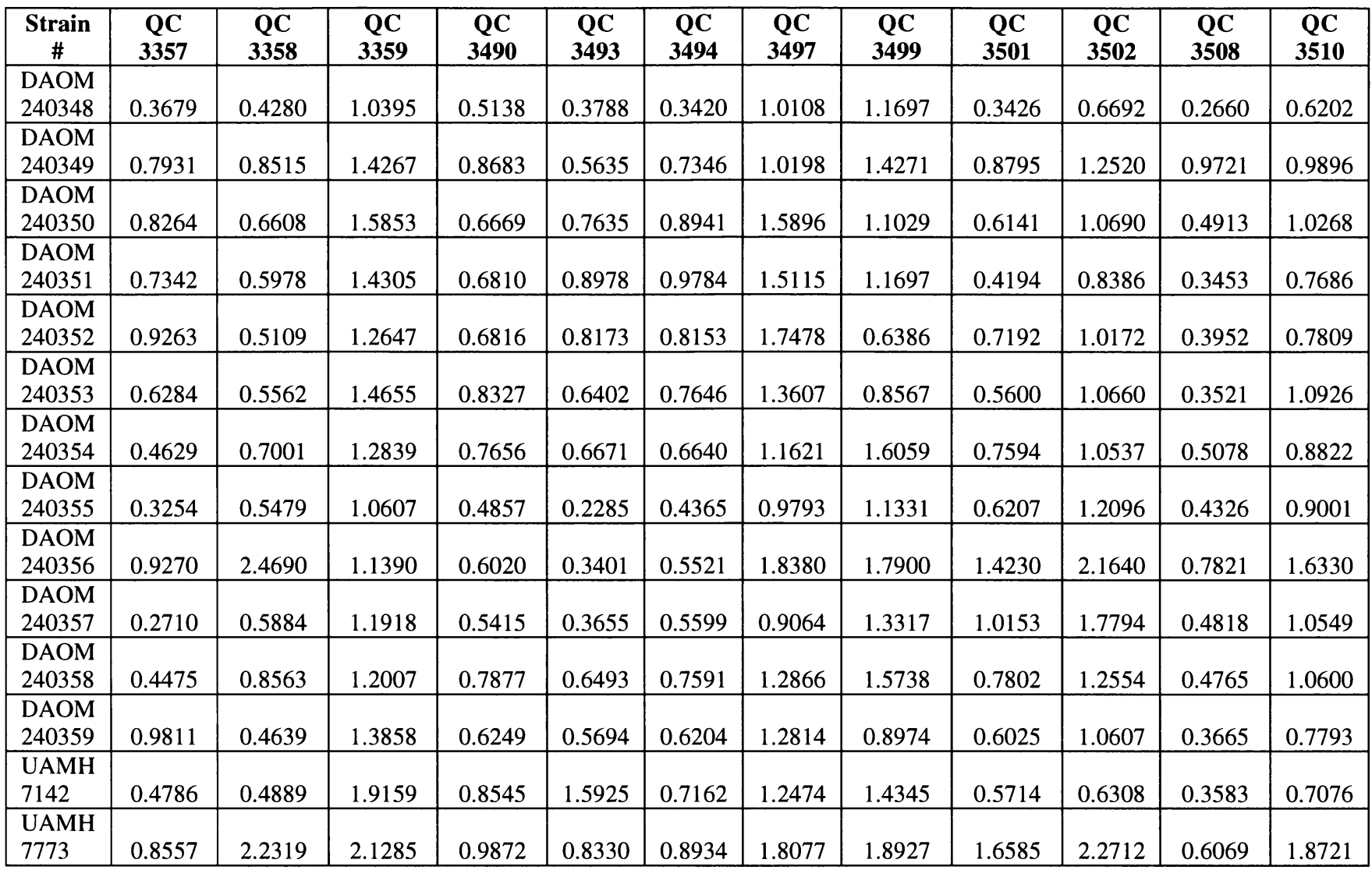

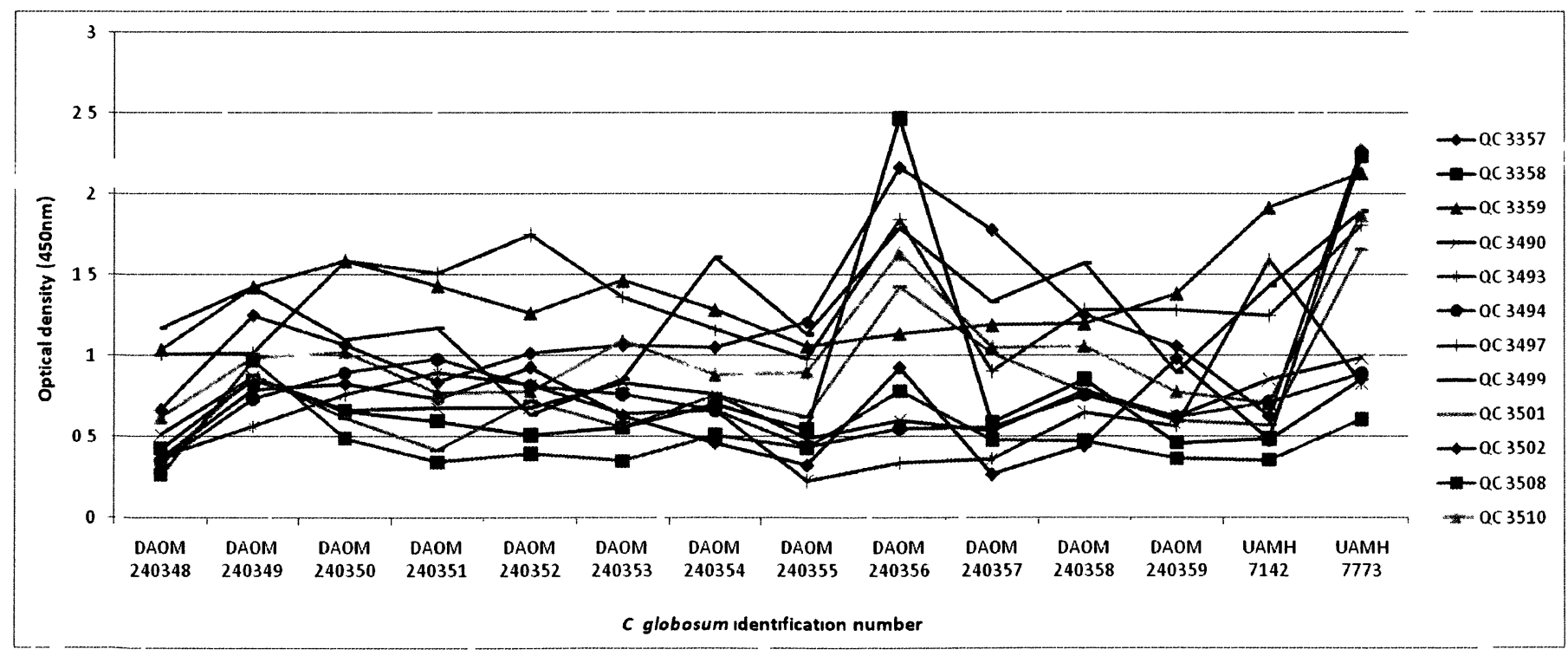

Figure A1.2 - ELISA response of C. globosumstrains against HpAbs QC 3357 to QC 3510 


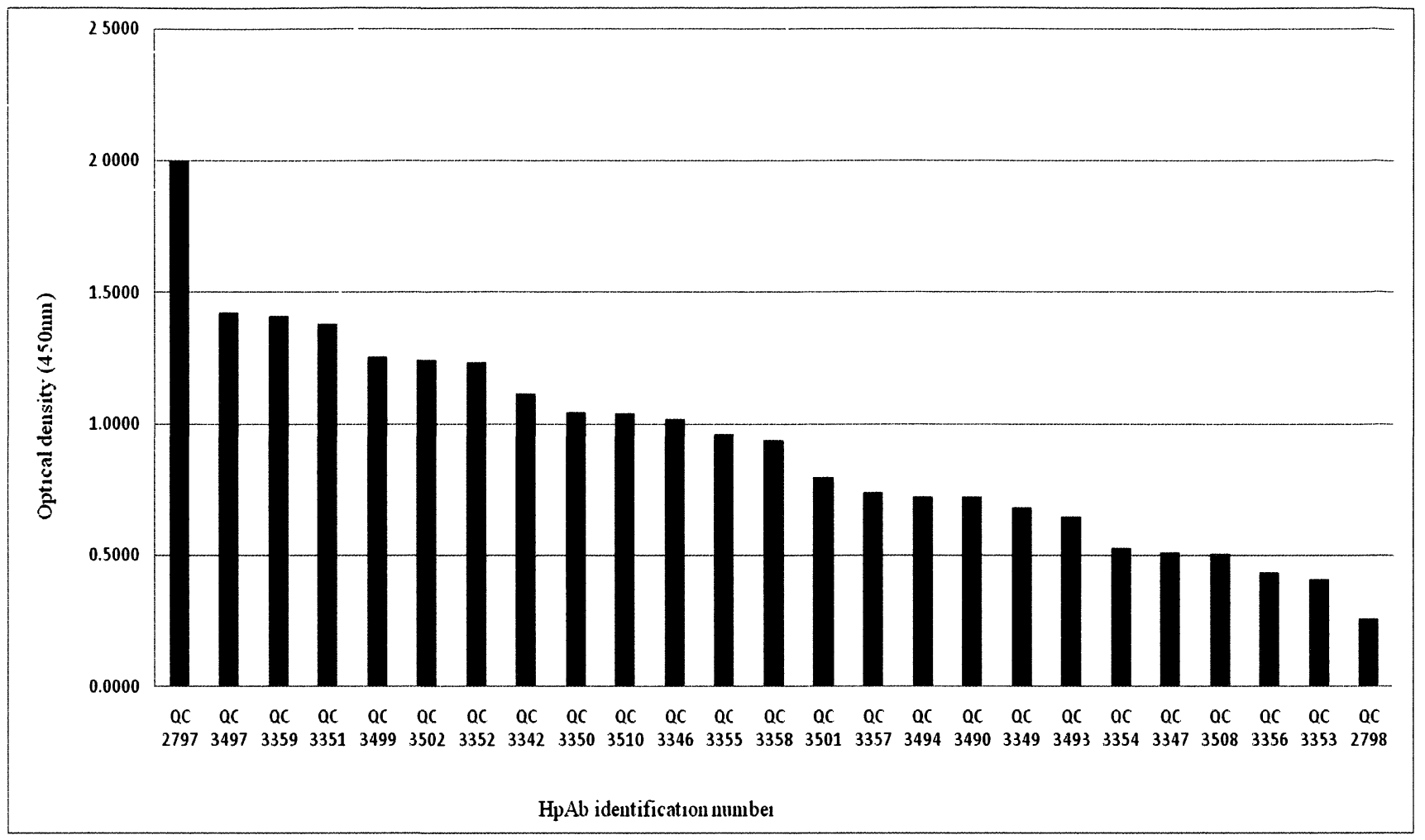

Figure A1.3 - The average optical density response of each HpAb to all of the $C$. globosumstrains 